\title{
PERIODICIDADE DO CRESCIMENTO E FORMAÇÃO DA MADEIRA DE ALGUMAS ESPÉCIES ARBÓREAS DE FLORESTAS ESTACIONAIS SEMIDECÍDUAS DA REGIÃO SUDESTE DO ESTADO DE SÃO PAULO
}

\section{LIGIA FERREIRA}

\author{
Dissertação apresentada à Escola Superior de \\ Agricultura "Luiz de Queiroz", Universidade de São \\ Paulo, para obtenção do título de Mestre em Recursos \\ Florestais, Área de Concentração: Recursos \\ Florestais, com opção em Tecnologia de Produtos \\ Florestais.
}

P I R A C I C A B A

Estado de São Paulo - Brasil

Fevereiro-2002 


\title{
PERIODICIDADE DO CRESCIMENTO E FORMAÇÃO DA MADEIRA DE ALGUMAS ESPÉCIES ARBÓREAS DE FLORESTAS ESTACIONAIS SEMIDECÍDUAS DA REGIÃO SUDESTE DO ESTADO DE SÃO PAULO
}

\author{
LIGIA FERREIRA \\ Bióloga
}

Orientador: Prof. Dr. MARIO TOMAZELLO FILHO

\begin{abstract}
Dissertação apresentada à Escola Superior de Agricultura "Luiz de Queiroz", Universidade de São Paulo, para obtenção do título de Mestre em Recursos Florestais, Área de Concentração: Recursos Florestais, com opção em Tecnologia de Produtos Florestais.
\end{abstract}

P I R A C I C A B A

Estado de São Paulo - Brasil

Fevereiro-2002 
Dados Internacionais de Catalogacão na Publicação (CIP) DIVISÃO DE BIBLIOTECA E DOCUMENTAÇÃO - ESALQ/USP

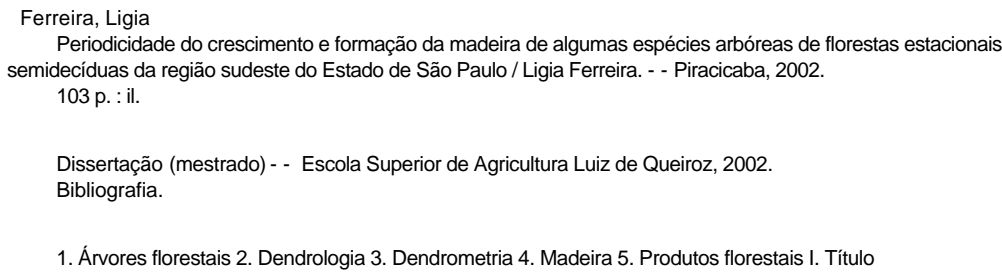




\section{DEDICO E O FEREC $O$}

Primeiramente a Deus pela força que me deu em todos os momentos dessa jornada e de minha vida

e aos meus pais, Luiz e Alice, que sempre me encorajaram me concedendo todo apoio, carinho, paciência e amor 


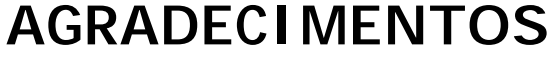

Ao Professor Dr. Mario Tomazello Filho, pela orientação, confiança e amizade.

Ao curso de Pós-Graduação em Recursos Florestais do Departamente de Ciências Florestais da Escola Superior de Agricultura "Luiz de Queiroz", pela oportunidade de estudo.

À Fundação de Amparo a Pesquisa do Estado de São Paulo (FAPESP), pela concessão da bolsa de estudos e da reserva técnica.

Ao Paulo Cesar Botosso pelo fornecimento dos dados anteriormente coletados e pelo auxílio quando necessário.

Aos Professores Dr. Luiz Carlos Estraviz Rodrigues e Ricardo Ribeiro Rodrigues, pelas sugestões apresentadas ao trabalho.

Ao Biol. Claudio Sergio Lisi, pela amizade e pelas ótimas sugestões apresentadas ao trabalho.

Ao Professor Dr. Pablo Vidal Torrado, pela orientação para caracterização do solo nas áreas de estudo.

A todos os funcionários do Departamento de Ciências Florestais e do IPEF, pelo convívio e auxílio necessário no decorrer do curso.

Aos funcionários da Biblioteca Central e da Secretaria de Pós-graduação pela atenção e esclarecimento de dúvidas.

A Cristiane G. Dall’Aglio-Holvorcem, pelo consentimento para realizar este trabalho na Reserva Florestal Mata de Santa Genebra.

Ao Edegar Giannotti, pelo consentimento para realizar este trabalho na Estação Ecológica de Ibicatu e Estação Experimental de Tupi. 
Ao Tiago Osório Ferreira, pela coleta de solo e auxílio na análise dos dados coletado.

Ao Charles da Silva, pelo auxílio na identificação de algumas espécies florestais em campo.

À amiga e técnica do Laboratório de Anatomia e Identificação de Madeiras Maria Ap. R. Chaves Bermudez, pelo auxílio em todos os momentos necessários.

À amiga Biol. Vivian Correia Ribeiro Baptista, pela grande amizade e companheiris mo nas viagens a campo.

Às amigas Graziela Cury e Bibiana Arango, companheiras de laboratório, pelo carinho, respeito e atenção.

Ao meu querido Eng. Florestal Marcio Fedele, pela coleta de amostras de madeiras em campo, pelas sugestões, pelo carinho e paciência.

Aos amigos e companheiros da turma do Curso de Pós-graduação em Recursos Florestais da ESALQ, pelo convívio durante todo este período.

Aos meus pais, pelo apoio, amor e compreensão.

A todos que me ajudaram, de alguma forma, para realização deste trabalho.

Meus mais sinceros agradecimentos. 


\section{$\mathcal{E S C O L \mathcal { A }}$}

\section{"Escola é...}

o lugar onde se faz amigos

não se trata só de prédios, salas, quadros,

programas, horários, conceitos...

Escola é, sobretudo, gente,

Gente que trabalha, que estuda,

Que se alegra, se conhece, se estima.

O diretor é gente,

o coordenador é gente, o professor é gente,

o aluno é gente.

Cada funcionário é gente.

E a escola será cada vez melhor

Na medida em que cada um

Se comporte como coleta, amigo, irmão.

Nada de 'ilha de gente por todos os lados'.

Nada de conviver com as pessoas e depois descobrir

Que não tem amizade a ninguém

Nada de ser como o tijolo que forma a parede,

Indiferente, frio, só.

Importante na escola não é só estudar, não é só trabalhar, é também criar laços de amizade, é criar ambiente de camaradagem,

é conviver, é se 'amarrar nela'!

Ora, é lógico...

Numa escola assim vai ser

fácil estudar, trabalhar, crescer,

fazer amigos, educar-se

ser feliz." 


\section{SUMÁRIO}

Página

LISTA DE FIGURAS................................................................................ ix

LISTA DE TABELAS .................................................................................. xiv

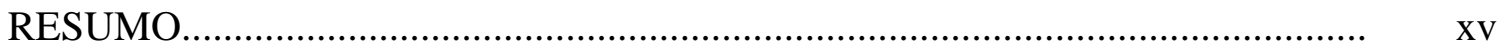

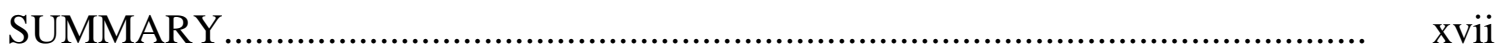

1 INTRODUÇÃO

2 REVISÃO DE LITERATURA...............................................................

2.1 Aplicação de faixas dendrométricas na avaliação do crescimento em circunferência do tronco das árvores...................................................................

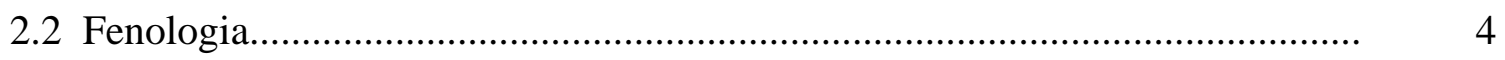

2.3 Variações climáticas relacionadas à atividade cambial...................................... 6

2.4 Idade e taxa de crescimento da árvore...............................................................

2.5 A estrutura anatômica e os anéis de crescimento................................................

3 MATERIAL E MÉTODOS ..................................................................... 12



3.2 Espécies florestais selecionadas.................................................................. 14

3.3 Dados dendrométricos: circunferência do tronco das árvores........................... 15

3.4 Análise das condições de crescimento das árvores............................................ 16

3.5 Determinação da taxa de crescimento em circunferência do tronco das

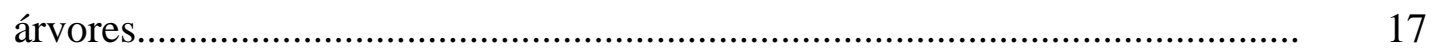

3.6 Avaliação da fenologia, das condições climáticas e do solo............................... 18

3.6.1 Avaliações fenológicas................................................................................ 18 
3.6.1.1 Desenvolvimento das folhas................................................................ 18

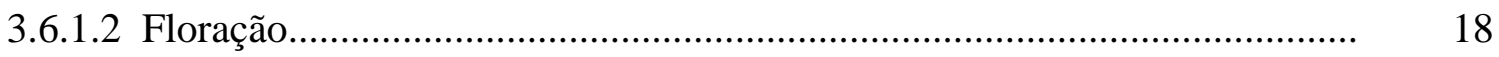

3.6.2.3 Frutificação...................................................................................... 20

3.6.2 Análise das condições climáticas................................................................. 20

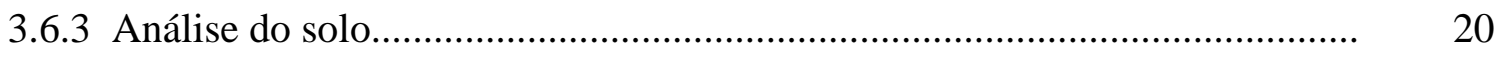

3.7 Coleta das amostras de madeira para a análise dos anéis de crescimento.......... 21

3.8 Análise da estrutura anatômica da madeira........................................................ 23

3.9 Correlação dos dados................................................................................ 23

4 RESULTADOS

4.1 Espécies florestais..................................................................................... 24

4.2 Análise das condições de crescimento das árvores............................................. 24

4.3 Estudo da taxa de crescimento em circunferência do tronco das árvores........... 25

4.4 Avaliação da fenologia................................................................................. 48

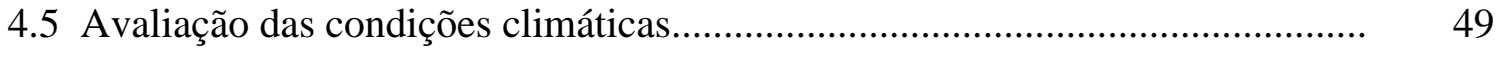

4.6 Idade e taxa de crescimento das árvores........................................................ 54

4.7 Características anatômicas do lenho e dos anéis de crescimento........................ 74

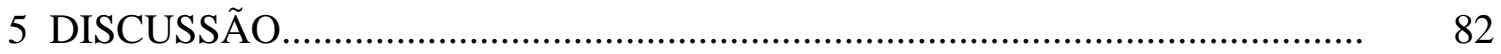

5.1 Relação das condições de crescimento das árvores com a atividade cambial... 82

5.2 Relação da fenologia das árvores com a atividade cambial............................... 84

5.3 Relação das variações climáticas com a atividade cambial das árvores............. 85

5.4 Correlação da fenologia, variáveis climáticas e a atividade cambial das



5.5 Largura dos anéis de crescimento................................................................. 88

5.6 Características anatômicas das madeiras e dos anéis de crescimento................. 89

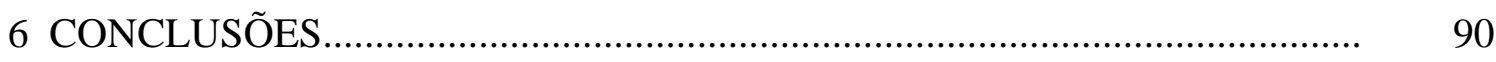

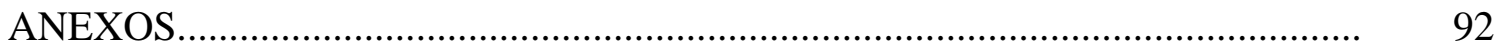

REFERÊNCIAS BIBLIOGRÁFICAS................................................................. 97 


\section{LISTA DE FIGURAS}

1 Etapas da montagem e da instalação da faixa dendrométrica de aço no tronco de uma árvore

Páginas

2 Modelo de faixa dendrométrica acoplada no tronco da árvore

3 Coleta de madeira pelo método não destrutivo com sonda de Pressler.........

4 Equipamentos utilizados na identificação e mensuração dos anéis de crescimento.

5 Modelo de atividade cambial, formação dos anéis de crescimento, correlação entre fenologia e condições ambientais, segundo Burchert (1999).

6 Variação do incremento médio mensal das espécies florestais na Estação Ecológica de Ibicatu (Piracicaba) no período dezembro de 1998 a outubro de 2001 (exceto fevereiro de 1999). (A) Aspidosperma polyneuron (peroba-rosa); (B) Centrolobium tomentosum (araribá); (março de 1999 a outubro de 2001) (C) Piptadenia gonoacantha (pau-jacaré).

7 Variação do incremento médio mensal das espécies florestais na Estação Ecológica de Ibicatu (Piracicaba) no período dezembro de 1998 a outubro de 2001 (exceto fevereiro de 1999). (A) Esenbeckia leiocarpa (guarantã); (B) Savia dyctiocarpa (guaraiúva)

8 Variação do incremento médio mensal das espécies florestais na Estação Experimental de Tupi (Piracicaba) no período de janeiro de 1999 a outubro de 2001. (A) Balfourodendron riedelianum (pau-marfim); (B) Caesalpinia ferrea (pau-ferro); (C) Esenbeckia leiocarpa (guarantã)... 
9 Variação do incremento médio mensal das espécies florestais na Es tação Experimental de Tupi (Piracicaba) no período de setembro de 1999 a outubro de 2001. (A) Aspidosperma polyneuron (peroba-rosa); (janeiro de 1999 a outubro de 2001) (B) Cariniana estrellensis (jequitibá-branco); (abril de 2000 a outubro de 2001) (C) Schizolobium parahyba (guapuruvu)

10 Variação do incremento médio mensal das espécies florestais na Reserva Florestal Mata de Santa Genebra no período de fevereiro de 2001 a outubro de 2001. (A) Centrolobium tomentosum (araribá); (B) Copaifera langsdorffii (copaíba); (C) Esenbeckia leiocarpa (guarantã).

11 Variação do incremento médio mensal das espécies florestais na Reserva Florestal Mata de Santa Genebra no período de outubro de 2000 a outubro de 2001. (A) Aspidosperma polyneuron (peroba-rosa); (janeiro a outubro de 2001) (B) Cedrella fissilis (cedro); (fevereiro a outubro de 2001) (C) Trichilia claussenii (catiguá).

12 Variação do incremento médio mensal das espécies florestais na Reserva Florestal Mata de Santa Genebra no período de novembro de 2000 a outubro de 2001. (A) Pachystroma longifolium (canxim); (B) Piptadenia gonoacantha (pau-jacaré)

13 Variação do incremento acumulado de espécies florestais na Estação Ecológica de Ibicatu (Piracicaba) no período dezembro de 1998 a outubro de 2001 (exceto fevereiro de 1999). (A) Aspidosperma polyneuron (peroba-rosa); (B) Centrolobium tomentosum (araribá); (C) Esenbeckia leiocarpa (guarantã).

14 Variação do incremento acumulado de espécies florestais na Estação Ecológica de Ibicatu (Piracicaba) no período de março de 1999 a outubro de 2001. (A) Piptadenia gonoacantha (pau-jacaré); (dezembro de 1998 a outubro de 2001 - exceto fevereiro de 1999) (B) Savia dyctiocarpa (guaraiúva).

15 Variação do incremento acumulado de espécies florestais na Estação Experimental de Tupi (Piracicaba) no período de setembro de 1999 a outubro de 2001. Aspidosperma polyneuron (peroba-rosa); (janeiro de 1999 a outubro de 2001) (B) Balfourodendron riedelianum (pau-marfim); (C) Esenbeckia leiocarpa (guarantã). 
16 Variação do incremento acumulado de espécies florestais na Estação Experimental de Tupi (Piracicaba) no período de janeiro de 1999 a outubro de 2001. (A) Caesalpinia ferrea (pau-ferro); (B) Cariniana estrellensis (jequitibá-branco) (abril de 2000 a outubro de 2001) (C) Schizolobium parahyba (guapuruvu)..........................................................

17 Variação do incremento acumulado de espécies florestais na Reserva Florestal Mata de Santa Genebra no período de outubro de 2000 a outubro de 2001. (A) Aspidosperma polyneuron (peroba-rosa); janeiro a outubro de 2001. (B) Cedrela fissilis (cedro); (fevereiro a outubro de 2001) (C) Centrolobium tomentosum (araribá).

18 Variação do incremento acumulado de espécies florestais na Reserva Florestal Mata de Santa Genebra no período de fevereiro de 2001 a outubro de 2001. (A) Copaifera langsdorffii (copaíba); (B) Esenbeckia leiocarpa (guarantã); (C) Trichilia claussenii (catiguá).

19 Variação do incremento acumulado de espécies florestais na Reserva Florestal Mata de Santa Genebra no período de outubro e novembro de 2000 a outubro de 2001. (A) Astronium graveolens (guaritá); (B) Pachystroma longifolium (canxim); (C) Piptadenia gonoacantha (pau-jacaré).

20 Variação do incremento médio mensal entre árvores de algumas espécies florestais no período de dezembro de 1999 a outubro de 2001. (A) Caesalpinia ferrea (pau-ferro); (B) Cariniana estrellensis (jequitibábranco) - Estação Ecológica de Tupi (Piracicaba) - (C) Centrolobium tomentosum (araribá) - Estação Ecológica de Ibicatu (Piracicaba) (D) Piptadenia gonoacantha (pau-jacaré) - Reserva Florestal Mata de Santa Genebra (Campinas).

21 Balanco Hídrico Normal. (A) Piracicaba - período de janeiro de 1999 a outubro de 2001; (B) Campinas - período de setembro de 2000 a outubro de 2001

22 Média de temperatura e umidade relativa. (A) Piracicaba - período de janeiro de 1999 a outubro de 2001; (B) Campinas - período de setembro de 2000 a outubro de 2001

23 Variação do incremento anual das árvores de Aspidosperma polyneuron (peroba-rosa) na Estação Ecológica de Ibicatu (Piracicaba). (A) Árvore 1; (B) Árvore 2; (C) Árvore 3; (D) Total. 
24 Variação do incremento anual das árvores de crescimento de Centrolobium tomentosum (araribá) na Estação Ecológica de Ibicatu (Piracicaba). (A) Árvore 2; (B) Árvore 3; (C) Árvore 6; (D) Total.

25 Variação do incremento anual das árvores de Esenbeckia leiocarpa (guarantã) na Estação Ecológica de Ibicatu (Piracicaba). (A) Árvore 4;



26 Variação do incremento anual das árvores de Piptadenia gonoacantha (pau-jacaré) na Estação Ecológica de Ibicatu (Piracicaba). (A) Árvore 1; (B) Árvore 2; (C) Árvore 6; (D) Total.

27 Variação do incremento anual das árvores de Savia dyctiocarpa (guaraiúva) na Estação Ecológica de Ibicatu (Piracicaba). (A) Árvore 1; (B) Árvore 4; (C) Árvore 5; (D) Total.

28 Variação do incremento anual das árvores de Aspidosperma polyneuron (peroba-rosa) na Estação Experimental de Tupi (Piracicaba). (A) Árvore 1; (B) Árvore 2; (C) Árvore 3; (D) Total.

29 Variação do incremento anual das árvores de Balfourodendron riedelianum (paut marfim) na Estação Experimental de Tupi (Piracicaba). (A) Árvore 1; (B) Árvore 2; (C) Árvore 3; (D) Total.

30 Variação do incremento anual das árvores de Caesalpinia ferrea (pauferro) na Estação Experimental de Tupi (Piracicaba). (A) Árvore 2; (B) Árvore 3; (C) Árvore 5; (D) Total.

31 Variação do incremento anual das árvores de Cariniana estrellensis (jequitibá-branco) na Estação Experimental de Tupi (Piracicaba). (A) Árvore 1; (B) Árvore 2; (C) Árvore 3; (D) Total

32 Variação do incremento anual das árvores de Esenbeckia leiocarpa (guarantã) na Estação Experimental de Tupi (Piracicaba). (A) Árvore 6; (B) Árvore 8; (C) Ârvore 9; (D) Total.

33 Variação do incremento anual das árvores de Aspidosperma polyneuron (peroba-rosa) na Reserva Florestal Mata de Santa Genebra (Campinas). (A) Árvore 1; (B) Árvore 3; (C) Árvore 4; (D) Total.

34 Variação do incremento anual das árvores de Cedrella fissilis (cedro) na Reserva Florestal Mata de Santa Genebra (Campinas). (A) Árvore 1; (B) Árvore 2; (C) Árvore 3; (D) Total. 
35 Variação do incremento anual das árvores de Centrolobium tomentosum (araribá) na Reserva Florestal Mata de Santa Genebra (Campinas). (A) Árvore 2; (B) Árvore 3; (C) Árvore 4; (D) Total..................................

36 Variação do incremento anual das árvores de Esenbeckia leiocarpa (guarantã) na Reserva Florestal Mata de Santa Genebra (Campinas). (A) Árvore 1; (B) Árvore 3; (C) Árvore 4; (D) Total.................................

37 Variação do incremento anual das árvores de Pachystroma longifolium (canxim) na Reserva Florestal Mata de Santa Genebra (Campinas). (A) Árvore 1; (B) Árvore 2; (C) Árvore 4; (D) Total.

38 Variação do incremento anual das árvores de Piptadenia gonoacantha (pau-jacaré) na Reserva Florestal Mata de Santa Genebra (Campinas). (A) Ârvore 1; (B) Árvore 4; (C) Árvore 5; (D) Total.

39 Variação do incremento anual das árvores de Trichilia claussenii (catiguá) na Reserva Florestal Mata de Santa Genebra (Campinas). (A) Árvore 1; (B) Árvore 2; (C) Árvore 4; (D) Total.

40 Fotomacrografias das secções transversais do lenho das árvores das espécies florestais. Aspidosperma polyneuron (peroba-rosa) (A,B); Balfourodendron riedelianum (pau-marfim) (C,D); Caesalpinia ferrea (pau-ferro) (E,F) - aumento de 8x (esquerda) e 12x (direita)......................

41 Fotomacrografias das secções transversais do lenho das árvores das espécies florestais. Cariniana estrellenisis (jequitibá-branco). (A,B); Cedrela fissilis (cedro) (C,D); Centrolobium tomentosum (araribá) (E,F) aumento de $8 x$ (esquerda) e 12x (direita)

42 Fotomacrografias das secções transversais do lenho das árvores das espécies florestais. Esenbeckia leiocarpa (guarantã). (A,B); Pachystroma longifolium (canxim) (C,D); Piptadenia gonoacantha (pau-jacaré) (E,F) aumento de $8 x$ (esquerda) e 12x (direita).....

43 Fotomacrografias das secções transversais do lenho das árvores das espécies florestais. Savia dyctiocarpa (guaraiúva) (A,B); Trichilia claussenii (cariguá) (C,D) - aumento de 8x (esquerda) e 12x (direita)......... 


\section{LISTA DE TABELAS}

1 Espécies selecionadas para o estudo.

Páginas

15

2 Intervalo de classe de circunferência (CAP - em centímetros), das 13 espécies florestais arbóreas nos locais de estudo.

3 Posição sociológica das árvore, das diferentes espécies, nas 3 áreas de estudo.

4 Localização das árvores, das diferentes espécies, quanto a posição que ocupam nas 3 áreas de estudo.

5 Presença ou ausência de lianas para todas as árvores, das diferentes espécies, nas 3 áreas de estudo...

6 Taxas médias mensais e acumuladas em circunferência do tronco das espécies em estudo e períodos de diminuição/retomada da atividade cambial....

7 Taxa de crescimento em circunferência médio mensal e acumulado de algumas árvores das espécies em estudo.

8 Fenologia de espécies arbóreas nas florestas estacionais semidecíduas em estudo.

9 Informações ecológicas das espécies arbóreas nas florestas estacionais semidecíduas em estudo.

10 Incremento médio anual e estimativa da idade das árvores das 3 áreas em estudo.

11 Descrição macroscópica das principais características da estrutura anatômica das madeiras das espécies em estudo. 


\section{PERIODICIDADE DO CRESCIMENTO E FORMAÇÃO DA MADEIRA DE ALGUMAS ESPÉCIES ARBÓREAS DE FLORESTAS ESTACIONAIS SEMIDECÍDUAS DA REGIÃO SUDESTE DO ESTADO DE SÃO PAULO}

Autora: LIGIA FERREIRA

Orientador: Prof. Dr. MARIO TOMAZELLO FILHO

\section{RESUMO}

Os estudos dendrocronológicos e dendroclimatológicos estão começando a ser utilizados nas florestais tropicais e subtropicais brasileiras. Estes estudos são importantes para correlacionar a taxa de crescimento das espécies florestais com a variações climáticas e fenológicas e determinar a idade das árvores. Desta forma, este trabalho teve como objetivos principais: (i) estudar a periodicidade da atividade cambial e da formação dos anéis de crescimento utilizando o método de faixas dendrométricas em três locais da região do sudeste do Estado de São Paulo; (ii) determinar a idade de algumas árvores das espécies selecionadas (dendrocronologia); (iii) correlacionar o crescimento em circunferência das árvores com as variações climáticas, fenológicas e condições de crescimento (dendroclimatologia e dendroecologia); (iv) fazer a identificação macroscópica das madeiras das espécies estudadas. Para esse trabalho foram escolhidas as seguintes reservas: Estação Ecológica de Ibicatu (Piracicaba/SP) e Reserva Florestal Mata de Santa Genebra (Campinas/SP) com espécies nativas e Estação Experimental de Tupi (Piracicaba/SP) plantios com essências nativas de idade conhecida. Através dos resultados obtidos constatou-se que (a) o local onde uma espécie se desenvolve e suas condições de crescimento podem interferir no ritmo de crescimento 
dos indivíduos; (b) a faixa dendrométrica colocada nos troncos das árvores é um equipamento fundamental, preciso e muito eficiente para se medir a taxa de crescimento em circunferência do tronco de espécies florestais; (c) as variáveis climáticas, como precipitação e temperatura, e o comportamento fenológico das espécies estão diretamente correlacionados com o crescimento em circunferência do tronco das mesmas; (d) a metodologia referente a dendrocronogia é fundamental e precisa para determinar a idade de uma árvore; (e) não houve diferenças na observação da estrutura anatômica macroscópica da madeira em relação a literatura e aos locais. 


\section{GROWTH PERIODICITY AND FORMATION OF WOOD OF SOME TREE SPECIES OF SEMIDECIDUOUS SEASONAL FOREST IN THE SOUTHEAST REGION OF THE STATE OF SÃO PAULO}

Author: LIGIA FERREIRA

Adviser: Prof. Dr. MARIO TOMAZELLO FILHO

\section{SUMMARY}

The dendrocronology and dendroclimatology studies are now being used in the tropical and subtropical Brazilian forest. These studies are important to correlate the growth rate of forest species with climatic conditions and phenological behaviour to determine the age of the trees. This way, this investigation had as main objectives: (i) study the cambial periodicity activity and the tree-ring formation by using the dendrometer bands method in three areas in the Southeast region of the state of São Paulo; (ii) determine the age of some selected trees species (dendrocronology); (iii) correlate the girth increment of the trees with climatic conditions and phenological behaviour and growth condition (dendroclimatology and dendroecology); (iv) to identify macroscopically the wood of these species. For this investigation were chosen the following reserves: Ibicatu Ecological Station - (Piracicaba/SP) and Santa Genebra Forest Reserve (Campinas/SP) with indigenous growing in natural conditions and Tupi Experimental Station (Piracicaba/SP) plantations of native species with known age. Through the results obtained, it was verified that (a) the local where the specie is developed and its growth condition can interfere in growth rhythm of the trees; (b) the 
dendrometer bands in the trunk of the trees is a fundamental equipment, accuracy and very efficient tool for measuring girth increment of the trunk of the forest tree species; (c) the climatic variation as, precipitation and temperature, and the phenological behavior of the species are closely correlated with the girth increment of the trunk of the trees; (d) dendrocronological method is fundamental and accurate to determine the age of the tree, and; (e) there is no espressive difference between the macroscopical wood structure of the tress species studied and that one cited in literature. 


\section{INTRODUÇÃO}

Os ecossistemas florestais brasileiros têm sido submetidos no último século e, principalmente, nas últimas décadas a uma intensa pressão antropogênica. Essa pressão tem sido detectada com mais intensidade em alguns ecossistemas, como nas florestas de Araucária, nos cerrados, na floresta Atlântica, nas florestas de planalto, etc., pelo uso da madeira para seus diversos fins, ocupação urbana e agrícola, atividades de mineração, dentre outras. Somente no Estado de São Paulo, os levantamentos atualizados indicam que a cobertura da vegetação natural remanescente atinge valores de 13,4\%, ou seja, uma área de 3.330.744 ha, concentrados principalmente na região do litoral sul. Nestes remanescentes estão incluídas as áreas de florestas, capoeira, cerrado, cerradão, campo cerrado, campo, vegetação de várzea, mangue e restinga. Este quadro reflete o quase completo desaparecimento das florestas estacionais semidecíduas do planalto paulista, concentradas atualmente, em algumas reservas governamentais e particulares. Como conseqüência verifica-se uma significativa e acentuada redução da biodiversidade, colocando sob risco de extinção inúmeros organismos, incluindo algumas de espécies florestais. O aspecto mais grave é a quase completa escassez de informações acerca da biologia, ecologia, genética, etc. de inúmeras espécies arbóreas das florestas estacionais semidecíduas. Essas espécies arbóreas, além de terem reduzida a sua base genética poderão desaparecer mesmo antes de serem realizados importantes e fundamentais estudos, relacionados a dendrocronologia e dendroecologia, como a determinação da idade, da taxa de crescimento, dinâmica de crescimento das populações e sua utilização como fonte de novos medicamentos.

Dessa forma, essas ciências, apenas recentemente aplicadas às condições tropicais e subtropicais, poderão auxiliar para o melhor conhecimento da biologia de inúmeras 
espécies florestais, contribuindo para a sua conservação, bem como para a implantação e/ou enriquecimento de novas populações. Os estudos da formação dos anéis de crescimento, da periodicidade da atividade cambial e da anatomia da madeira e suas relações com a fenologia e fatores climáticos de árvores de espécies tropicais e subtropicais podem ser aplicados em diferentes áreas, como a dendrocronologia, silvicultura, manejo florestal, etc.

Durante muito tempo considerourse que plantas nesses ecossistemas cresciam de forma contínua durante todo o ano sem a demarcação de anéis de crescimento. Entretanto, pesquisas revelam que em muitas regiões tropicais e subtropicais as árvores apresentam sazonalidade de crescimento bem definida. Portanto, a aplicação de novas áreas da ciência, como a dendroecologia, são imprescindíveis para entender a dinâmica desses ecossistemas florestais que, apesar de sua importância e biodiversidade, encontram-se ainda dentre os menos conhecidos do país.

Sendo assim, é de grande importância obter o conhecimento destas espécies tropicais e subtropicais. Neste sentido, o presente trabalho teve como principais objetivos, (i) estudar a periodicidade da atividade cambial e da formação dos anéis de crescimento utilizando o método de faixas dendrométricas em três locais da região sudeste do Estado de São Paulo; (ii) determinar a idade de algumas árvores das espécies selecionadas (dendrocronologia); (iii) correlacionar o crescimento em circunferência das árvores com as variações climáticas, fenológicas e condições de crescimento (dendroclimatologia e dendroecologia); (iv) fazer um identificação macroscópica das madeiras das espécies estudadas.

A partir destes objetivos, o presente trabalho teve como hipóteses: (a) o local e as condições de crescimento das espécies arbóreas interferem em suas taxas de crescimento; (b) a utilização das faixas dendrométricas é eficaz para verificar a periodicidade de crescimento das árvores; (c) todas as variáveis climáticas estão diretamente relacionadas com o crescimento em circunferência das árvores; (d) as fenofases interferem na atividade cambial das espécies em estudo; (e) a metodologia para analisar a idade das árvores é precisa; (f) há diferença na estrutura macroscópica das madeiras dependendo da localização das mesmas. 


\section{REVISÃO DE LITERATURA}

\subsection{Aplicação de faixas dendrométricas na avaliação do crescimento em circunferência do tronco das árvores}

As espécies arbóreas que crescem em regiões temperadas revelam oscilações periódicas do crescimento em circunferência do seu tronco enquanto que, as de climas tropicais são geralmente consideradas de crescimento contínuo, ou seja, não sazonais. No entanto, muitas espécies tropicais e subtropicais apresentam crescimento rítmico sendo necessário pesquisar fatores que controlam essa periodicidade, atribuída aos ritmos internos das árvores e às variações climáticas (Alvim, 1964).

A avaliação contínua dos incrementos em circunferência do tronco dessas espécies possibilita, à médio e longo prazos, a determinação do ritmo e da taxa de crescimento, da periodicidade da atividade cambial e da influência dos fatores climáticos. Para essa avaliação são utilizadas faixas dendrométricas (em associação com as marcações anuais do câmbio das árvores), que são fáceis de montar, instalar, de baixo custo e com leituras precisas (Botosso \& Tomazello Filho, 2001).

As faixas dendrométricas têm sido plicadas pelo "Centre Technique Forestier Tropical" (CTFT), na França, desde 1965, em estudos da periodicidade do crescimento em circunferência do tronco de árvores tropicais em diversos continentes, além de análises de identificação dos anéis de crescimento à partir das características anatômicas da madeira e marcações cambiais (Détienne, 1989).

O método de faixas dendrométricas foi utilizado em Turrialba (Costa Rica) para verificar a relação entre os fatores climáticos com a periodicidade do crescimento do tronco de espécies florestais de clima subtropical (Lojan, 1967). Na Malásia, Jalil et al. 
(1998) determinaram a periodicidade do crescimento em circunferência do tronco de árvores de Hevea brasiliensis com dendrômetros de alumínio.

Na África e na Guiana Francesa, Mariaux (1969), citado por Worbes, (1995), Mariaux (1970) e Détienne (1989) utilizaram faixas dendrométricas de aço na determinação do ritmo, da taxa de crescimento do tronco e da periodicidade de formação dos anéis de crescimento de inúmeras espécies de árvores tropicais relacionando-as com a fenologia e variações climáticas.

As faixas dendrométricas foram utilizadas para determinar a periodicidade e a taxa de crescimento do tronco de algumas espécies tropicais e sua relação com o clima, na região de Manaus (AM) (Vetter \& Botosso, 1988 e Botosso, et al., 2000). Da mesma forma, Tomazello Filho \& Botosso (1999) obtiveram informações acerca da periodicidade da taxa de crescimento do tronco e da atividade cambial de árvores de espécies tropicais da região sudeste do Estado de São Paulo.

As faixas dendrométricas são atualmente confeccionadas com fitas de aço inoxidável e, segundo Kätsch et al. (1992), citado por Worbes (1995), permitem a medição contínua do crescimento em circunferência do tronco das árvores com excelente nível de precisão. Botosso (2000) verificou que estas faixas têm se mostrado indispensáveis nas medições contínuas e de médio a longo prazos, analisando a periodicidade do crescimento do tronco de árvores de várias espécies de matas estacionais semidecíduas no Estado de São Paulo

\subsection{Fenologia}

As observações fenológicas vêm sendo realizadas desde os primórdios da história, sendo que há mais de 2 mil anos já havia, na China, um calendário fenológico. Muito da sabedoria tradicional dos lavradores advém da observação dos fenômenos meteorológicos e fenológicos (Larcher, 1986).

A fenologia é o estudo das fases ou atividades do ciclo de vida das plantas e sua ocorrência temporal ao longo do ano (Leitão Filho \& Morellato, 1995). No entanto, segundo o Comitê de Fenologia do Programa Internacional de Biologia, a fenologia é o estudo dos eventos biológicos repetitivos e das causas de sua ocorrência, em relação as 
forças bióticas e abióticas e da inter-relação entre fases caracterizadas por eventos na mesma ou em diferentes espécies (Matthes, 1980).

Para Fournier (1967), citado por Cardoso (1991), os estágios fenológicos apresentados por uma determinada espécie são de grande importância para o entendimento da sua adaptação e da dinâmica na comunidade, além de ser possível indicador das variações das condições climáticas do ambiente.

As variações da temperatura, precipitação, radiação solar e de outros fatores climáticos em áreas tropicais são, freqüentemente, consideradas de menor significação ecológica em comparação com os climas temperados, quando é discutido o ritmo do crescimento das árvores. Contudo, os estudos dos eventos fenológicos de espécies arbóreas tropicais têm demonstrado uma nítida periodicidade desses eventos, na produção e queda de folhas, frutificação, floração, etc., induzidos por fatores climáticos, refletindo na atividade cambial e na formação de anéis de crescimento (Alvim, 1964 e Jacoby, 1989).

Fonseca (1998) fez um estudo sobre a fenologia de espécies florestais de uma área de floresta estacional semidecidual localizada em Botucatu-SP. Verificou que a comunidade florestal estudada apresentou padrões sazonais para as fenofases de queda de folhas, brotamento, floração e frutificação das árvores e algumas variações na fenologia das espécies de acordo com a sua estratificação e distribuição no mosaico florestal (clareira e borda da clareira).

Cardoso (1991) estudou o ciclo completo do crescimento e desenvolvimento de árvores de Tectona grandis (teca) relacionando a idade e a taxa de crescimento com os eventos fenológicos, a formação da madeira e características dos anéis de crescimento anuais e as variações climáticas. O mesmo verificou que, quando as árvores possuíam as folhas amareladas, secas e em queda e os frutos em fase de dispersão o câmbio vascular das árvores encontrou-se em dormência e quando as folhas estavam renovadas e em fase de desenvolvimento ocorreu a ativação do câmbio.

Em regiões tropicais, da América Central e Ásia, com um longo período seco, as árvores decíduas apresentaram a fenologia e a atividade cambial correlacionadas entre si, em relação à precipitação. Para as semidecíduas e perenes, a correlação com a atividade 
cambial não foi significativa, principalmente, em locais com grande disponibilidade de água no solo (Borchert, 1999).

As observações fenológicas realizadas juntamente com a avaliação do período de atividade cambial em árvores de duas espécies tropicais na Malásia, mostraram que a formação da madeira é contínua e não parece estar relacionada com a variação de precipitação e fenologia (Sass et al., 1995). Entretanto, estudo realizado com árvores de Zigophylum dumosum mostrou que a periodicidade da atividade cambial está relacionada com a queda das folhas (Waisel, 1970).

No Brasil, estudos iniciais realizados no sudeste do Estado de São Paulo, correlacionaram a atividade cambial com a fenologia das árvores mostrando uma relação entre a fase de perda das folhas coincidente, com o período de diminuição e/ou cessação da atividade cambial das árvores (Botosso, 2000).

\subsection{Variações climáticas relacionadas à atividade cambial}

A fisionomia das florestas tropicais é determinada principalmente pela quantidade, época e distribuição de chuvas durante o ano. Mudanças climáticas podem resultar no aumento dos períodos secos e as árvores de florestas tropicais podem apresentar mecanismos adaptativos, como quedas de folhas, raízes suculentas, etc. (Borchert, 1999). Muitos pesquisadores têm demonstrado a associação da periodicidade no crescimento de árvores tropicais com as variações na temperatura, fotoperíodo e precipitação. Estes fatores do ambiente podem estar relacionados, ao surgimento de expressões anatômicas no xilema, derivadas de alterações da atividade cambial, resultantes do crescimento rítmico (Smith, 1997).

$\mathrm{O}$ crescimento em diâmetro do tronco das árvores em ambientes xéricos, na Argentina, tem sido extremamente influenciado pela mudança de precipitação. Nestes locais, através da análise dos anéis de crescimento, foi detectado um aumento da precipitação durante três décadas, causando o transporte de quantidade maior de massas úmidas da região tropical para as regiões subtropicais semiáridas (Villalba et al., 1998).

A correlação entre variáveis climáticas e a periodicidade de crescimento das árvores das espécies vegetais foi analisada por Lojan (1965), com seis espécies na Costa 
Rica. As observações feitas no período de um ano, possibilitaram concluir que fatores internos da planta (genéticos, idade, fisiológico) e externos (climáticos, competição) foram relacionados com diferentes taxas de crescimento do tronco das plantas.

Com o objetivo de avaliar a variação do crescimento do tronco das árvores com relação às mudanças climáticas e ao habitat, nas florestas montanhosas do Colorado, Villalba (1994) verificou que as árvores de algumas espécies de áreas mais secas mostraram maior correlação entre a atividade cambial e as variações climáticas em relação aos locais mais úmidos.

Os períodos sazonais da fenologia e da atividade cambial foram comparados com a precipitação e observado que nas árvores decíduas, em locais com menor umidade, a fenologia e a atividade cambial foram diretamente relacionadas com o período de chuva, determinando a formação dos anéis de crescimento anuais (Borchert, 1999).

A influência da precipitação e da temperatura no crescimento das árvores de 2 espécies sazonais em florestas tropicais secas foi investigada por Enquist \& Leffer (2001) na Costa Rica. A formação dos anéis de crescimento relacionou-se com as árvores com fenologias mais contrastantes, apresentando pequeno crescimento em diâmetro do tronco nos meses de maior precipitação.

A variação climática e sua influência na taxa de crescimento do tronco de árvores de 37 espécies florestais na Reserva Florestal de Caparaó, Venezuela, foi investigada por Worbes (1999). A atividade cambial foi geralmente alta durante a época de chuvas e no final deste período, decrescendo no início do período seco até a dormência cambial.

A sazonalidade da atividade cambial e a periodicidade do crescimento de árvores de 3 espécies, Citharexylum myrianthum, Cedrela fissilis e Copaifera langsdorffii, foram estudadas por Marcati (2000). A autora verificou um ritmo anual de crescimento caracterizado por atividade cambial diferenciada nos períodos chuvoso e seco. A atividade cambial das árvores foi mais intensa no período chuvoso, em relação ao seco, através de exames histológicos da região cambial, realizados ao longo das estações do ano. 


\subsection{Idade e taxa de crescimento da árvore}

A atividade periódica do câmbio das árvores proporciona a formação dos anéis de crescimento que representam os seus incrementos anuais do tronco, permitindo a determinação da idade da planta. Mudanças abruptas na disponibilidade de água e/ou de outros fatores ambientais podem ser responsáveis pela produção de mais de um anel de crescimento no mesmo ano, denominado falsos anéis de crescimento. Estes tipos de anéis de crescimento não estão presentes em toda a circunferência do tronco da árvore, como ocorre com os verdadeiros anéis de crescimento. Esse estudo dos anéis de crescimento e sua relação com a idade das árvores e com os fatores climáticos é feita pela dendrocronogia (Burger \& Richter, 1991 e Raven, 1996).

A dendrocronologia inicioutse como ciência com observações dos anéis de crescimento, nos séculos XVIII-XIX, para a determinação da idade das árvores de várias espécies. A aplicação da dendrocronologia é difícil em espécies tropicais pois, muitas vezes, os anéis de crescimento não estão perfeitamente visíveis ou são inexistentes. Para obter bons resultados é necessário que as estações do ano sejam definidas, para induzir a sazonalidade da atividade cambial (Ashton, 1981 e Jacoby, 1989).

A existência da periodicidade do crescimento do tronco das árvores tropicais não implica, necessariamente, na ocorrência do ritmo sazonal do câmbio, devendo ser analisada para cada espécie e local. As condições climáticas de certas áreas tropicais permitem o uso da dendrocronologia na caracterização dos anéis de crescimento e do ritmo de crescimento das árvores (Worbes, 1989, 1995). Sendo assim, Devall et al. (1995) citam vários estudos com árvores de espécies tropicais feitos no Brasil, Índia e na Tailândia, mostrando resultados promissores quanto a identificação dos anéis de crescimento e datação das árvores.

Estudos realizados com 30 espécies de árvores tropicais da África e da América do Sul mostraram variações da estrutura anatômica da madeira em alguns gêneros e condições de clima, possibilitando a demarcação dos anéis de crescimento anuais no tronco das árvores (Détienne,1989). 
A datação das árvores de espécies tropicais e a reconstrução climática de épocas passadas podem ser possíveis se houver a correlação entre a largura dos anéis de crescimento e os dados climáticos (Botosso \& Tomazello Filho, 2001).

Em árvores de floresta de igapó e de várzea na Amazônia Central, os anéis de crescimento são distintos e a sua largura depende da duração do período de inundação. No entanto, a estimativa de idade das árvores, em ambos ecossistemas pelos anéis de crescimento, mostrou diferenças explicadas pela estratégia de adaptação das diferentes espécies no período de inundação (Worbes, 1987).

Lojan (1967) estudando a periodicidade do crescimento do tronco de árvores de espécies tropicais em Turriaba, Costa Rica, constatou que as árvores decíduas apresentaram 6 meses de crescimento seguidos de 6 meses de repouso; as perenifólias mostraram 6 meses de menor crescimento, seguidos de 6 com maior taxa de crescimento do tronco.

Os anéis de crescimento das árvores indicam as condições de conservação e as mudanças antropogênicas de ecossistemas florestais. As mudanças na largura dos anéis de crescimento de árvores de cada espécie mostram significativa redução de crescimento de forma tão visível que dispensam a aplicação de técnicas sofisticadas para a visualização dos mesmos (Eckstein \& Krause, 1989).

A reação individual de uma árvore, e também de uma população, indicando o efeito do clima, das perturbações no ambiente, da poluição, do fogo, enchentes e até de erupções vulcânicas pode ser mostrada pelos anéis de crescimento e esses diferentes tipos de perturbações podem refletir no crescimento em diâmetro das árvores (Eckstein et al., 1981 e Latimer et al.,1996).

\subsection{A estrutura anatômica e os anéis de crescimento}

A anatomia da madeira constitui-se no estudo dos diversos tipos de células que formam o lenho, bem como suas funções, organização e peculiaridades estruturais. Tem como objetivos, o conhecimento da madeira para a identificação das espécies, distinção de madeiras aparentemente idênticas, emprego correto, etc. Além disso, a anatomia é 
importante para a definição da estrutura dos anéis de crescimento e as características que definem seus limites (Worbes, 1989 e Burger \& Richter, 1991).

A estrutura anatômica da madeira varia dentro de uma espécie dependendo das condições de crescimento das árvores. Para Piranhea trifolia (Euphorbiaceae), localizada em floresta de inundação, as árvores mais jovens mostraram anéis de crescimento distintos, ao contrário das árvores mais velhas, em floresta de terra firme. No lenho de árvores de Tabebuia barbata (Bignoniaceae) de locais com condições luminosas variáveis, os anéis de crescimento mostraram-se distintos nos limites do lenho mais jovem do que no mais antigo (Worbes, 1989).

Em áreas tropicais da América do Sul e da África, muitas espécies florestais, tais como a Tectona grandis (Verbenaceae) e Cedrela odorata (Meliaceae), apresentaram anéis de crescimento semi-porosos, visíveis a olho nu, com uma espessa faixa de parênquima axial inicial e vasos de maior diâmetro demarcando o limite do anel de crescimento. Nas árvores jovens de crescimento rápido, alguns anéis de crescimento são espessos e mostram faixas de parênquima axial e vasos largos alternadas por faixas com vasos de diâmetro menor. Os anéis de crescimento são bem marcados pelo parênquima apotraqueal em faixas ou por zonas porosas de vasos (Détienne, 1989).

Boninsegna et al. (1989) realizaram estudos anatômicos observando a presença de zonas de crescimento em 13 espécies da Selva Misionera, Argentina. As principais estruturas anatômicas relacionadas com a visibilidade dos anéis de crescimento foram, (i) anéis porosos ou semi-porosos (Cedrela fissilis e Cordia trichotoma); (ii) parênquima axial marginal uni ou multisseriado, com as células freqüentemente preenchidas por substâncias cristalinas (Parapiptadenia rigida, Peltophorum dubuiem, Myrocarpus frondosus); (iii) várias faixas de fibras com pequeno diâmetro radial e paredes espessas (Chorosia speciosa, Aspidosperma polyneuron, Oconea puberula, Nectandra saligna) e (iv) parênquima alongado na camada de crescimento (Cabralea oblongifolia).

As amostras de madeira de Acacia melanoxylon de várias localidades na Austrália foram examinadas com relação a sua estrutura anatomia e a latitude. O comprimento da membrana dos vasos, a proporção das fibras e dos raios multisseriados tiveram relação 
com a latitude, ao contrário da frequiência e o diâmetro dos vasos, abundância de cristais, proporção de raio e a densidade básica da madeira (Wilkins, 1989).

Para árvores de Drybalanops sumatrensis e de Shorea leprosula, foi observada uma forte reação aos ferimentos no câmbio na fase de formação do xilema, provocando a formação de saliência de tecidos de cicatrização de parênquima na direção radial e tangencial (Sass et al., 1995).

Para algumas espécies florestais do Estado de São Paulo Botosso \& Tomazello Filho (2001) observaram que as alterações anatômicas da madeira indicam a resposta da atividade cambial a determinadas condições de crescimento. As camadas de crescimento podem ser evidenciadas por alguns padrões anatômicos como, canais intercelulares axiais em disposição tangencial, aumento da espessura e achatamento da parede radial das fibras, tipo de organização e arranjo do parênquima axial e diâmetro e frequiência dos poros.

Villalba \& Boninsegna (1989) analisaram o diâmetro e a distribuição dos vasos na madeira de Prosopis flexuosa em 2 locais ecologicamente diferentes em Mendoza, Argentina. Observaram uma distribuição homogênea do diâmetro em alguns locais e diferenças do diâmetro dos vasos em outros relacionadas com o aumento do sistema radicular e maior absorção de água.

Em árvores de Tabebuia barbata, da floresta de inundação na Amazônia verificou-se que os limites das zonas de crescimento podem ser identificados pela presença de parênquima terminal (Worbes, 1988). 


\section{MATERIAL E MÉTODOS}

\section{1 Áreas experimentais}

As seguintes áreas experimentais de florestas estacionais semidecíduas na região sudeste do Estado de São Paulo foram selecionadas:

- Estação Ecológica de Ibicatu: propriedade do Instituto Florestal do Estado de São Paulo, localizada no município de Piracicaba, SP (Anexo A), entre as coordenadas geográficas $22^{\circ} 46^{\prime}-22^{\circ} 47^{\prime}$ latitude $\mathrm{S}$ e $47^{\circ} 43^{\prime}-47^{\circ} 45^{\prime}$ longitude $\mathrm{W}$ e a altitude

média é de $500 \mathrm{~m}$. Segundo Köeppen, o clima é mesotérmico úmido com inverno seco, CWa. A temperatura média do mês mais quente de $23,9{ }^{\circ} \mathrm{C}$ (janeiro) e a temperatura média do mês mais frio, $16,1^{\circ} \mathrm{C}$ (julho). Os solos são argissolo amarelo, distrófico arênico (PAd), textura média/arenosa, hipodistrófico, álico, Ta, ácido. Ocupa uma área de 76,4 ha, sendo contornada por culturas agrícolas como cana de açúcar e pastagens (Custódio Filho et al., 1994).

- Estação Experimental de Tupi: administrada pelo Instituto Florestal do Estado de São Paulo, situada no município de Piracicaba, SP (Anexo A) entre as coordenadas geográficas $22^{\circ} 43^{\prime} 21^{\prime \prime}-22^{\circ} 44^{\prime} 24^{\prime \prime}$ latitude S e $47^{\circ} 31^{\prime} 47^{\prime \prime}-47^{\circ} 32^{\prime} 30^{\prime \prime}$ longitude W e altitude média de $515 \mathrm{~m}$, ocupando uma área de cerca de 198 ha o clima é do tipo Cwa (Köppen), mesotérmico úmido subtropical de inverno seco. Temperatura média do mês mais quente de $23,7^{\circ} \mathrm{C}$ (janeiro) e média do mês mais frio de $17,1^{\circ} \mathrm{C}$ (julho). A média anual de precipitação é de $1351 \mathrm{~mm}$. O solo é argilossolo vermelhoamarelo, distrófico arênico (PVAd), textura média/argilosa/arenosa, horizonte A húmico, hipodistrófico, álico, Ta/Tb, ácido. A área hoje ocupada pela Estação Experimental de Tupi foi intensamente cultivada com culturas anuais até 1949, 
acarretando o esgotamento natural da fertilidade do solo. Recebida pelo Serviço Florestal como uma área depauperada, timidamente se iniciaram os trabalhos de recuperação, através de reflorestamento com essências nativas, em 1952. Os fragmentos remanescentes com cobertura vegetal natural, constituem mostra da vegetação original que dominava essa região do Estado, e dada à florística observada entre as populações que ocorrem nesses fragmentos permitem caracterizá-la como floresta estacional semidecídua, comparadas com trabalhos de autores que estudaram esse tipo de comunidade vegetal (Pinheiro, 1999).

- Reserva Florestal Mata de Santa Genebra: administrada pela Fundação José Pedro de Oliveira, está localizada no município de Campinas (Anexo A), entre as coordenadas geográficas $22^{\circ} 44^{\prime} 45^{\prime \prime}$ latitude S e $47^{\circ} 06^{\prime} 33^{\prime \prime}$ longitude W, altitude média de 670 m. O clima é sazonal, apresentando uma estação seca e mais fria, de abril a setembro, e uma estação úmida e quente (outubro a março) seguindo o padrão climático geral para o interior do Estado de São Paulo. Foi definida uma terceira estação ou período transicional, que compreende os meses de setembro e outubro. Neste período, de transição da estação seca para a úmida, as oscilações de temperatura e comprimento do dia e a irregularidade das chuvas são grandes. Temperatura média do mês mais quente de $24,4^{\circ} \mathrm{C}$ (fevereiro) e média do mês mais frio de $18,2^{\circ} \mathrm{C}$ (julho). A Reserva ocupa uma área de 251,77 ha, em solo classificado como latossolo vermelho, distroférrico húmico ou típico ( $\mathrm{LVdf}$ ), textura muito argilosa, hipodistrófico, ácido. Apresenta três áreas baixas e úmidas com cerca de 15\% da área com floresta semidecídua higrófila (área de brejo) e duas áreas elevadas com $85 \%$ de áreas semidecíduas mais secas. Dentro desta última área, uma superfície correspondendo a 5\% da área total foi parcialmente queimada em 1981. Em maio de 2001, houve uma tempestade muito forte na cidade de Campinas onde várias árvores foram derrubadas, sendo abertas grandes clareiras em vários pontos da Reserva. Em parte da floresta há também um grande efeito de borda, sendo estas mantidas aceiradas para conservação das vias de acesso causando inevitavelmente impacto na floresta e sendo diretamente afetadas pelos ventos (Leitão Filho \& Morellato, 1995). 


\subsection{Espécies florestais selecionadas}

As espécies florestais indicadas para o presente estudo incluem os agrupamentos taxonômicos mais representativos das três áreas experimentais, selecionadas nas visitas de reconhecimento de acordo com Botosso (2000) na Estação Ecológica de Ibicatu e Estação Experimental de Tupi. Compreende um total de 65 árvores, divididas em 9 espécies, pertencentes a 7 famílias botânicas.

Na Reserva Florestal Mata de Santa Genebra a seleção das espécies florestais atendeu as mesmas condições adotadas nas 2 áreas, como descrita a seguir:

- Dispersão e abundância: através de levantamentos florísticos foram verificadas quais espécies predominavam e sua localização, como na borda da trilha, interior ou na borda da mata.

- Importância ecológica e silvicultural: foram selecionadas espécies de importância para os animais que vivem no mesmo ecossistema, e/ou espécies úteis para a utilização da sua madeira.

- Estrutura anatômica do xilema: as espécies que apresentam anéis de crescimento distintos e com potencial para o estudo da sazonalidade cambial, para datação das árvores, para o estudo da dinâmica na população e do efeito das variações climáticas.

- Quantidade de indivíduos: para a análise dos resultados obtidos, determinou-se um número de cerca de 5 árvores por espécie.

Com base nesses parâmetros foram escolhidos 41 indivíduos, de 8 espécies e 7 famílias botânicas, localizados em 4 áreas distintas da Reserva (Anexo B). Desta maneira, o trabalho apresenta um total de 106 árvores, de 13 espécies, e 8 famílias (Tabela 1). 
Tabela 1. Espécies selecionadas para o estudo.

\begin{tabular}{|c|c|c|c|c|c|c|}
\hline FAMÍLIA & NOME CIENTÍFICO & $\begin{array}{c}\text { NOME } \\
\text { VULGAR }\end{array}$ & $\mathrm{IB}$ & $\mathrm{SG}$ & $\mathrm{TP}$ & DPTP* \\
\hline Apocynaceae & Aspidosperma polyneuron & peroba & 3 & 11 & 5 & 1952 \\
\hline Caesalpinaceae & Caesalpinia ferrea & pau-ferro & - & - & 5 & 1952 \\
\hline Caesalpinaceae & Copaifera langsdorffii & copaíba & - & 2 & - & \\
\hline Caesalpinaceae & Schizolobium parahybum & guapuruvu & - & - & 2 & 1952 \\
\hline Euphorbiaceae & Pachystroma longifolium & canxim & - & 5 & - & \\
\hline Euphorbiaceae & Savia dyctiocarpa & guaraiúva & 5 & - & - & \\
\hline Fabaceae & Centrolobium tomentosum & araribá & 6 & 5 & - & \\
\hline Lecythidaceae & Cariniana estrellensis & jequitibá-branco & - & - & 4 & 1952 \\
\hline Meliaceae & Cedrela fissilis & cedro & - & 5 & - & \\
\hline Meliaceae & Trichilia claussenii & catiguá & - & 5 & - & \\
\hline Mimosaceae & Piptadenia gonoacantha & pau-jacaré & 5 & 5 & - & \\
\hline Rutaceae & Balfourodendron riedelianum & pau marfim & - & - & 9 & 1952 \\
\hline Rutaceae & Esenbeckia leiocarpa & guarantã & 12 & 3 & 9 & 1960 \\
\hline TOTAL & & & 31 & 41 & 34 & \\
\hline
\end{tabular}

IB: Estação Ecológica de Ibicatu

SG: Reserva Florestal Mata de Santa Genebra

TP: Estação Experimental de Tupi

DPTP*: Data dos plantios realizadas na Estação Experimental de Tupi. Nesta coluna estão listadas os anos de plantio das espécies selecionadas.

\subsection{Dados dendrométricos: circunferência do tronco das árvores}

Para as árvores das espécies florestais selecionadas, foram obtidos os CAPs (circunferência do tronco à altura do peito - 1,30 m) e utilizados para a preparação de faixas dendrométricas permanentes.

Os valores das circunferência do tronco mínimos e máximos das árvores das diferentes espécies na Estação Ecológica de Ibicatu, Estação Experimental de Tupi e Reserva Florestal Mata de Santa Genebra, estão apresentados na Tabela 2. Os dados de circunferência para cada árvore do período de coleta de dados, estão no Anexo C. Vale lembrar, que não foi possível estabelecer um padrão nos valores (mínimos - médio máximos) de circunferência do tronco por ocasião da seleção das árvores. 
Tabela 2. Intervalo de classe de circunferência do tronco (CAP - em centímetros), das 13 espécies florestais arbóreas nos locais de estudo.

\begin{tabular}{|c|c|c|c|}
\hline FAMÍLIAS & $\mathrm{C}(\mathrm{cm})^{*}$ & ESPÉCIES & $\begin{array}{c}\text { N. 'Á Árvores/ } \\
\text { espécie }\end{array}$ \\
\hline Apocynaceae & $44-119$ & Aspidosperma polyneuron (peroba-rosa) & 19 \\
\hline Caesalpinaceae & $51-80$ & Caesalpinia ferrea (pau-ferro) & 5 \\
\hline Caesalpinaceae & $62-177$ & Copaifera langsdorffi (copaíba) & 2 \\
\hline Caesalpinaceae & $92,5-119$ & Schizolobium parahybum (guapuruvu) & 2 \\
\hline Euphorbiaceae & $65-98$ & Pachystroma longifolium (canxim) & 5 \\
\hline Euphorbiaceae & $31-91,5$ & Savia ductiocarpa (guariúva) & 5 \\
\hline Fabaceae & $28-106$ & Centrolobium tomentosum (araribá) & 11 \\
\hline Lecythidaceae & $48,5-100$ & Cariniana estrellensis (jequitibá-branco) & 4 \\
\hline Meliaceae & $31-65$ & Cedrela fissilis (cedro) & 5 \\
\hline Meliaceae & $25-70$ & Trichilia claussenii (catiguá) & 5 \\
\hline Mimosaceae & $36,5-105$ & Piptadenia gonoacantha (pau-jacaré) & 10 \\
\hline Rutaceae & $41,5-132$ & Balfourodendron riedelianum (pau marfim) & 9 \\
\hline Rutaceae & $31-121$ & Esenbeckia leiocarpa (guarantã) & 24 \\
\hline TOTAL & & & 106 \\
\hline
\end{tabular}

* C.: Circunferências mínima e máxima, das árvores estudadas, respectivamente

\subsection{Análise das condições de crescimento das árvores}

As condições de crescimento de cada árvore foram avaliadas pela determinação da sua posição sociológica na população e intensidade de competição com lianas.

A posição sociológica possibilitou a sua classificação em 3 categorias:

- Dominantes: árvores com copa exposta a pleno sol até atingir 50\%;

- Co-dominantes: árvores com a copa exposta com menos de 50\% de luz solar;

- Dominadas: árvores no estrado inferior da mata ou do sub-bosque, sem incidência de luz solar plena.

Para a localização das árvores foi observada quanto a sua proximidade em relação à borda da trilha, da mata ou no interior da mata.

A presença ou ausência de lianas foi realizada por observações a olho nu ou com binóculo, seguindo-se os critérios indicados por Fonseca (1998): 
- Copa tomada por lianas: árvore entre $2 / 3$ a toda copa preenchida por lianas; não sendo possível observá-la;

- Copa com presença de lianas: árvore entre $1 / 3$ à $2 / 3$ da copa tomada por lianas; sendo possível observar parte da copa das árvores.

- Árvores com poucas lianas: árvores com menos de 1/3 da copa com a presença de lianas; sendo possível visualizar praticamente toda a copa.

- Ausência de lianas: árvore sem lianas em sua copa.

\subsection{Determinação da taxa de crescimento em circunferência do tronco} das árvores

O método de avaliação do crescimento das árvores denominado "dinâmico", foi descrito por Fahl et al. (1981) sendo utilizado por diversos autores (Lojan, 1967, Vetter \& Botosso, 1988 e 1989, Détienne, 1989, Botosso \& Vetter, 1991, Jalil et al., 1998 Botosso \& Tomazello Filho, 1999 e Botosso, 2000). Consiste na implantação de faixas dendrométricas permanentes na altura do DAP do tronco das árvores e a avaliação contínua do crescimento em circunferência.

As faixas dendrométricas foram confeccionadas em aço inoxidável com escala graduada em mm e nônio com precisão de leitura de $0,2 \mathrm{~mm}$, sendo mantidas no tronco das árvores com uma mola de aço inoxidável de 100 x 8 mm (comprimento e circunferência) (Figura 1). Para a montagem das faixas dendrométricas; (a) determinouse a circunferência do tronco da árvore em mm na altura do seu CAP, (b) cortourse a fita de aço adicionando, no mínimo, um segmento de $170 \mathrm{~mm}$ ao valor da circunferência, necessário para as extremidades e sobreposição da escala com o nônio recobrindo a escala graduada; (c) demarcoutse a graduação da escala e nônio na fita de aço com gabarito composto de 2 placas de metal de $13 \times 8 \mathrm{~cm}$, sendo a borda de uma das placas apresentando 41 fendas espaçadas de $2 \mathrm{~mm}$ formando uma graduação de $80 \mathrm{~mm}$ (borda inferior da placa - escala de leitura) e outra, com 11 fendas espaçadas de 1,8 mm formando as 10 divisões do nônio (borda superior da placa), coincidindo com 9 divisões da escala principal de leitura (ou seja $18 \mathrm{~mm}$ ). 
As faixas dendrométricas foram preparadas no Laboratório de Anatomia e Identificação de Madeiras do Departamento de Ciências Florestais da ESALQ/USP, de acordo com a metodologia utilizada por Botosso (2000). Na Figura 2, observa-se como as faixas são instaladas no tronco das árvores de modo fixo, obtendo-se assim uma maior precisão na leitura dos dados.

Os resultados das leituras mensais dos incrementos em circunferência do tronco foram anotados em fichas de campo para cada árvore e, posteriormente, foram armazenados em arquivos específicos em computador para análise, confecção de gráfico, etc.

\subsection{Avaliação da fenologia, das condições climáticas e do solo}

\subsubsection{Avaliações fenológicas}

As observações fenológicas foram feitas a olho nu e com auxílio de um binóculo considerando os estágios fenológicos preconizados por Koriba (1958), citado por Matthes (1980) e Cardoso (1991).

\subsubsection{Desenvolvimento das folhas}

Para o estágio fenológico "desenvolvimento das folhas" foram consideradas as árvores com folhas: (i) em senescência adiantada ou desfolhadas; (ii) novas em início de desenvolvimento; (iii) parte em fase de expansão final do limbo e a maioria em desenvolvimento e (iv) em fase de envelhecimento e queda.

\subsubsection{Floração}

Para o estágio fenológico "floração" foram consideradas as árvores com: (i) botões florais em início de desenvolvimento; (ii) flores abertas desenvolvidas; (iii) estágios finais de floração. 


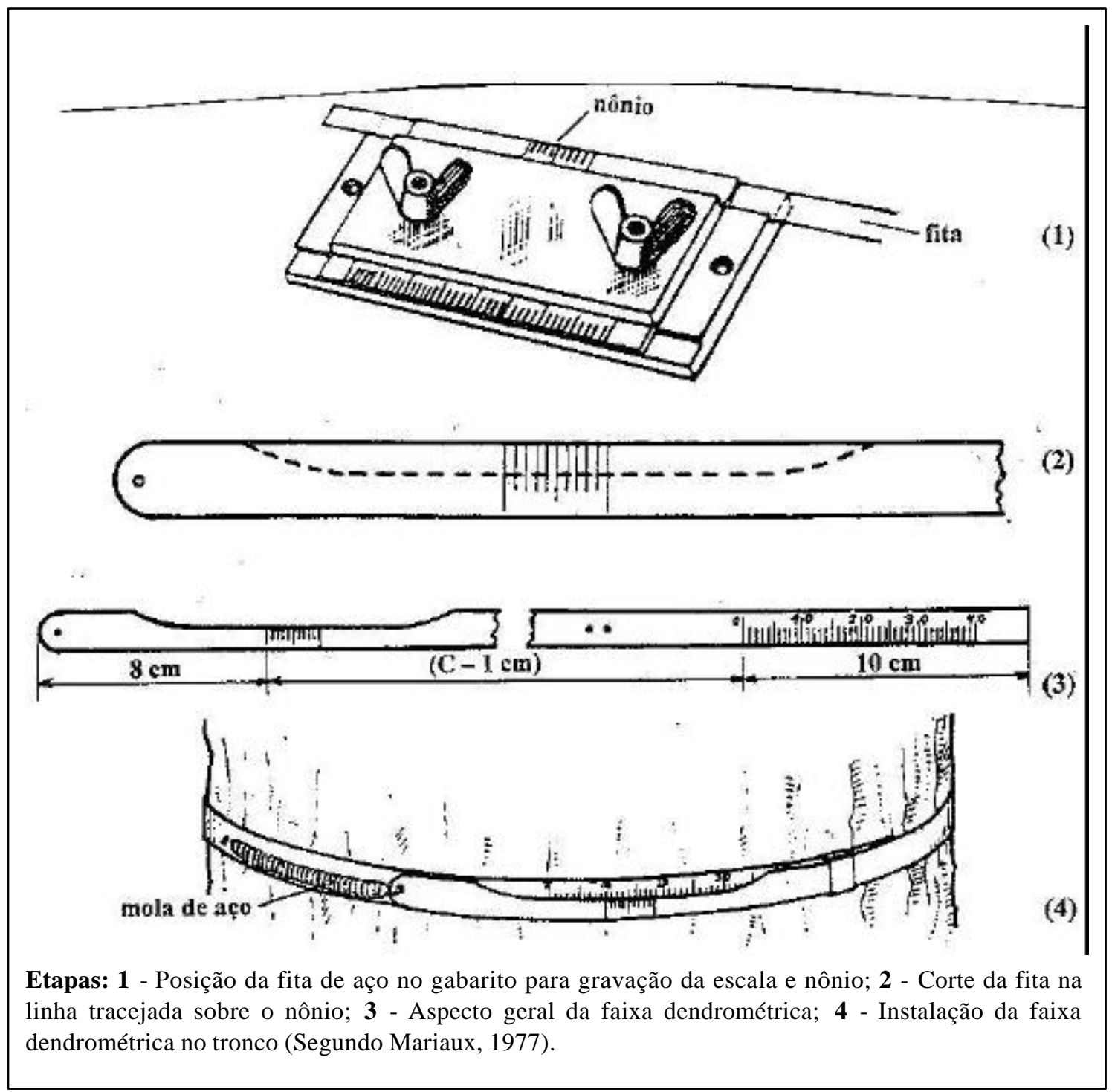

Figura 1 - Etapas da montagem e da instalação da faixa dendrométrica de aço no tronco de uma árvore. 


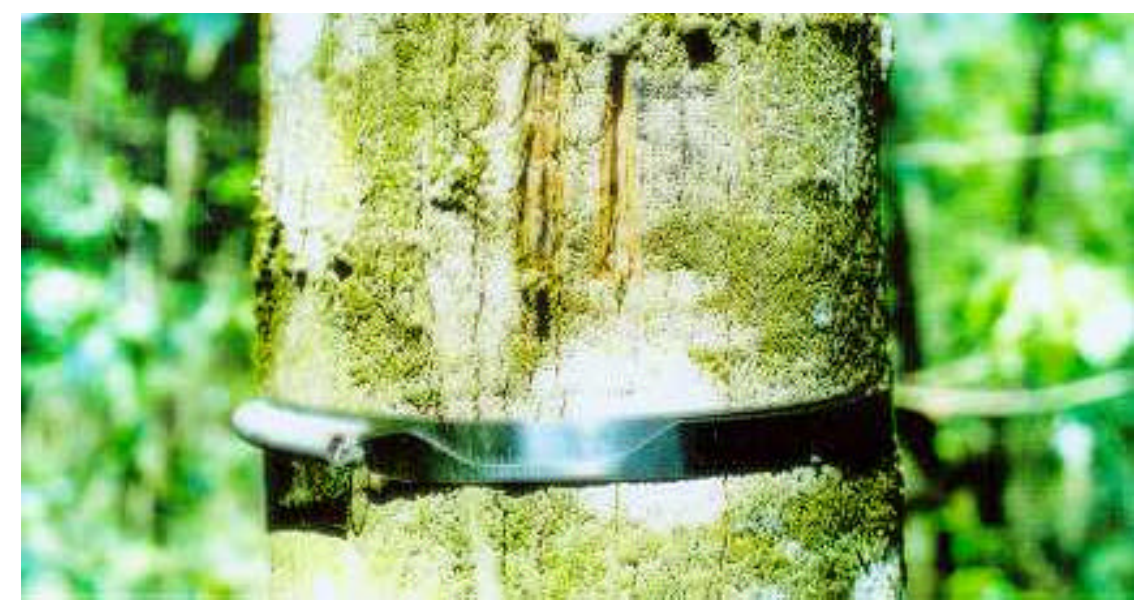

Figura 2 - Modelo de faixa dendrométrica acoplada no tronco da árvore

\subsubsection{Frutificação}

Para o estágio fenológico "frutificação" foram consideradas as árvores com frutos: (i) novos, na fase inicial de desenvolvimento; (ii) em desenvolvimento; (iii) amadurecendo, maduros e/ou em queda; (iv) secos.

\subsubsection{Análise das condições climáticas}

Os dados climáticos coletados foram temperatura média $\left({ }^{\circ} \mathrm{C}\right)$, umidade relativa do ar (\%), precipitação (mm), etc., obtidos junto ao IAC (Instituto Agronômico de Campinas) e FEAGRI (Faculdade de Engenharia Agrícola)/UNICAMP (Campinas/SP) e na ESALQ / USP (Piracicaba/SP).

\subsubsection{Análise do solo}

Para a caracterização dos solos foram feitas coletas com trado tipo "caneco", nos meses de maio e junho de 2001, em locais representativos da área experimental, de acordo com as diferentes posições topográficas. As tradagens do solo foram realizadas a 
0-20 $\mathrm{cm}$ e 60-80 $\mathrm{cm}$. As amostras do solo tiveram sua cor úmida (carta de Munsell) e textura determinadas diretamente no campo.

No caso da existência de mudança textural, realizourse coleta a 40-60 $\mathrm{cm}$ para identificar uma possível mudança textural abrupta. As amostras foram embaladas, identificadas e levadas ao laboratório do Setor de Solos e Nutrição de Plantas na ESALQ/USP para a realização das análises física e química, determinando-se os seguintes parâmetros:

- Química: pH, N, P, K, Ca, Mg, Al, etc.

- Física: areia total, silte e argila, densidade das partículas.

Os resultados da análise química e granulométrica dos solos permitiram a sua caracterização e classificação segundo o Sistema Brasileiro de Classificação de Solos (Embrapa, 1999). Os dados já constam no § 3.1 (Áreas experimentais).

\subsection{Coleta das amostras de madeira para a análise dos anéis de crescimento}

O método adotado para a coleta das amostras de madeira para a análise dos anéis de crescimento é o denominado não destrutivo. Nesse método são retiradas amostras de madeira na forma de "baguetas" utilizando a sonda de Pressler (Figura 3).

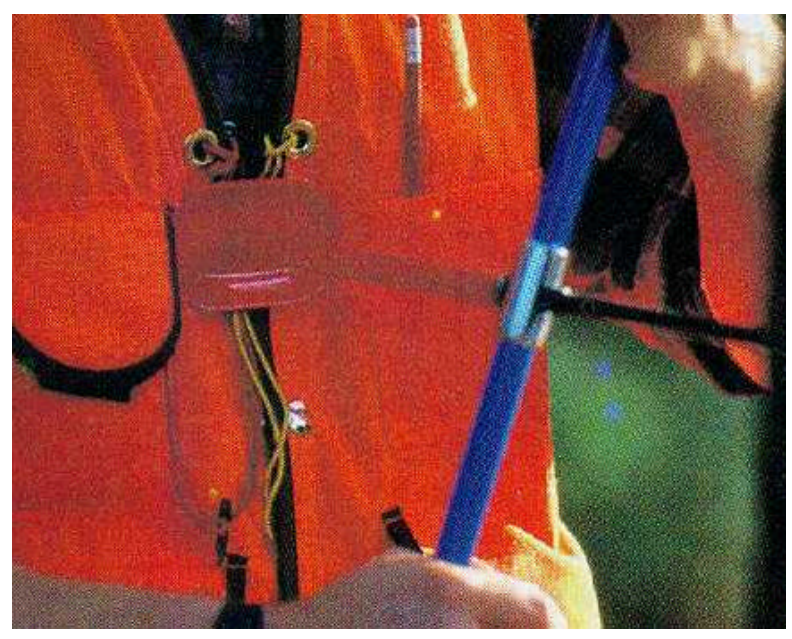

Figura 3 - Coleta de madeira pelo método não destrutivo com sonda de Pressler. 
Foram retiradas 2 amostras de madeira de 3 árvores de cada espécie, nas 3 áreas em estudo, para as avaliações dendrocronológicas e anatômicas. As análises dos anéis de crescimento foram conduzidas no Laboratório de Anatomia e de Identificação de Madeiras do Departamento de Ciências Florestais - ESALQ/USP.

As amostras ou "baguetas" do lenho das árvores com $5 \mathrm{~mm}$ de diâmetro, foram fixadas em suporte de madeira e feito um polimento da sua superfície transversal com papel abrasivo (série de lixas de diferentes granulometrias: 110, 220, 300, 400, 600 e 1000), para evidenciar os limites dos anéis de crescimento e demarcá-los sob lupa binocular marca Leica (aumento de 6.3 - 40x). Para a determinação da idade das árvores, a largura dos anéis de crescimento das árvores foi mensurada utilizando equipamentos específicos para estudos dendrocrológicos como (i) mesa de mensuração marca Lintab III, com deslocamento horizontal e precisão de $1 / 100 \mathrm{~mm}$, (ii) microscópio esteroscópio marca Leica, (iii) sistema de iluminação de fibra ótica - Leica modelo KL 1500 e (iv) microcomputador Pentium 100 (Figura 4).

Para a aquisição e tratamento dos dados da largura dos anéis de crescimento, no sentido medula-casca das amostras, foi utilizado o programa "TSAP" e, em seguida, montados os gráficos das curvas de crescimento anual do tronco das árvores.

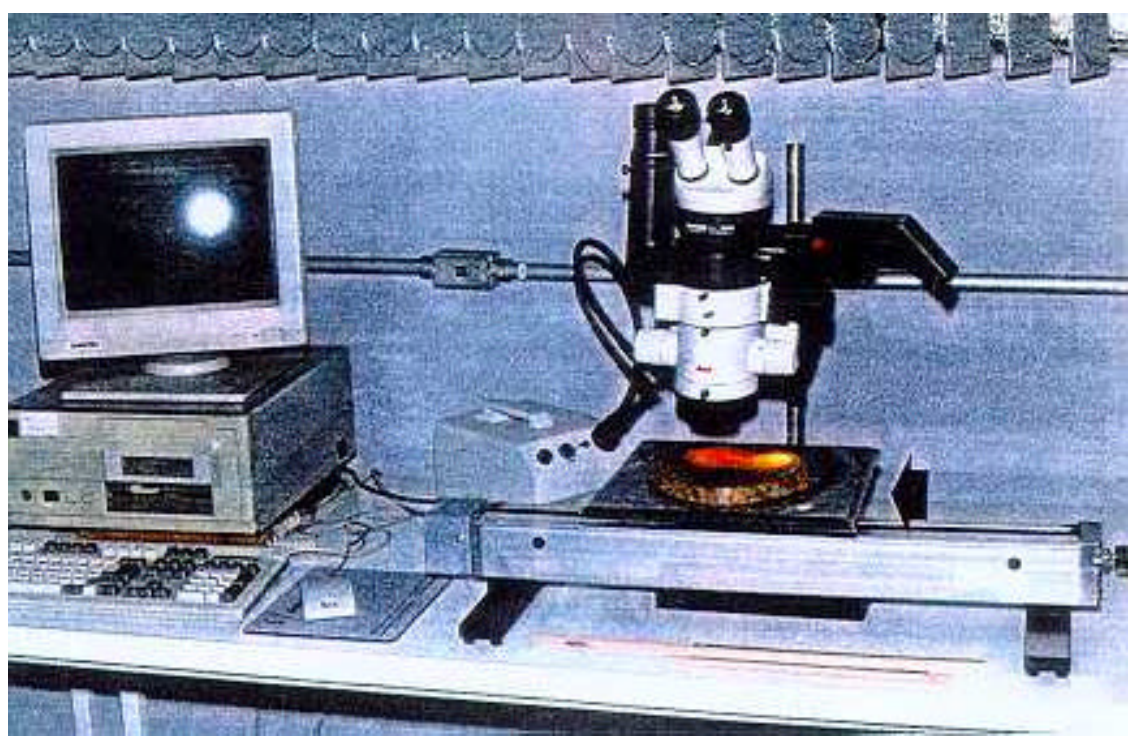

Figura 4 - Equipamentos utilizados na identificação e mensuração dos anéis de crescimento. 


\subsection{Análise da estrutura anatômica da madeira}

A estrutura macroscópica da madeira foi analisada no corte transversal, a partir das amostras de madeiras obtidas com sonda de Pressler (metodologia conf. § 3.7) e visualizadas com auxílio de microscópio esteroscópico marca Leica para facilitar a descrição. Posteriormente foram obtidas fotomacrografias do lenho de cada espécie em estudo.

\subsection{Correlação dos dados}

As avaliações mensais do incremento em circunferência do tronco das árvores foram relacionados com as fenofases e condições climáticas do período. Da mesma forma, os resultados das análises do crescimento expressam a atividade cambial, retratando a biologia da formação do lenho.

Os fatores ligados à biologia e fisiologia das espécies (fenologia, crescimento em circunferência do tronco), aos fatores climáticos (temperatura, precipitação, etc.) foram relacionados às condições de crescimento das árvores (competição interna, presença de lianas na copa das árvores, etc.) (Figura 5).

FENOLOGIA

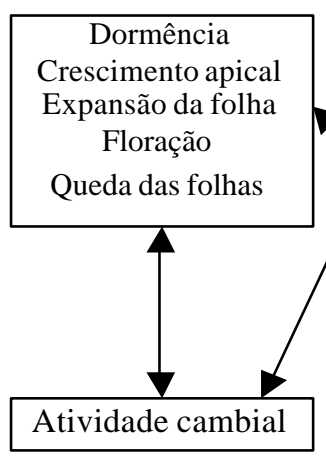

FISIOLOGIA DA ÁRVORE

 \\ TRANSPRAC̃̃O}

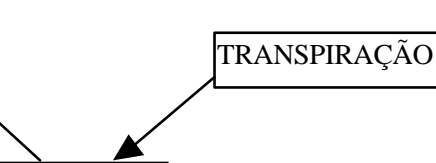

Área da folha Idade da folha Estrutura da folha ÂGUA
ÁRVORES



ABSORÇÃO DA ÁGUA Tamanho da raiz Pressão do déficit de vapor Temperatura

AMBIENTE
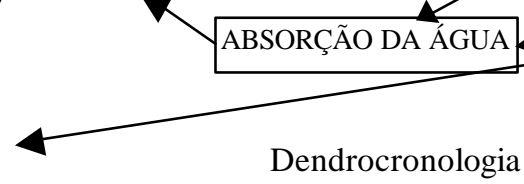

Figura 5 - Modelo de atividade cambial, formação dos anéis de crescimento, correlação entre fenologia e condições ambientais, segundo Burchert (1999). 


\section{RESULTADOS}

\subsection{Espécies florestais}

As espécies na Estação Ecológica de Ibicatu e Estação Experimental de Tupi foram escolhidas de acordo com Botosso (2000) e na Reserva Florestal Mata de Santa Genebra foram selecionadas de acordo com os critérios relacionados nos itens (cf. $\S 3.2$ ). Pachystroma longifolium (canxim) e Aspidosperma polyneuron (peroba-rosa) são abundantes e Cariniana estrellensis (jequitibá-branco), Esenbeckia leiocarpa (guarantã) e Caesalpinia ferrea (pau-ferro) são importantes para recuperação em áreas degradadas, dentre outras aplicações.

Para cada espécie procurou-se selecionar um número mínimo de 5 árvores, embora para Copaifera langsdorffii (copaíba) não atingiu-se este número, obtendo-se apenas 2 indivíduos. Esenbeckia leiocarpa (guarantã) constituiu-se de 5 indivíduos, mas em maio de 2001 ocorreu um evento climático natural provocando a queda de 2 árvores em razão dos fortes ventos. Na Tabela 1 são apresentadas as espécies e o número de árvores selecionadas, nas respectivas áreas experimentais.

\subsection{Análise das condições de crescimento das árvores}

Nas Tabelas 3 e 4 são apresentadas, respectivamente, a posição sociológica e a localização das árvores nas áreas de estudo.

Com relação a posição sociológica, cerca de 44\% das árvores são dominantes, $43 \%$ são co-dominantes e $13 \%$ são dominados. Quanto a localização, cerca de $82 \%$ estão dentro 
da mata, $15 \%$ na borda da trilha e $3 \%$ na borda da mata. Desta forma, a maior porcentagem das árvores são dominantes e co-dominantes e encontram-se dentro da mata.

O estudo sobre a existência ou não de lianas indicou a sua presença em significativa parte das árvores. Em 12\% das árvores as copas estão tomadas pela presença de lianas, em 29\% há poucas lianas nas copas e em 53\% não há presença de lianas. A alta porcentagem de árvores sem lianas deve-se ao fato de que na Estação Experimental de Tupi 100\% das árvores não mostram lianas em suas copas (Tabela 5).

\subsection{Estudo da taxa de crescimento em circunferência do tronco das árvores}

O período de coleta dos dados na Estação Ecológica de Ibicatu é de 34 meses (dezembro/1998 a outubro/2001), exceto para a espécie Piptadenia gonoacantha (paujacaré) com um total de 32 meses (março/1999 a outubro/2001). Devido às más condições da estrada, no mês de fevereiro/1999, não foi possível o acesso à área, não tendo sido, portanto, realizada a coleta de dados (Figuras 6A e B, 7A e B, 13A, B e C e 14B).

Na Estação Experimental de Tupi os dados coletados corresponderam a um período

de 34 meses (janeiro/1999 a outubro/2001), à exceção de Aspidosperma polyneuron (peroba-rosa) e Balfourodendron riedelianum - 5 a 9 (pau-marfim) com um total de 26 meses (setembro/1999 a outubro/2001), e Schizolobium parahyba (guapuruvu), com 19 meses de coleta (Figuras 8 e 9, 15 e 16).

Na Reserva Florestal Mata de Santa Genebra o período de coleta de dados foi de 9 a 13 meses, dependendo da espécie estudada (Figuras 10 - 12 e 17 - 19). Nas Figuras 6 - 12 são apresentadas as taxas de crescimento médio mensal em circunferência do tronco das árvores das espécies estudadas. As taxas de crescimento mensal acumulado destas mesmas espécies são apresentadas nas Figuras 13 - 19, para as 3 áreas de estudo. 
Tabela 3. Posição sociológica das árvores, das diferentes espécies, nas 3 áreas de estudo.

\begin{tabular}{|c|c|c|c|c|}
\hline \multirow[t]{2}{*}{$\begin{array}{c}\text { POSIÇÃO } \\
\text { SOCIOLÓGICA }\end{array}$} & \multirow[t]{2}{*}{ NOME DA ESPÉCIE } & \multicolumn{3}{|c|}{$\begin{array}{l}\text { NÚMERO DE IDENTIFICAÇÃO DAS } \\
\text { ÁRVORES NAS ÁREAS }\end{array}$} \\
\hline & & IB & $\mathrm{TP}$ & SG \\
\hline \multirow{11}{*}{ DOMINANTES } & Aspidosperma polyneuron (peroba-rosa) & 2 e 3 & - & 1 a 8 e 10 \\
\hline & Balfourodendron riedelianum (pau-marfim) & - & 4 e 5 & - \\
\hline & Caesalpinia ferrea (pau-ferro) & - & 1 e 2 & - \\
\hline & Cariniana estrellensis (jequitibá-branco) & - & 1 e 2 & - \\
\hline & Centrolobium tomentosum (araribá) & 5 e 6 & - & 3 \\
\hline & Copaifera langsdorffii (copaíba) & - & - & Todas \\
\hline & Esenbeckia leiocarpa (guarantã) & $1,4,11$ e 12 & 1,5 a 9 & - \\
\hline & Pachystroma longifolium (canxim) & - & - & Todas \\
\hline & Piptadenia gonoacantha (pau-jacaré) & 1,5 e 6 & - & 4 e 5 \\
\hline & Savia dyctiocarpa (guaraiúva) & 1 & - & - \\
\hline & Schizolobium parahyba (guapuruvu) & - & Todas & - \\
\hline \multirow{9}{*}{ CO-DOMINANTES } & Aspidosperma polyneuron (peroba) & 1 & Todas & 9 e 11 \\
\hline & Balfourodendron riedelianum (pau-marfim) & - & 1 a 3 e 6 a 9 & - \\
\hline & Caesalpinia ferrea (pau-ferro) & - & 3 a 5 & - \\
\hline & Cariniana estrellensis (jequitibá-branco) & - & 4 & - \\
\hline & Cedrela fissilis (cedro) & - & - & Todas \\
\hline & Centrolobium tomentosum (araribá) & 1 a 4 & - & 1 e 2 \\
\hline & Esenbeckia leiocarpa (guarantã) & 7 e 13 & 2 a 4 & 1,2 e 4 \\
\hline & Piptadenia gonoacantha (pau-jacaré) & 2 e 4 & - & 1,2 e 3 \\
\hline & Savia dyctiocarpa (guaraiúva) & 2 a 5 & - & - \\
\hline \multirow{4}{*}{ DOMINADAS } & Cariniana estrellensis (jequitibá-branco) & - & 3 & - \\
\hline & Centrolobium tomentosum (araribá) & - & - & 4 e 5 \\
\hline & Esenbeckia leiocarpa (guarantã) & $3,5,6,8$ a 10 & - & - \\
\hline & Trichilia claussenii (catiguá) & - & - & Todas \\
\hline
\end{tabular}


Tabela 4. Localização das árvores, das diferentes espécies, quanto a posição que ocupam nas 3 áreas de estudo.

\begin{tabular}{|c|c|c|c|c|}
\hline \multirow[t]{2}{*}{ LOCALIZAÇÃO } & \multirow[t]{2}{*}{ NOME DA ESPÉCIE } & \multicolumn{3}{|c|}{$\begin{array}{c}\text { NÚMERO DE IDENTIFICAÇÃO DAS } \\
\text { ÁRVORES NAS ÁREAS }\end{array}$} \\
\hline & & IB & $\mathrm{TP}$ & $\mathrm{SG}$ \\
\hline \multirow{11}{*}{ DENTRO DA MATA } & Aspidosperma polyneuron (peroba) & 1 & Todas & Todas \\
\hline & Balfourodendron riedelianum (pau-marfim) & - & Todas & - \\
\hline & Caesalpinia ferrea (pau-ferro) & - & Todas & - \\
\hline & Cariniana estrellensis (jequitibá-branco) & - & Todas & - \\
\hline & Cedrela fissilis (cedro) & - & - & 1,2 e 3 \\
\hline & Centrolobium tomentosum (araribá) & 1 a 4 & - & 4 e 5 \\
\hline & Esenbeckia leiocarpa (guarantã) & Todas & Todas & Todas \\
\hline & Pachystroma longifolium (canxim) & - & - & Todas \\
\hline & Piptadenia gonoacantha (pau-jacaré) & - & - & 1 a 4 \\
\hline & Savia dyctiocarpa (guaraiúva) & Todas & - & - \\
\hline & Trichilia claussenii (catiguá) & - & - & Todas \\
\hline \multirow{6}{*}{ BORDA DA TRILHA } & Aspidosperma polyneuron (peroba) & 2 e 3 & - & - \\
\hline & Cedrela fissilis (cedro) & - & - & 4 e 5 \\
\hline & Centrolobium tomentosum (araribá) & 5 e 6 & - & 1,2 e 3 \\
\hline & Copaifera langsdorffii (copaíba) & - & - & 2 \\
\hline & Piptadenia gonoacantha (pau-jacaré) & 4,5 e 6 & - & 5 \\
\hline & Schizolobium parahyba (guapuruvu) & - & Todas & - \\
\hline \multirow{2}{*}{ BORDA DA MATA } & Copaifera langsdorffii (copaíba) & - & - & 3 \\
\hline & Piptadenia gonoacantha (pau-jacaré) & $1 \mathrm{e} 2$ & - & - \\
\hline
\end{tabular}


Tabela 5. Presença ou ausência de lianas para todas as árvores, das diferentes espécies, nas 3 áreas de estudo.

\begin{tabular}{|c|c|c|c|c|}
\hline \multirow[t]{2}{*}{ LIANAS } & \multirow[t]{2}{*}{ NOME DA ESPÉCIE } & \multicolumn{3}{|c|}{$\begin{array}{c}\text { NÚMERO DE IDENTIFICAÇÃO DAS } \\
\text { ÁRVORES NAS ÁREAS }\end{array}$} \\
\hline & & IB & $\mathrm{TP}$ & SG \\
\hline \multirow{6}{*}{$\begin{array}{l}\text { COPA TOMADA } \\
\text { POR LIANAS }\end{array}$} & Aspidosperma polyneuron (peroba) & - & - & $1,2,4,5$ e 10 \\
\hline & Centrolobium tomentosum (araribá) & - & - & 1 e 2 \\
\hline & Copaifera langsdorffii (copaíba) & - & - & 2 \\
\hline & Esenbeckia leiocarpa (guarantã) & 1 & - & 1 \\
\hline & Piptadenia gonoacantha (pau-jacaré) & 4 & - & - \\
\hline & Trichilia claussenii (catiguá) & - & - & 1 \\
\hline \multirow{4}{*}{$\begin{array}{c}\text { COPA COM } \\
\text { PRESENÇA DE LIANAS }\end{array}$} & Aspidosperma polyneuron (peroba) & - & - & $3,6,8,9$ e 11 \\
\hline & Centrolobium tomentosum (araribá) & - & - & 3 a 5 \\
\hline & Esenbeckia leiocarpa (guarantã) & 6 a 8 & - & - \\
\hline & Piptadenia gonoacantha (pau-jacaré) & 5 & - & 4 \\
\hline \multirow{8}{*}{$\begin{array}{l}\text { COPA COM } \\
\text { POUCAS LIANAS }\end{array}$} & Aspidosperma polyneuron (peroba) & 1 e 3 & - & 7 \\
\hline & Cedrela fissilis (cedro) & - & - & Todas \\
\hline & Centrolobium tomentosum (araribá) & Todas & - & - \\
\hline & Copaifera langsdorffii (copaíba) & - & - & 3 \\
\hline & Esenbeckia leiocarpa (guarantã) & 3 a 5 & - & 2 e 4 \\
\hline & Piptadenia gonoacantha (pau-jacaré) & - & - & 1 a 3 \\
\hline & Savia dyctiocarpa (guaraiúva) & 1,3 e 5 & - & - \\
\hline & Trichilia claussenii (catiguá) & - & - & 2 a 4 \\
\hline \multirow{10}{*}{$\begin{array}{l}\text { AUSÊNCIA } \\
\text { DE LIANAS }\end{array}$} & Aspidosperma polyneuron (peroba) & 2 & Todas & - \\
\hline & Balfourodendron riedelianum (pau-marfim) & - & Todas & - \\
\hline & Caesalpinia ferrea (pau-ferro) & - & Todas & - \\
\hline & Cariniana estrellensis (jequitibá-branco) & - & Todas & - \\
\hline & Esenbeckia leiocarpa (guarantã) & 9 a 13 & Todas & - \\
\hline & Pachystroma longifolium (canxim) & - & - & Todas \\
\hline & Piptadenia gonoacantha (pau-jacaré) & $1,2,5$ e 6 & - & 5 \\
\hline & Savia dyctiocarpa (guaraiúva) & 2 e 4 & - & - \\
\hline & Schizolobium parahyba (guapuruvu) & - & Todas & - \\
\hline & Trichilia claussenii (catiguá) & - & - & 5 \\
\hline
\end{tabular}





Figura 6 - Variação do incremento médio mensal das espécies florestais na Estação Ecológica de Ibicatu (Piracicaba) no período dezembro de 1998 a outubro de 2001 (exceto fevereiro de 1999). (A) Aspidosperma polyneuron (peroba-rosa); (B) Centrolobium tomentosum (araribá); (março de 1999 a outubro de 2001) (C) Piptadenia gonoacantha (pau-jacaré). 

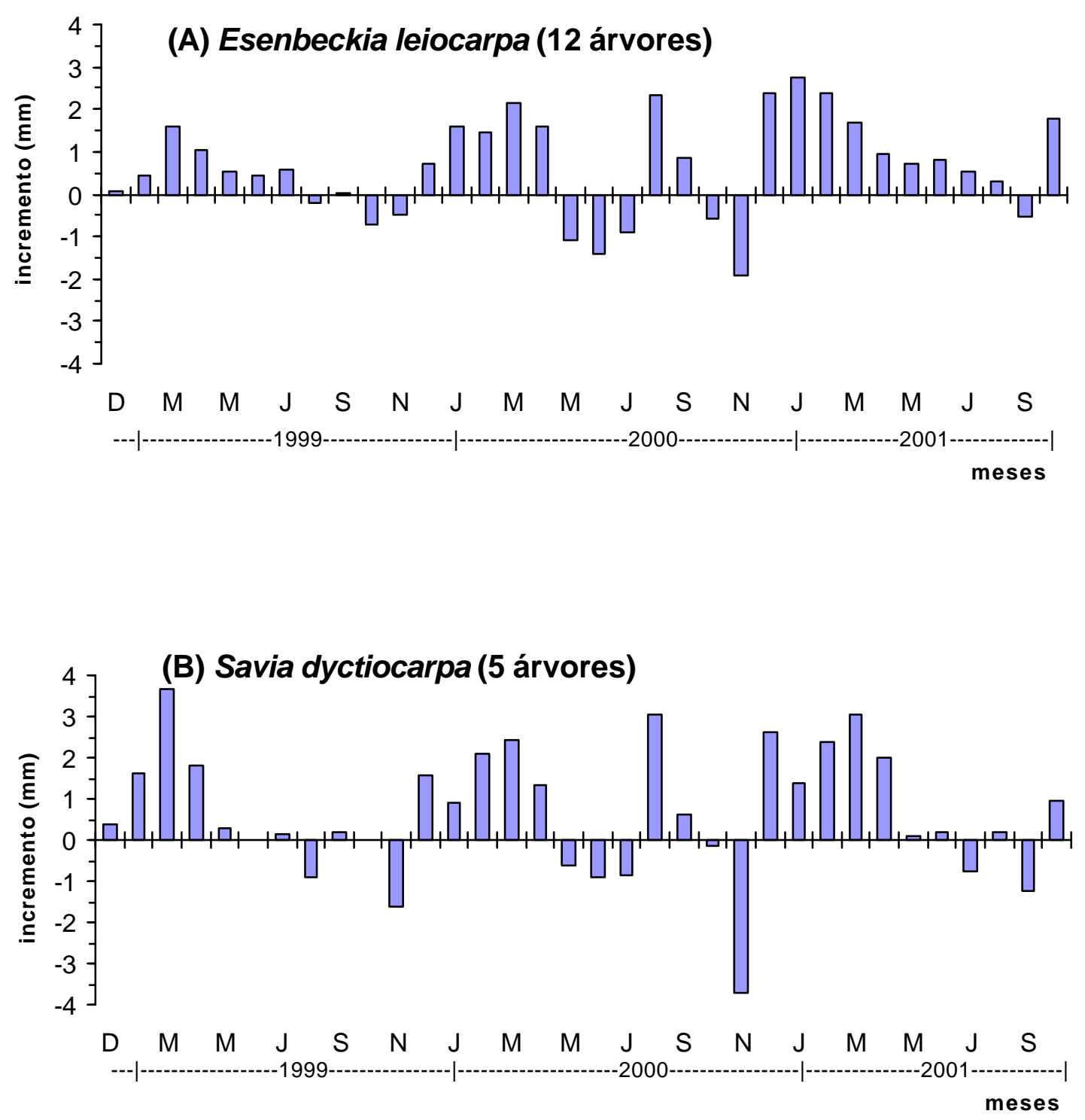

Figura 7 - Variação do incremento médio mensal das espécies florestais na Estação Ecológica de Ibicatu (Piracicaba) no período dezembro de 1998 a outubro de 2001 (exceto fevereiro de 1999). (A) Esenbeckia leiocarpa (guarantã); (B) Savia dyctiocarpa (guaraiúva). 

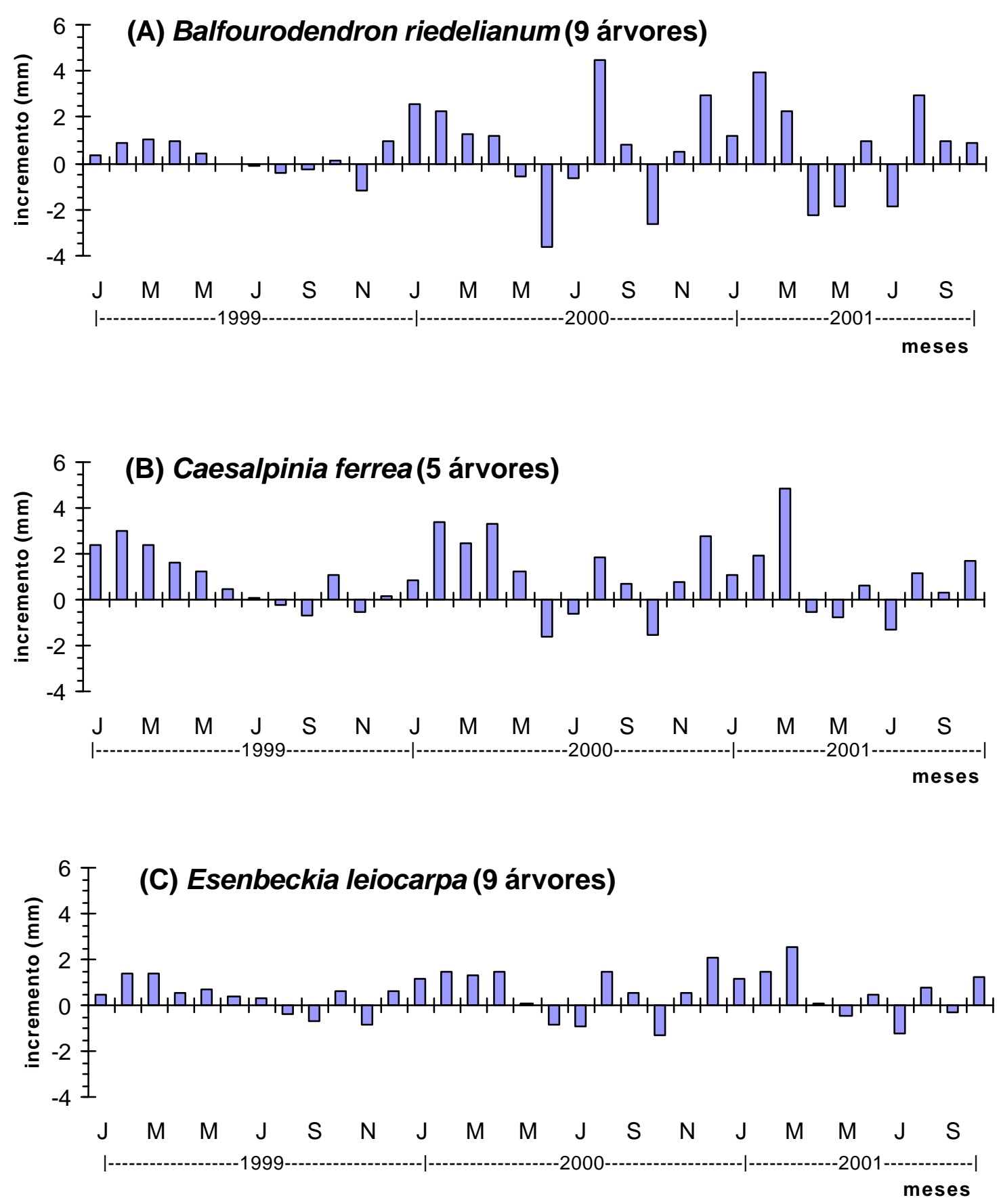

Figura 8 - Variação do incremento médio mensal das espécies florestais na Estação Experimental de Tupi (Piracicaba) no período de janeiro de 1999 a outubro de 2001. Balfourodendron riedelianum (pau-marfim); (B) Caesalpinia ferrea (pau-ferro); Esenbeckia leiocarpa (guarantã). 



Figura 9 - Variação do incremento médio mensal das espécies florestais na Estação Experimental de Tupi (Piracicaba) no período de setembro 1999 a outubro de 2001. (A) Aspidosperma polyneuron (peroba-rosa); (janeiro de 1999 a outubro de 2001) (B) Cariniana estrellensis (jequitibá-branco); (abril de 2000 a outubro de 2001) (C) Schizolobium parahyba (guapuruvu). 

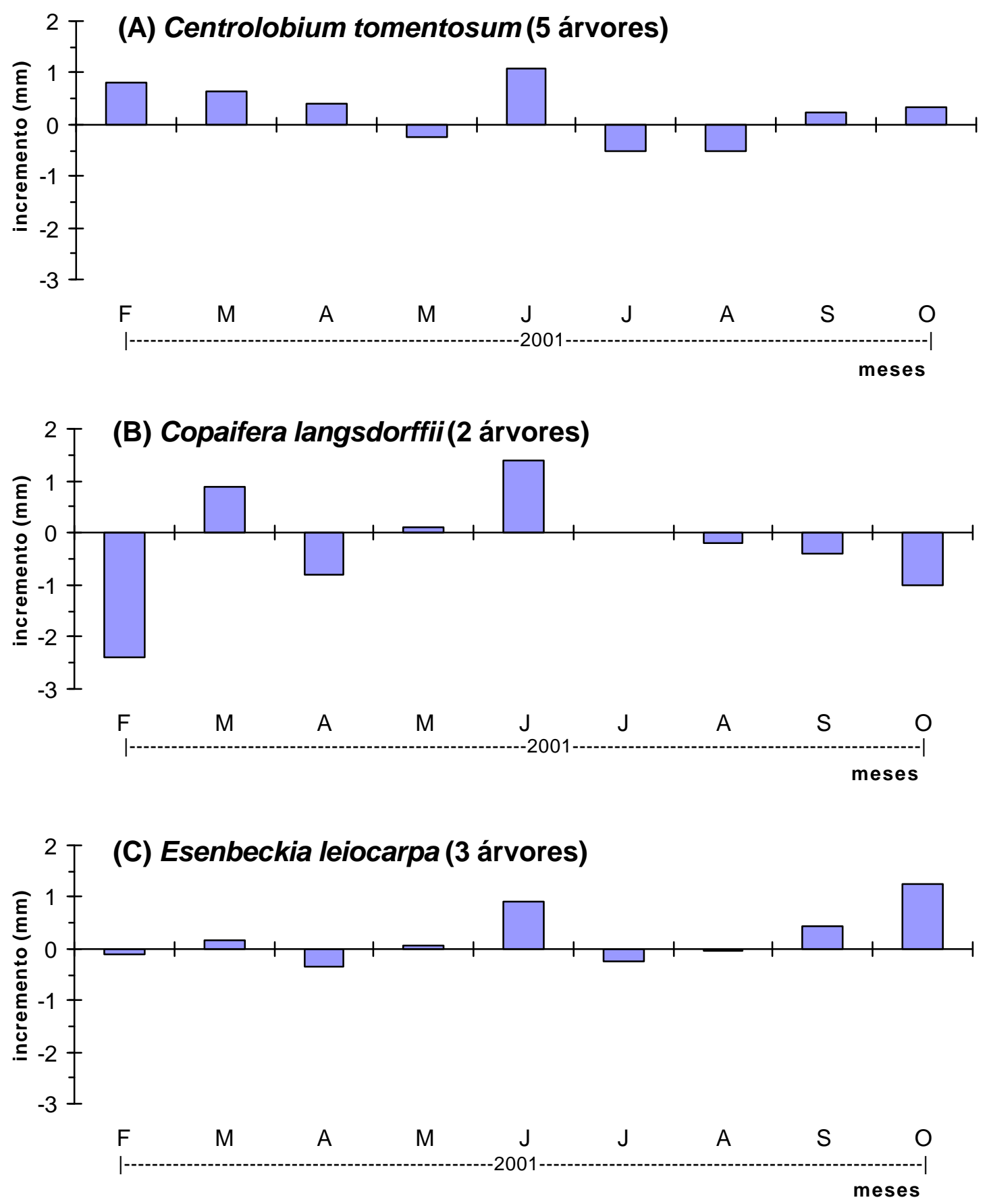

Figura 10 - Variação do incremento médio mensal das espécies florestais na Reserva Florestal Mata de Santa Genebra no período de fevereiro de 2001 a outubro de 2001. (A) Centrolobium tomentosum (araribá); (B) Copaifera langsdorffii (copaíba); (C) Esenbeckia leiocarpa (guarantã). 

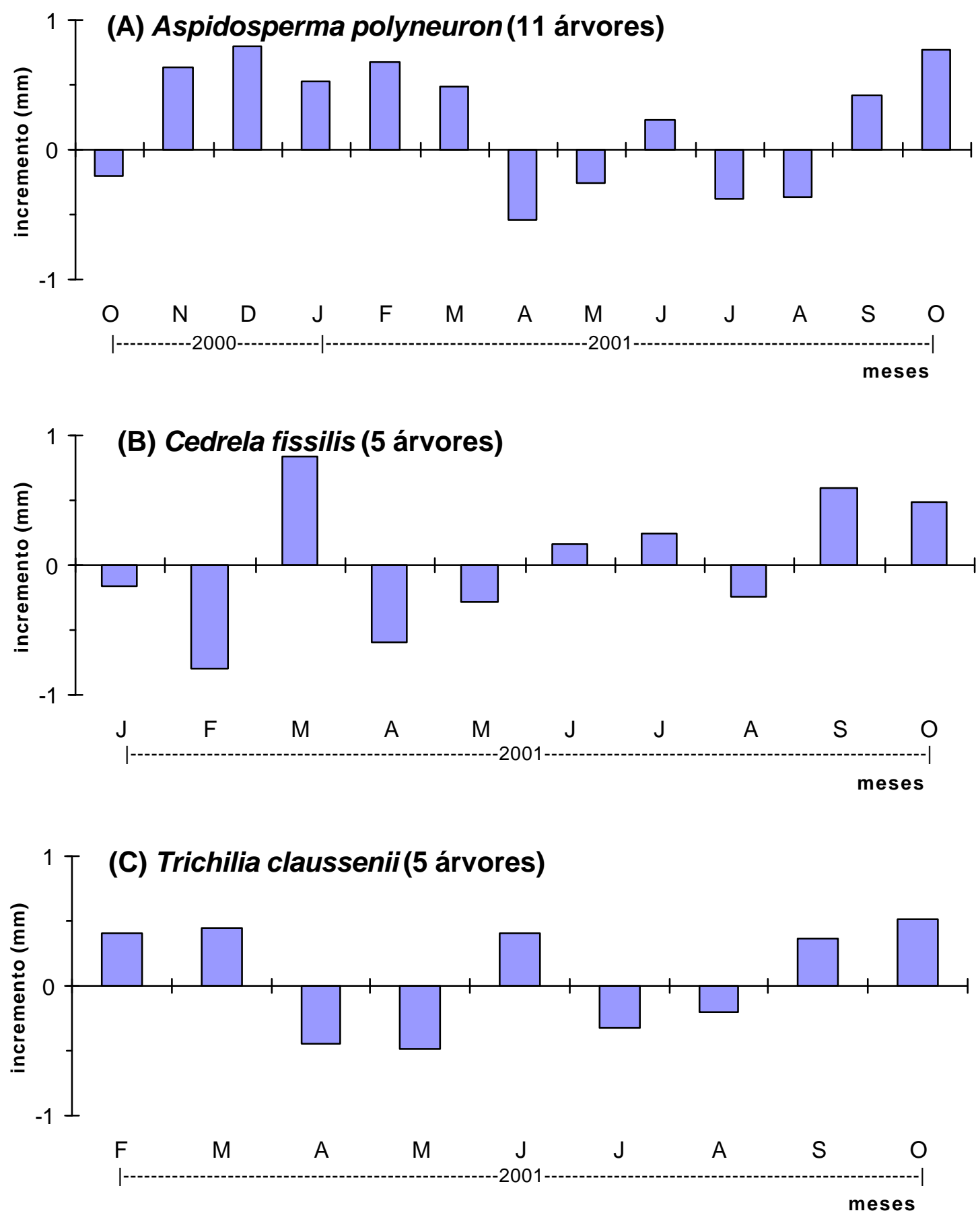

Figura 11 - Variação do incremento médio mensal das espécies florestais na Reserva Florestal Mata de Santa Genebra no período de outubro de 2000 a outubro de 2001. (A) Aspidosperma polyneuron (peroba-rosa); (janeiro a outubro de 2001) (B) Cedrela fissilis (cedro); (fevereiro a outubro de 2001) (C) Trichilia claussenii (catiguá). 

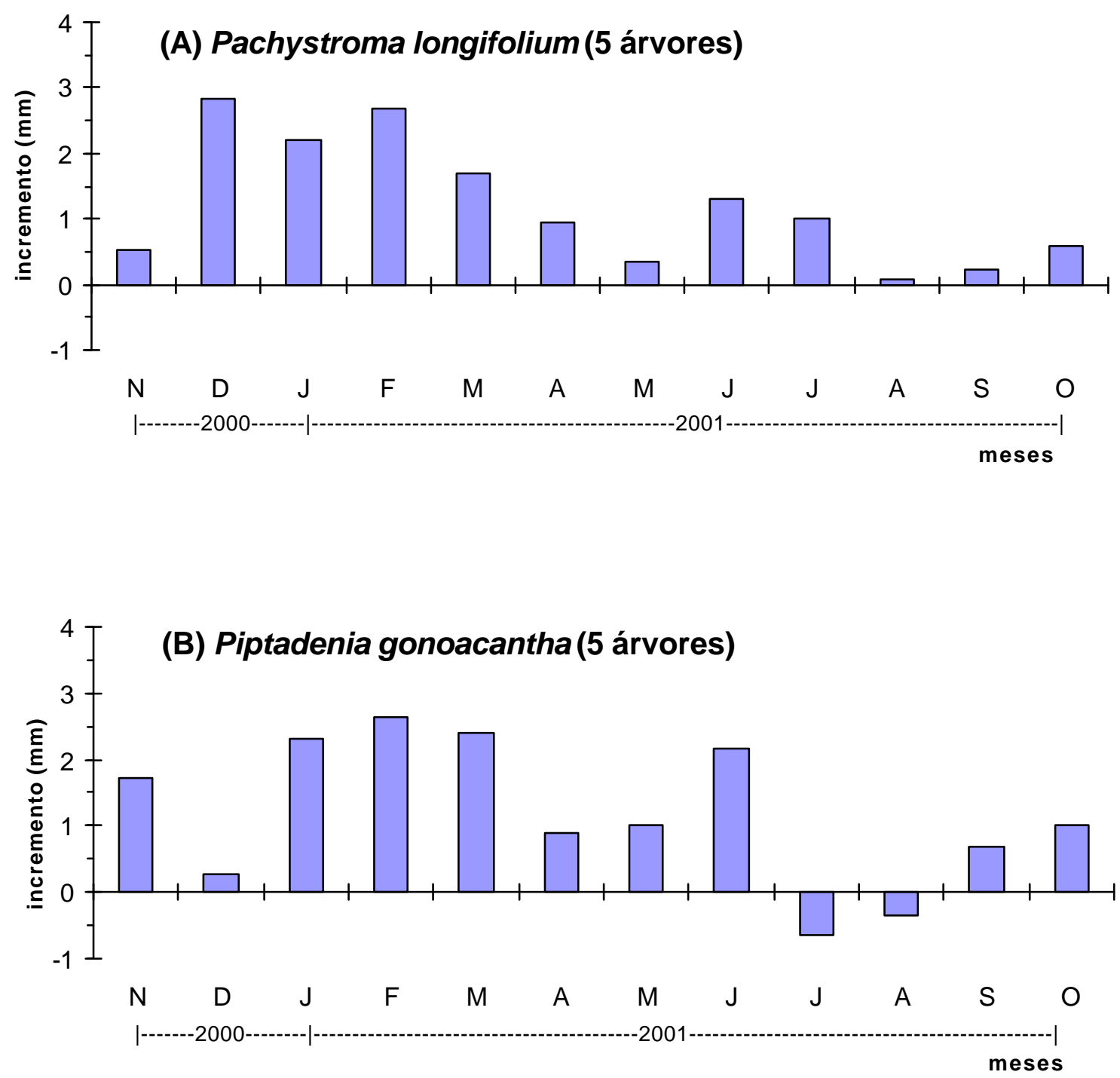

Figura 12 - Variação do incremento médio mensal das espécies florestais na Reserva Florestal Mata de Santa Genebra no período de novembro de 2000 a outubro de 2001. (A) Pachystroma longifolium (canxim); (B) Piptadenia gonoacantha (pau-jacaré). 

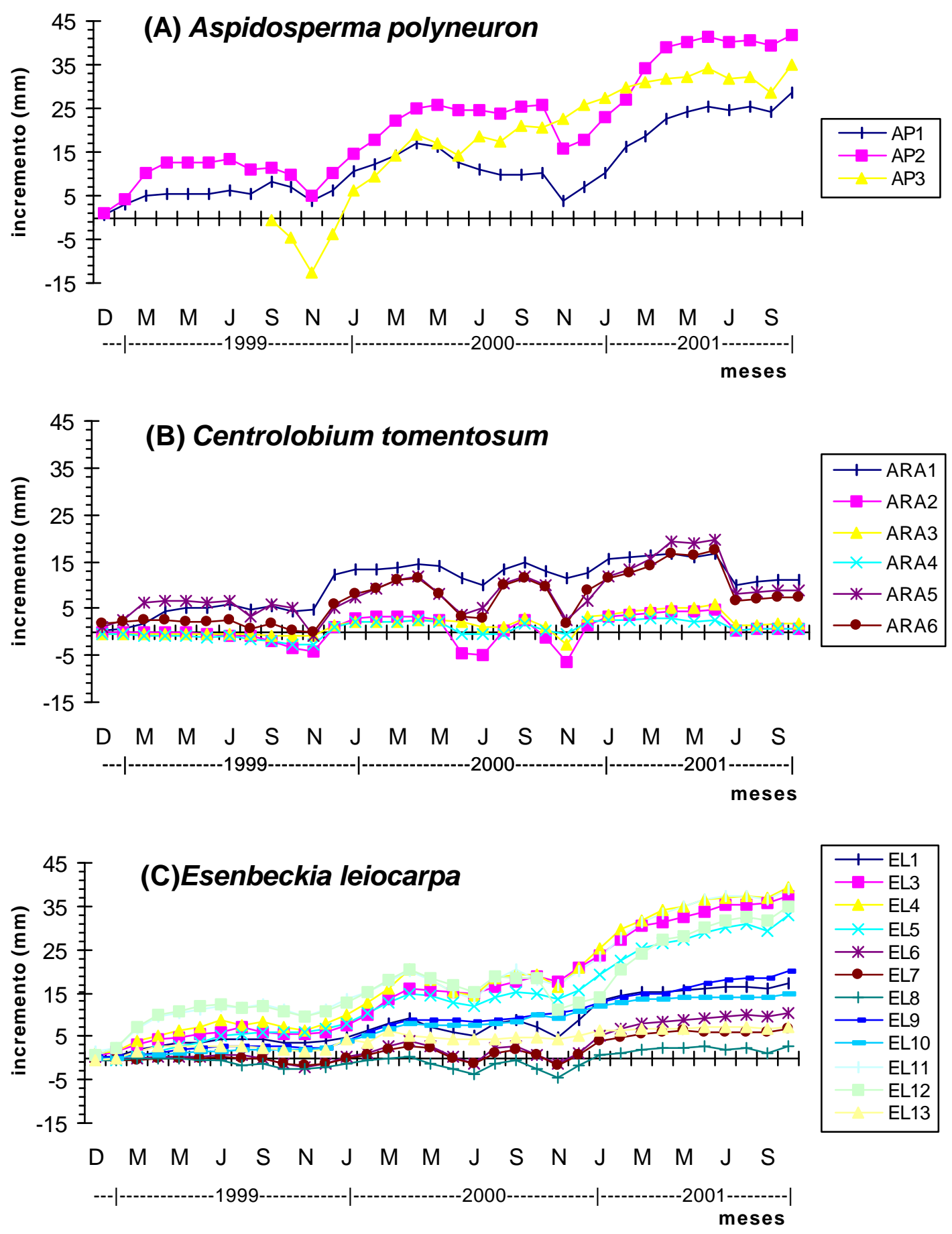

Figura 13 - Variação do incremento acumulado de espécies florestais na Estação Ecológica de Ibicatu (Piracicaba) no período dezembro de 1998 a outubro de 2001 (exceto fevereiro de 1999). (A) Aspidosperma polyneuron (peroba-rosa); (B) Centrolobium tomentosum (araribá); (C) Esenbeckia leiocarpa (guarantã). 

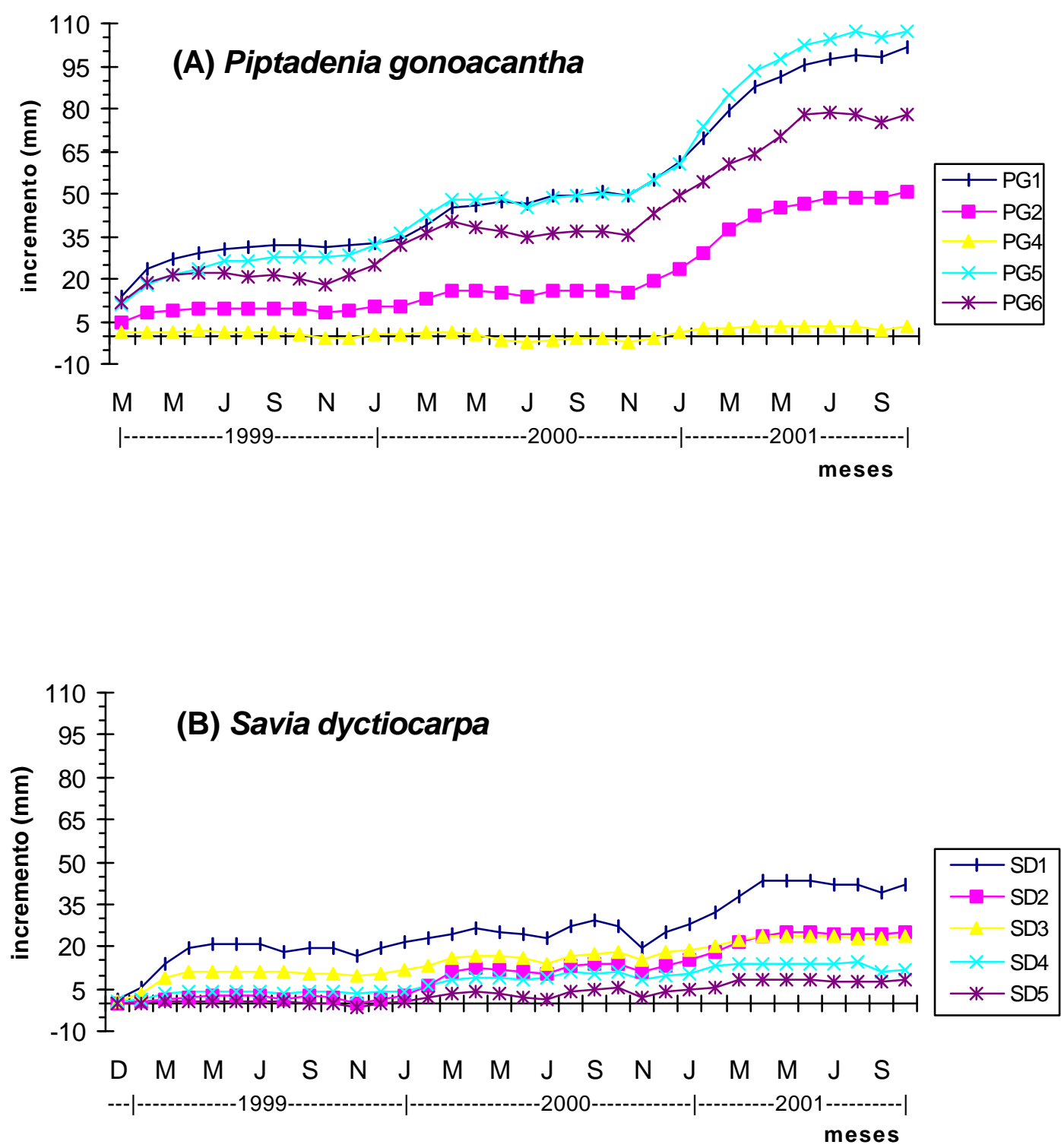

Figura 14 - Variação do incremento acumulado de espécies florestais na Estação Ecológica de Ibicatu (Piracicaba) no período de março de 1999 a outubro de 2001. (A) Piptadenia gonoacantha (pau-jacaré); (dezembro de 1998 a outubro de 2001 - exceto fevereiro de 1999) (B) Savia dyctiocarpa (guaraiúva). 

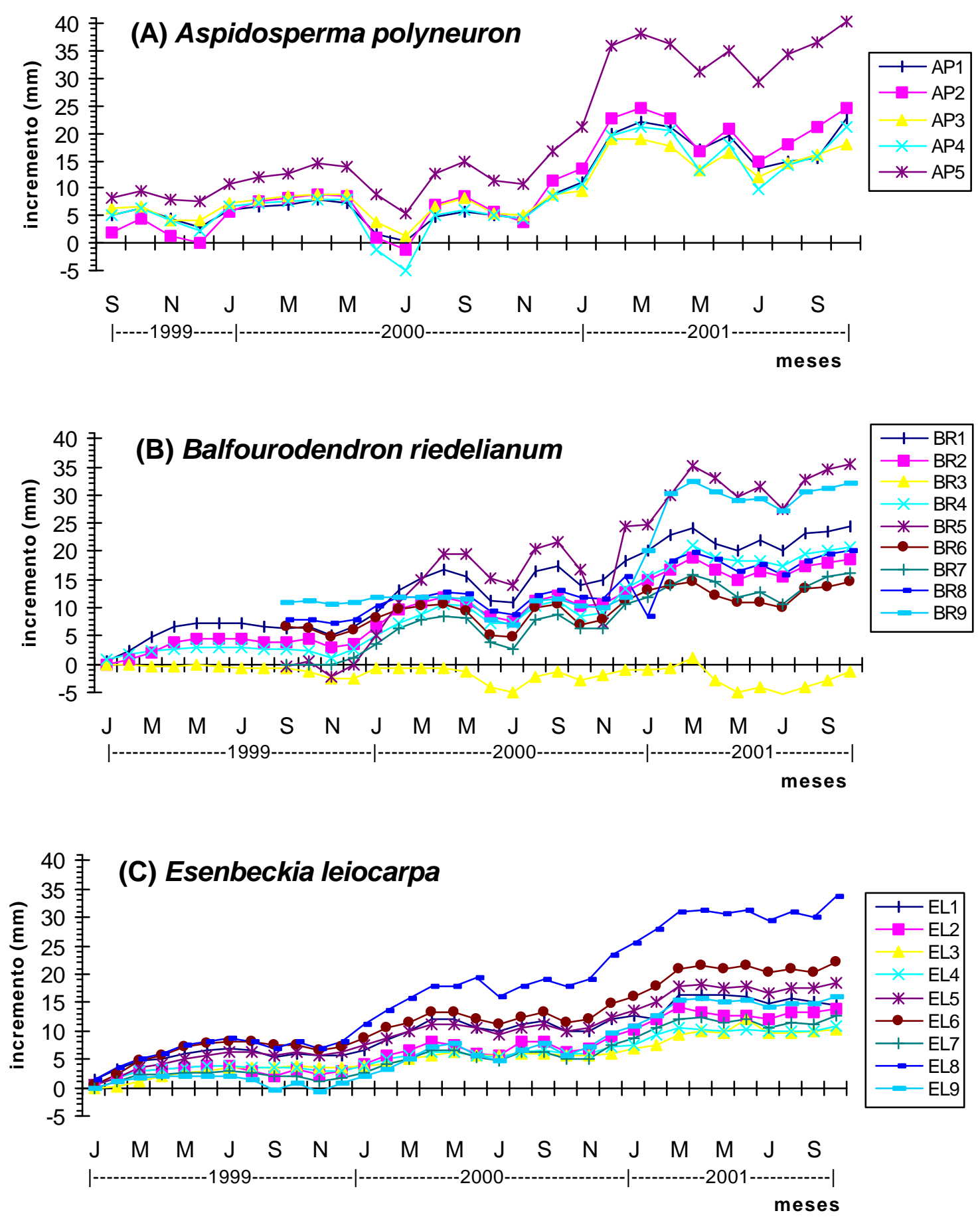

Figura 15 - Variação do incremento acumulado de espécies florestais na Estação Experimental de Tupi (Piracicaba) no período de setembro de 1999 a outubro de 2001. (A) Aspidosperma polyneuron (peroba-rosa); (janeiro de 1999 a outubro de 2001) (B) Balfourodendron riedelianum (pau-marfim); (C) Esenbeckia leiocarpa (guarantã). 

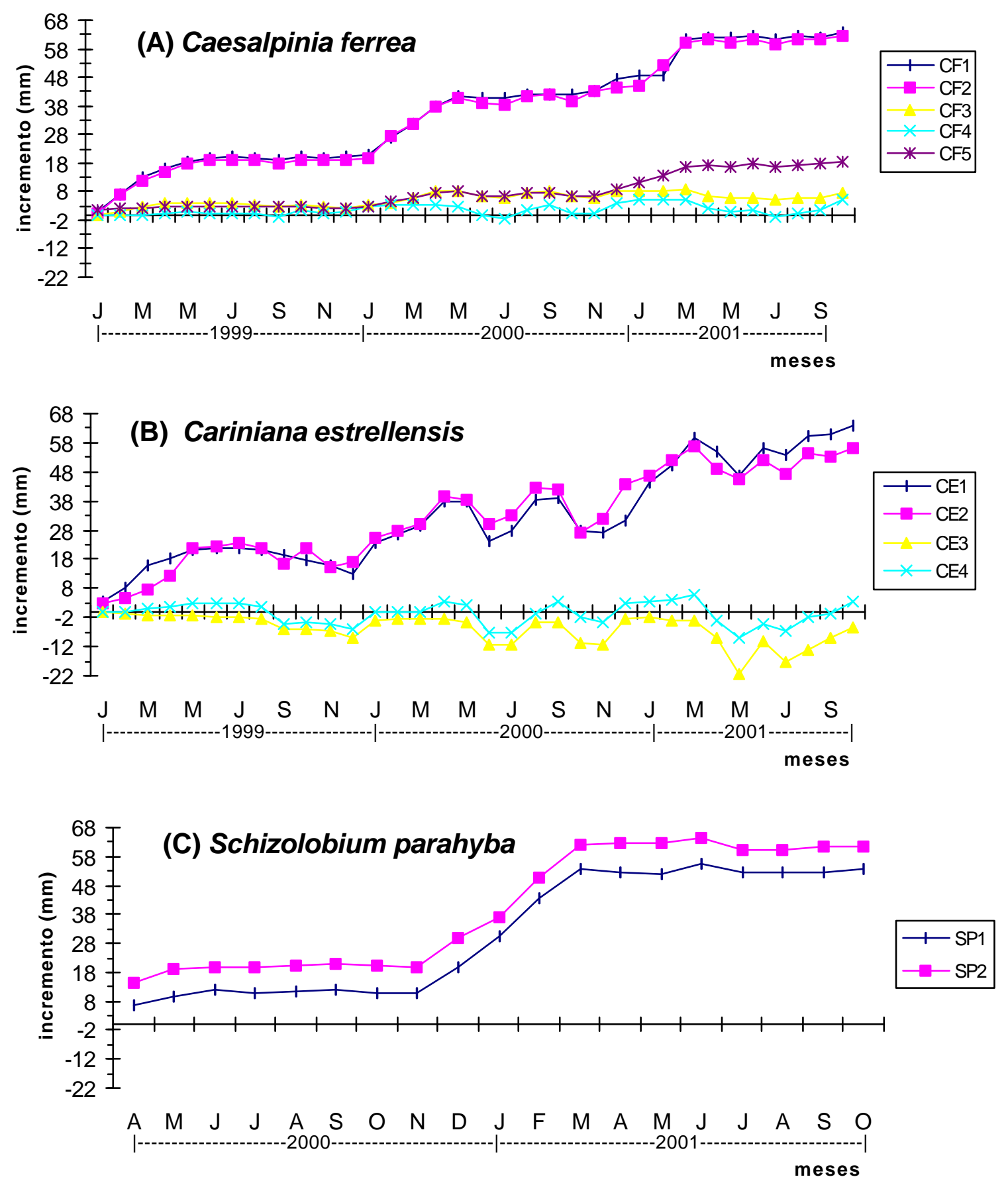

Figura 16 - Variação do incremento acumulado de espécies florestais na Estação Experimental de Tupi (Piracicaba) no período de janeiro de 1999 a outubro de 2001. (A) Caesalpinia ferrea (pau-ferro); (B) Cariniana estrellensis (jequitibá-branco); (abril de 2000 a outubro de 2001) (C) Schizolobium parahyba (guapuruvu). 



Figura 17 - Variação do incremento acumulado de espécies florestais na Reserva Florestal Mata de Santa Genebra no período de outubro de 2000 a outubro de 2001. (A) Aspidosperma polyneuron (peroba-rosa); (janeiro a outubro de 2001) (B) Cedrela fissilis (cedro); (fevereiro a outubro de 2001) (C) Centrolobium tomentosum (araribá). 



Figura 18 - Variação do incremento acumulado de espécies florestais na Reserva Florestal Mata de Santa Genebra no período de fevereiro de 2001 a outubro de 2001. (A) Copaifera langsdorffii (copaíba); (B) Esenbeckia leiocarpa (guarantã); (C) Trichilia claussenii (catiguá). 

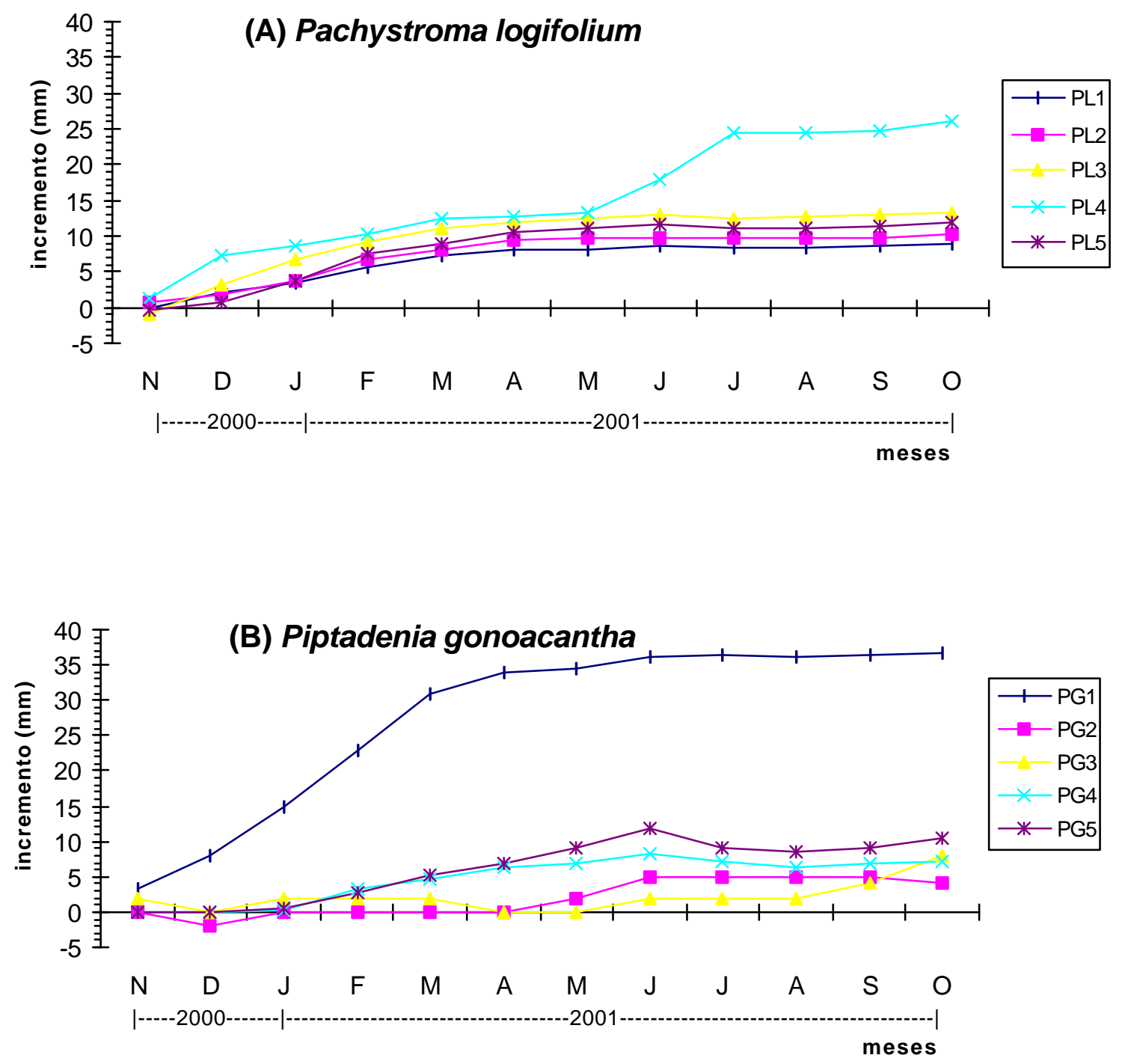

Figura 19 - Variação do incremento acumulado de espécies florestais na Reserva Florestal Mata de Santa Genebra no período de novembro de 2000 a outubro de 2001. (A) Pachystroma longifolium (canxim); (B) Piptadenia gonoacantha (pau-jacaré). 
Observando as Figuras 6 - 12 pode-se verificar que, de modo geral, na maioria das espécies há uma diminuição da atividade cambial a partir do mês de abril (início do período seco) e uma retomada entre os meses de novembro e dezembro (início do período chuvoso). Na transição entre o período seco e o chuvoso houve algumas variações quanto a média da taxa de crescimento em circunferência do tronco das árvores. Mesmo no período seco a taxa de crescimento aumentou para algumas espécies, como em Esenbeckia leiocarpa (guarantã) e Savia dyctiocarpa (guaraiúva) (Figuras 7A e B) com alto crescimento em circunferência do tronco em agosto de 2000. O mesmo ocorreu em Balfourodendron riedelianum (paumarfim), Aspidosperma polyneuron (peroba-rosa) e Cariniana estrellensis (jequitibábranco) (Figuras 8A, 9A e B). Em alguns casos ocorreu o inverso, ou seja, diminuição do crescimento do tronco no início do período chuvoso, para todas as espécies da Estação Ecológica de Ibicatu (Figuras 6 - 7) e algumas da Estação Experimental de Tupi. Na primeira todas as árvores diminuíram suas taxas de crescimento do tronco em novembro de 1999 e 2000 e na segunda área o mesmo ocorreu com Balfourodendron riedelianum (pau-marfim), Caesalpinia ferrea (jequitibá-branco) e Esenbeckia leiocarpa (guarantã) (Figuras 8A, B e C) no mês de outubro de 2000.

Outro fator importante é a variação da taxa de crescimento em circunferência do tronco entre as espécies, como por exemplo, em Aspidosperma polyneuron (peroba-rosa) e Cariniana estrellensis (jequitibá-branco) (Figuras 9A e B) foram bem maiores do que em Esenbeckia leiocarpa (guarantã) e Savia dyctiocarpa (guaraiúva) (Figuras 8C e 7B).

A taxa de crescimento acumulado do tronco para a maioria das espécies foi sincronizado, ou seja, ocorreu o mesmo comportamento, à exceção de Centrolobium tomentosum (araribá 1, 5, 6 e 2, 3, 4) (Figura 13B), Caesalpinia ferrea (pau-ferro 1, 2 e 3, 4, 5) (Figura 16A), Cariniana estrellensis (jequitibá-branco 1, 2 e 3, 4) (Figura 16B) e Piptadenia gonoacantha (pau-jacaré 1 e 2, 3, 4, 5) (Figura 19B).

Na Tabela 6, são apresentadas as taxas de crescimento em circunferência médio e acumulado do tronco das árvores, o período de diminuição e da retomada da atividade cambial e o mês de maior e menor crescimento das espécies, em cada área de estudo. Para 
Centrolobium tomentosum (araribá), Copaifera langsdorffii (copaíba), Esenbekia leiocarpa (guarantã), Cedrela fissilis (cedro), Trichilia claussenii (catiguá) da Reserva Florestal Mata de Santa Genebra não foi realizada esta análise. Neste caso há necessidade de, no mínimo, um ano de coleta de dados para se obter resultados mais precisos e confiáveis.

Na Estação Ecológica de Ibicatu a maior e a menor taxa de crescimento médio mensal e acumulado foram observadas em Piptadenia gonoacantha (pau-jacaré) e Centrolobium tomentosum (araribá), respectivamente. Na Estação Experimental de Tupi, as mesmas foram verificadas em Schizolobium parahyba (guapuruvu) e Esenbeckia leiocarpa (guarantã), e na Reserva Florestal Mata de Santa Genebra para as espécies Piptadenia gonoacantha (paujacaré) e Aspidosperma polyneuron (peroba-rosa).

A média mais elevada de incremento mensal em circunferência do tronco ocorreu para Schizolobium parahyba (guapuruvu), com 13,5 mm em fevereiro de 2001, e a mais baixa para Cariniana estrellensis (jequitibá-branco), com um incremento - 9,75 mm, em junho de 2000, na Estação Experimental de Tupi (Tabela 6 e Figuras 9C e B).

Notou-se também que, para a maioria das espécies, o período entre a diminuição e/ou cessação da atividade cambial e a retomada do crescimento em circunferência do tronco das árvores, teve uma duração de 6 - 8 meses, iniciando-se em abril e prosseguindo até novembro - dezembro (Tabela 6).

Na Tabela 7 e Figura 20, são apresentadas para as 4 espécies a taxa de crescimento médio mensal dividindo-se as árvores de uma mesma espécie em 2 diferentes grupos em função da grande diferença observada na taxa de crescimento destas árvores. 
Tabela 6. Taxas médias mensais e acumuladas em circunferência do tronco das espécies em estudo e períodos de diminuição / retomada da atividade cambial.

\begin{tabular}{|c|c|c|c|c|c|c|}
\hline \multirow[t]{2}{*}{ ESPÉCIES ANALISADAS } & \multirow{2}{*}{$\begin{array}{c}\text { TCMM } \\
(\mathrm{mm})\end{array}$} & \multirow{2}{*}{$\begin{array}{c}\text { TCMA } \\
(\mathrm{mm})\end{array}$} & \multirow{2}{*}{$\begin{array}{c}\mathrm{TC} \\
\text { (mm/mês) } \\
\text { (Min-Max) }\end{array}$} & \multicolumn{2}{|c|}{ Crescimento* } & \multirow{2}{*}{$\begin{array}{c}\text { Suspensão e/ou } \\
\text { diminuição** } \\
\text { (meses) }\end{array}$} \\
\hline & & & & Diminuição & Retomada & \\
\hline \multicolumn{7}{|l|}{ ESTAÇÃO ECOLÓGICA DE IBICATU } \\
\hline Aspidosperma polyneurom (peroba-rosa) & 1,12 & 17,81 & $-5,33$ a 6,2 & abril/maio & dez. & 7 a 8 \\
\hline Centrolobium tomentosum (araribá) & 0,36 & 4,83 & $-4,53$ a 4,93 & abril & dez. & 8 \\
\hline Esenbeckia leiocarpa (guarantã) & 0,66 & 10,05 & $-1,9$ a 2,73 & abril/maio & dez. & 7 a 8 \\
\hline Piptadenia gonoacantha (pau-jacaré) & 2,13 & 34,07 & $-1,72$ a 8,44 & maio/jun. & dez. & 6 a 7 \\
\hline Savia dyctiocarpa (guaraiúva) & 0,65 & 12,75 & $-3,72$ a 3,68 & abril & dez. & 8 \\
\hline \multicolumn{7}{|l|}{ ESTAÇÃO EXPERIMENTAL DE TUPI } \\
\hline Aspidosperma polyneurom (peroba-rosa) & 0,75 & 12,01 & $-6,48$ a 10,32 & abril & dez. & 8 \\
\hline Balfourodendron riedelianum (pau-marfim) & 0,52 & 10,46 & $-3,6$ a 4,44 & abril/maio & nov./dez. & 7 \\
\hline Caesalpinia ferrea (pau-ferro) & 0,93 & 17,98 & $-1,64$ a 4,88 & abril/maio & nov./dez. & 7 \\
\hline Cariniana estrellensis (jequitibá-branco) & 0,86 & 14,76 & $-9,75$ a 8,55 & maio/jun. & dez./jan. & 7 \\
\hline Esenbeckia leiocarpa (guarantã) & 0,50 & 9,03 & $-1,33$ a 2,51 & maio/jun. & nov./dez. & 6 \\
\hline Schizolobium parahyba (guapuruvu) & 3,02 & 36,03 & $-3,3$ a 13,5 & maio & dez & 7 \\
\hline \multicolumn{7}{|c|}{ RESERVA FLORESTAL MATA DE SANTA GENEBRA } \\
\hline Aspidosperma polyneuron (peroba-rosa) & 0,21 & 1,59 & 0,8 a 0,55 & abril & nov. & 7 \\
\hline Pachystroma longifolium (canxim) & 1,09 & 8,66 & 0,08 a 2,84 & abril & nov. & 7 \\
\hline Piptadenia gonoacantha (pau-jacaré) & 1,17 & 8,63 & $-0,64$ a 2,64 & abril & nov. & 7 \\
\hline
\end{tabular}

TCMM: Taxa de crescimento em circunferência médio mensal (mm);

TCMA: Taxa de crescimento em circunferência média acumulada (mm);

TC: Taxa de incremento média mensal em circunferência, máxima e mínima obtidas durante o período de 13 a 34 meses de estudo;

* Época (meses do ano) de diminuição e retomada de crescimento das árvores;

** Período de tempo de suspensão e/ou diminuição da atividade cambial (n. ${ }^{\circ}$ de meses). 
Tabela 7. Taxas de crescimento em circunferência do tronco médio mensal e acumulado de algumas árvores das espécies em estudo.

\begin{tabular}{|c|c|c|c|}
\hline Espécies analisadas & $\begin{array}{c}\text { TCMM } \\
\text { (mm) }\end{array}$ & $\begin{array}{c}\text { TCMA } \\
\text { (mm) }\end{array}$ & $\begin{array}{c}\text { TC } \\
\text { (mm/mês) } \\
\text { (Min-Max) }\end{array}$ \\
\hline \multicolumn{4}{|l|}{ ESTAÇÃO ECOLÓGICA DE IBICATU } \\
\hline Centrolobium tomentosum (araribá) - 1,5,6 & 0,44 & 8,81 & $-5,73$ a 5,27 \\
\hline Centrolobium tomentosum (araribá) - 2,3,4 & 0,24 & 0,85 & $-5,47$ a 3,33 \\
\hline \multicolumn{4}{|l|}{ ESTAÇÃO EXPERIMENTAL DE TUPI } \\
\hline Caesalpinia ferrea (pau-ferro) - 1,2 & 1,86 & 36,20 & $-1,5$ a 10,1 \\
\hline Caesalpinia ferrea (pau-ferro) - 3,4,5 & 0,31 & 4,98 & $-2,07$ a 2,73 \\
\hline Cariniana estrellensis (jequitibá-branco) - 1,2 & 1,76 & 32,80 & -13 a 10,2 \\
\hline Cariniana estrellensis (jequitibá-branco) - 3,4 & $-0,03$ & $-3,27$ & -9 a 7,9 \\
\hline \multicolumn{4}{|c|}{ RESERVA FLORESTAL MATA DE SANTA GENEBRA } \\
\hline Piptadenia gonoacantha (pau-jacaré) - 1 & 3,07 & 27,48 & $-0,2$ a 8 \\
\hline Piptadenia gonoacantha (pau-jacaré) - 2,3,4,5 & 0,66 & 3,76 & -2 a 2,3 \\
\hline
\end{tabular}

TCMM: Taxa de crescimento em circunferência médio mensal (mm);

TCMA: Taxa de crescimento em circunferência média acumulada $(\mathrm{mm})$;

TC: Taxa de incremento médias mensais em circunferência, máxima e mínima obtidas durante os 13 a 34 meses de estudo. 

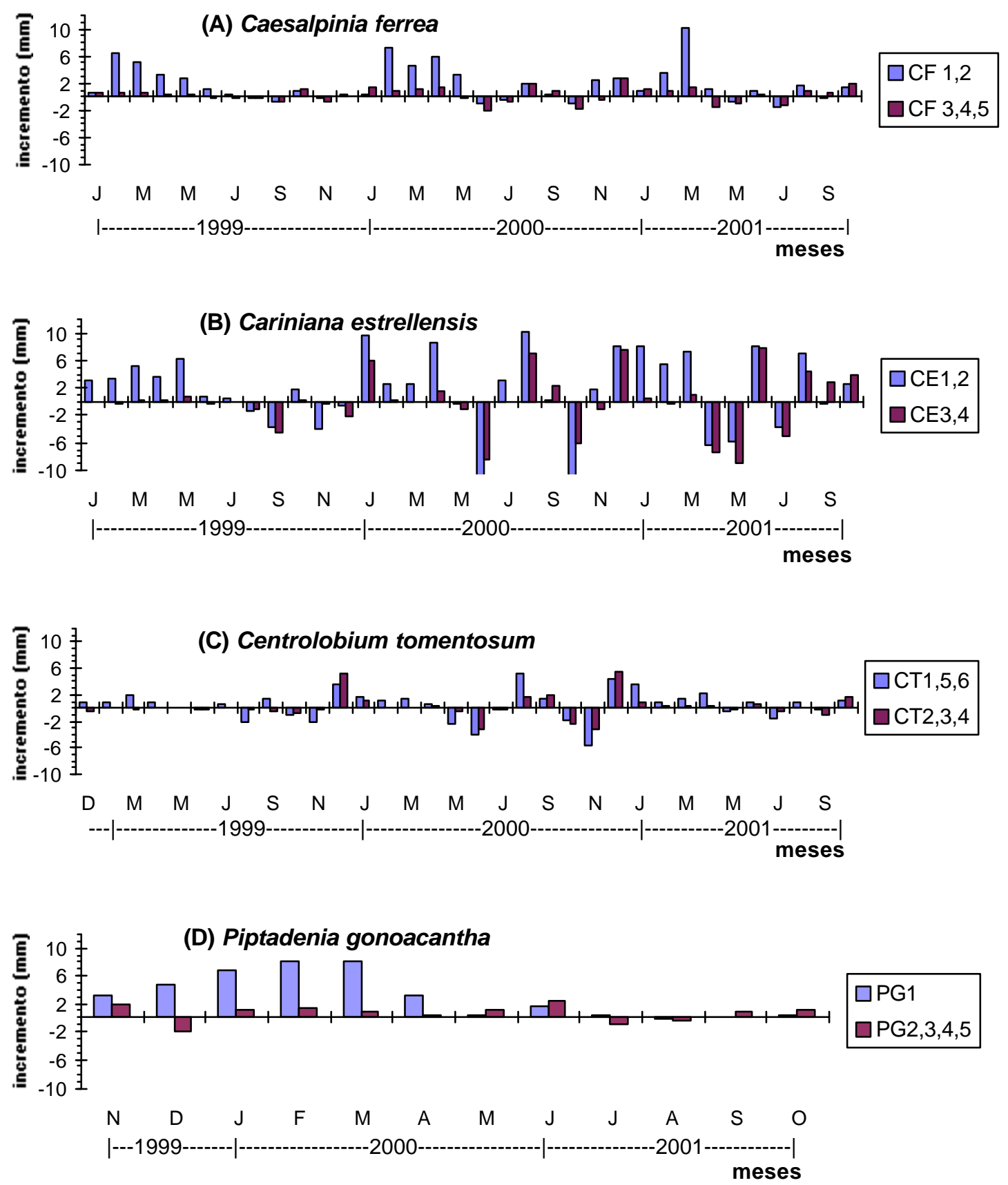

Figura 20 - Variação do incremento médio mensal entre árvores de algumas espécies florestais no período de dezembro de 1999 a outubro de 2001. (A) Caesalpinia ferrea (pau-ferro); (B) Cariniana estrellensis (jequitibá-branco) - Estação Ecológica de Tupi (Piracicaba) (C) Centrolobium tomentosum (araribá) - Estação Ecológica de Ibicatu (Piracicaba) (D) Piptadenia gonoacantha (pau-jacaré) - Reserva Florestal Mata de Santa Genebra (Campinas). 


\subsection{Avaliação da fenologia}

As observações fenológicas realizadas mensalmente nas 3 áreas, juntamente com a medição do incremento em circunferência das árvores são apresentadas na Tabela $8 . \mathrm{Na}$ Reserva Florestal Mata de Santa Genebra as observações fenológicas para Centrolobium tomentosum (araribá), Copaifera langsdorffii (copaíba), Esenbekia leiocarpa (guarantã), Cedrela fissilis (cedro), Trichilia claussenii (catiguá), não chegaram a completar 12 meses, sendo, desta maneira, considerados os dados extraídos da literatura especializada (Morellato, 1991 e Lorenzi, 1992).

As fenofases, das espécies nas diferentes épocas do ano para os 3 locais indicam:

- Brotamento: a maioria das árvores iniciou o crescimento vegetativo com emissão de folhas ainda nos períodos secos e de baixa umidade (final do inverno), como em Aspidosperma polyneuron (peroba-rosa), Caesalpenia ferrea (pau-ferro), etc. Outras espécies iniciaram a emissão das folhas no início do período das primeiras chuvas, estendendo-se até a época de maior precipitação no ano (verão), como em, Cariniana estrellensis (jequitibá-branco), Savia dyctiocarpa (guaraiúva), Cedrela fissilis (cedro), etc.

- Queda de folhas: a queda das folhas de todas as árvores ocorreu no período de menor temperatura e precipitação (inverno). Para as espécies perenes como Esenbeckia leiocarpa (guarantã), Aspidosperma polyneuron (peroba-rosa) e Pachystroma longifolium (canxim) a queda de folhas não é tão intensa enquanto que, para Cedrela fissilis (cedro) e Caesalpinia ferrea (pau-ferro), espécies decídua e semidecídua, respectivamente, observa-se que, a maioria das folhas velhas é substituída por novas.

- Floração: grande parte das árvores iniciou a sua floração nos meses de baixa temperatura e de menor precipitação (inverno), sendo que outras no início do período chuvoso (primavera). Somente Centrolobium tomentosum (araribá), Pachystroma 
longifolium (canxim) e Copaifera langsdorffii (copaíba) tiveram o período de floração durante a época mais quente e úmida do ano (verão).

- Frutificação: esta fenofase ocorreu nas árvores de todas as espécies no final do período de menor temperatura e precipitação (inverno) e início do período chuvoso (primavera), sem exceções.

As informações ecológicas obtidas para as árvores de cada espécie indicam que a sua maioria são classificadas como semidecíduas, heliófitas, seletivas higrófilas e secundárias tardias (Tabela 9).

\subsection{Avaliação das condições climáticas}

Na Figura 21 e 22 são apresentados os valores de balanço hídrico, de temperatura e umidade relativa (\%) de Piracicaba e Campinas, no período de janeiro de 1999 a outubro de 2001. Esses valores de precipitação, temperatura e umidade relativa começam a diminuir a partir de abril e permanecem baixos até meados dos meses de agosto e/ou início de setembro (período seco), aumentando em outubro e se estendendo até fevereiro (período chuvoso). 
Tabela 8. Fenologia de espécies arbóreas nas florestas estacionais semidecíduas em estudo.

\begin{tabular}{lcccc}
\hline \multicolumn{1}{c}{ ESPÉCIES } & \multicolumn{2}{c}{ FENOFASES } \\
& Brotamento & Queda das folhas & Floração & Frutificação \\
\hline Aspidosperma polyneuron (peroba-rosa) & ago- out & jun-ago & ago-nov & jul-out \\
Balfourodendron riedelianum (pau-marfim) & ago-out & jul-set & ago-out & jul-set \\
Caesalpinia ferrea (pau-ferro) & ago-set & ago-nov & out-nov & jun-set \\
Cariniana estrellensis (jequitibá-branco) & out-dez & jul-set & set-nov & ago-out \\
Cedrela fissilis (cedro) & out-nov & jun-set & ago-set & jun-ago \\
Centrolobium tomentosum (araribá) & set-jan & jun-nov & jan-mar & ago-set \\
Copaifera langsdorffii (copaíba) & ago-out & jun-ago & dez-mar & jul-set \\
Esenbeckia leiocarpa (guarantã) & set-dez & mai-set & set-jan & jul-set \\
Pachystroma longifolium (canxim) & out-dez & jul-out & out-jan & ago-out \\
Piptadenia gonoacantha (pau-jacaré) & set-nov & jun-ago & set-nov (jan) & ago-out \\
Savia dyctiocarpa (guaraiúva) & out-dez & jun-set & out-nov & jul-out \\
Schizolobium parahyba (guapuruvu) & set-out & mai-ago & set-nov & jun-ago \\
Trichilia claussenii (catiguá) & set-out & jun-ago & ago-out & mai-jun \\
\hline
\end{tabular}


Tabela 9. Informações ecológicas das espécies arbóreas nas florestas estacionais semidecíduas em estudo.

\begin{tabular}{|c|c|c|c|c|c|c|c|c|}
\hline \multirow[t]{2}{*}{ ESPÉCIES } & \multicolumn{8}{|c|}{ INFORMAÇÕES ECOLÓGICAS } \\
\hline & Decídua & Semidecídua & Perene & Heliófita & Esciófita & $\begin{array}{l}\text { Seletiva } \\
\text { higrófila }\end{array}$ & $\begin{array}{l}\text { Seletiva } \\
\text { xerófita }\end{array}$ & Classif.* \\
\hline Aspidosperma polyneuron (peroba-rosa) & & & $\mathrm{X}$ & & $\mathrm{X}$ & & & St \\
\hline Balfourodendron riedelianum (pau-marfim) & & $\mathrm{X}$ & & $\mathrm{X}$ & & & & $\mathrm{Si}$ \\
\hline Caesalpinia ferrea (pau-ferro) & & $\mathrm{X}$ & & $\mathrm{X}$ & & $\mathrm{X}$ & & $\mathrm{St}$ \\
\hline Cariniana estrellensis (jequitibá-branco) & & $\mathrm{X}$ & & $\mathrm{X}$ & & & & St \\
\hline Cedrela fissilis (cedro) & $\mathrm{X}$ & & & $\mathrm{X}$ & $\mathrm{X}$ & & & St \\
\hline Centrolobium tomentosum (araribá) & & $\mathrm{X}$ & & $\mathrm{X}$ & & & & $\mathrm{Si}$ \\
\hline Copaifera langsdorffii (copaíba) & & $\mathrm{X}$ & & $\mathrm{X}$ & & & $\mathrm{X}$ & St \\
\hline Esenbeckia leiocarpa (guarantã) & & & $\mathrm{X}$ & & $\mathrm{X}$ & & & St \\
\hline Pachystroma longifolium (canxim) & & & $\mathrm{X}$ & $\mathrm{X}$ & $\mathrm{X}$ & $\mathrm{X}$ & & St \\
\hline Piptadenia gonoacantha (pau-jacaré) & & $\mathrm{X}$ & & $\mathrm{X}$ & & $\mathrm{X}$ & & $\mathrm{Si}$ \\
\hline Savia dyctiocarpa (guaraiúva) & & $\mathrm{X}$ & & & $\mathrm{X}$ & & & St \\
\hline Schizolobium parahyba (guapuruvu) & $\mathrm{X}$ & & & $\mathrm{X}$ & & $\mathrm{X}$ & & $\mathrm{P}$ \\
\hline Trichilia claussenii (catiguá) & & $\mathrm{X}$ & & & $\mathrm{X}$ & $\mathrm{X}$ & & St \\
\hline
\end{tabular}

* Classificação das árvores: P: Árvore pioneira; $\quad$ Si: Árvore secundária inicial; $\quad$ St: Árvore secundária tardia 


\section{(A) Piracicaba}

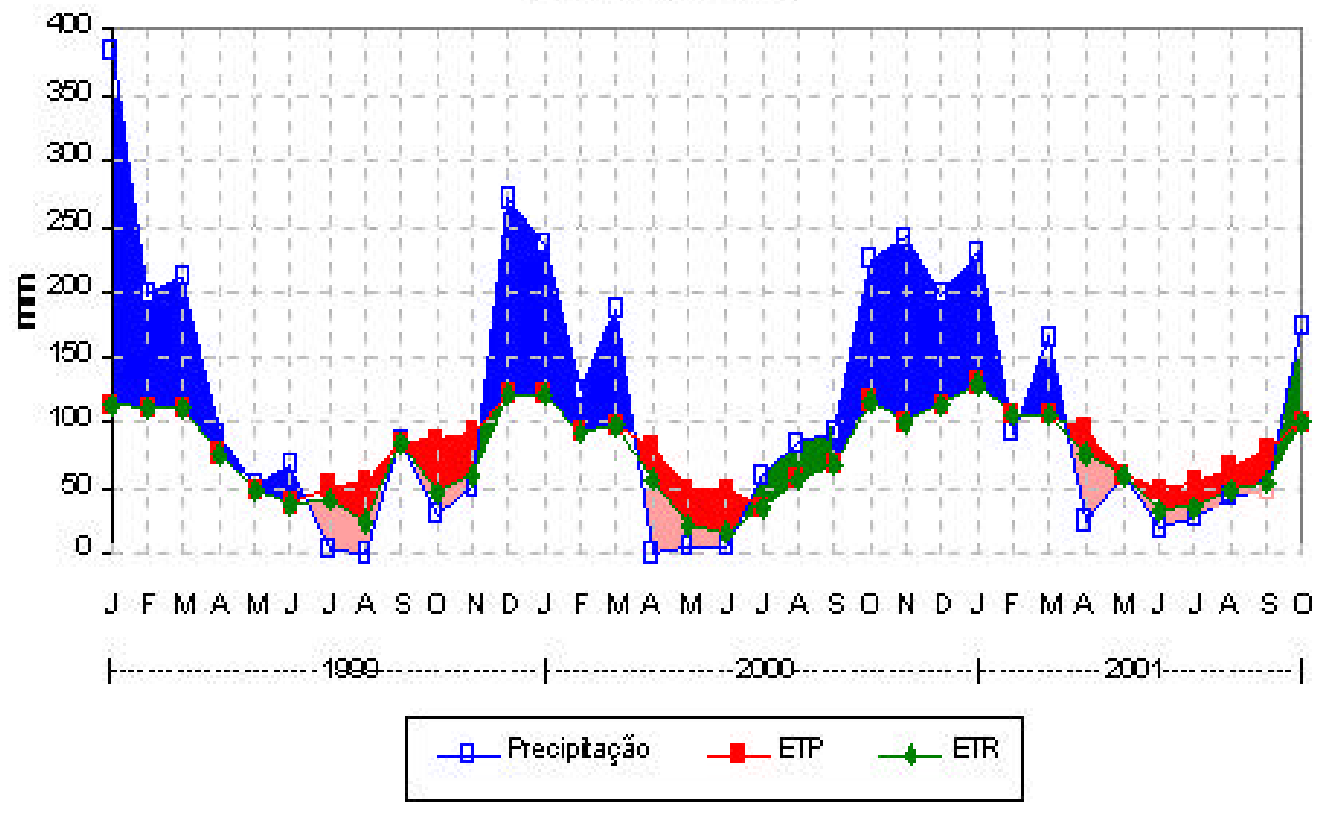

Fonte: Sentelhas, P.C, 2001 - Departamento de Ciências Exatas - ESALQ/USP

Dados coletados no Departamento de Ciências Exatas - ESALQ/USP

Dados coletados no IAC (Campinas) e FEAGRI/UNICAMP (Campinas)

\section{(B) Campinas}

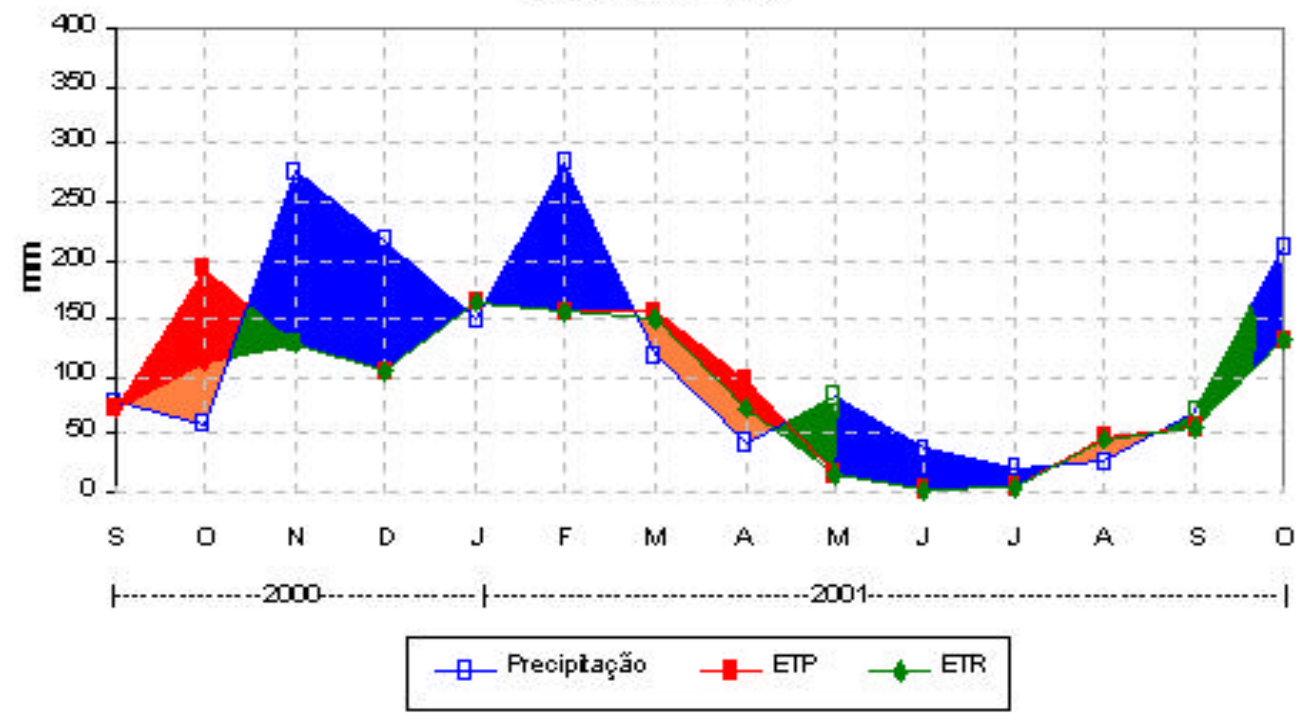

Figura 21 - Balanço Hídrico Normal. (A) Piracicaba - período de janeiro de 1999 a outubro de 2001; (B) Campinas - período de setembro de 2000 a outubro de 2001. 


\section{(A) Piracicaba}

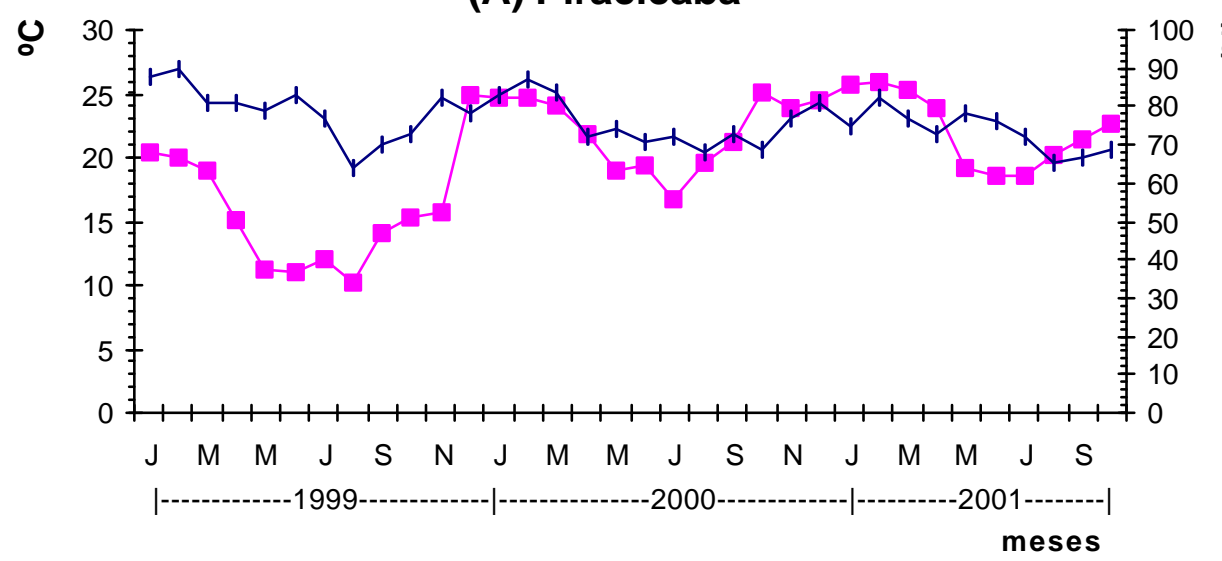

๙

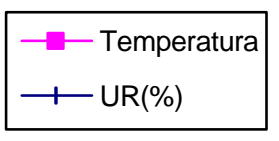

Dados coletados no Departamento de Ciências Exatas - ESALQ/USP

\section{(B) Campinas}

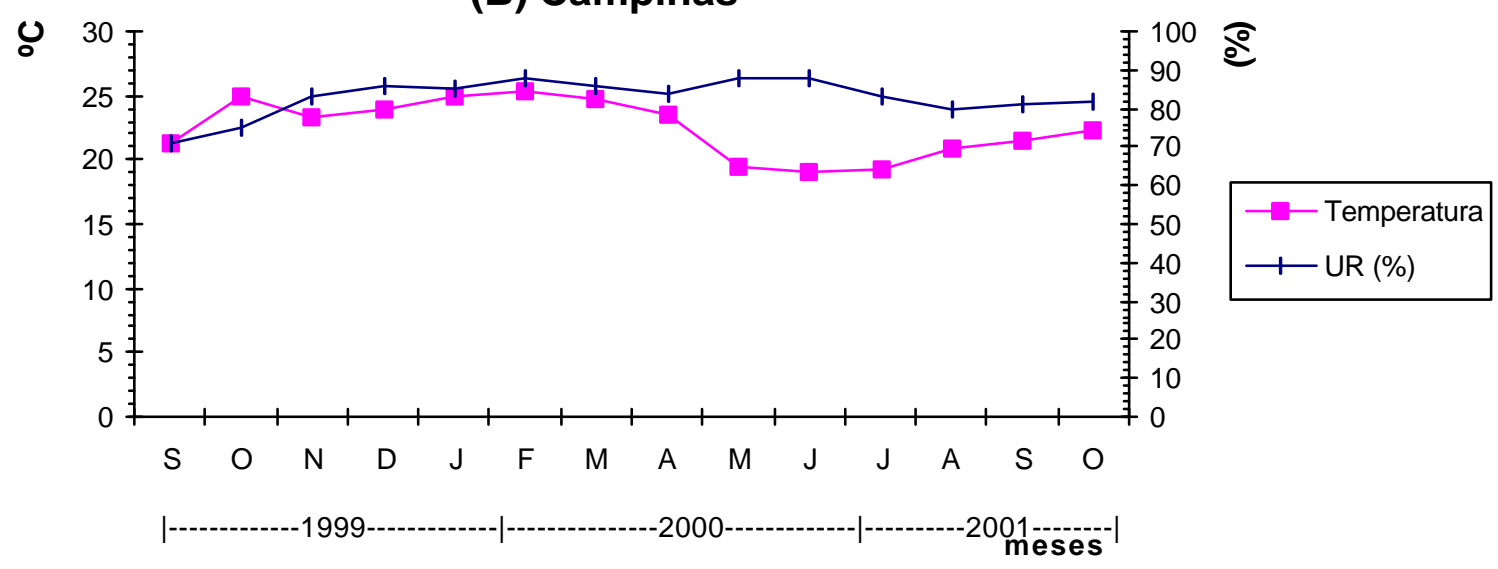

Dados coletados no IAC (Campinas) e FEAGRI/UNICAMP (Campinas)

Figura 22 - Média de temperatura e umidade relativa. (A) Piracicaba - período de janeiro de 1999 a outubro de 2001; (B) Campinas - período de setembro de 2000 a outubro de 2001. 


\subsection{Idade e taxa de crescimento das árvores}

Os anéis de crescimento, presentes no lenho das espécies, apresentam estrutura anatômica característica e distinta, apresentando também variações em suas larguras.

Os resultados que permitem estimar a idade e o incremento médio anual (mm) das árvores são apresentados na Tabela 10. Os valores de incremento médio mensal das árvores de cada espécie são próximos, mesmo em diferentes áreas, como para Aspidosperma polyneuron (peroba-rosa), com valores de 1,66 a 2,44 $\mathrm{mm}$. Para a maioria das árvores ocorre a mesma situação, à exceção de Cariniana estrellensis (jequitibá-branco), Cedrela fissilis (cedro), Piptadenia gonoacantha (pau-jacaré) e Savia dyctiocarpa (guaraiúva).

A espécie com menor taxa de incremento anual foi Trichilia claussenii (catiguá), com variação do incremento anual de 1,43 a 1,98 mm e a com maior foi Piptadenia gonoacantha (pau-jacaré), variando de 3,64 a 8,44 mm

Para se a idade exata de uma árvore exata é necessário que se tenha um disco transversal de madeira, para se obter toda sua superfície e poder verificar, desta forma, todos os limites dos anéis de crescimento são mais facilmente visualizados. Por se tratar, neste trabalho, de um método não destrutivo, foi possível coletar apenas duas amostras de madeira (baguetas), sendo assim a datação torna-se mais complexa por estar trabalhando com apenas dois raios da circunferência da árvore.

Para as espécies da Estação Experimental de Tupi, com a idade de plantio determinada, verificou-se que a maior parte das árvores teve a sua idade estimada bastante próxima da real, a exceção de algumas (Cariniana estrellensis 3 - jequitibá-branco e Caesalpinia ferrea 3 a 5 -pau-ferro) devido a fatores como competição com outras árvores, etc.

As taxas de incremento das árvores das espécies estudadas são apresentadas nas Figuras 23 a 39 sendo mostradas individualmente e no seu conjunto. Observa-se que para todas as árvores há períodos com variações significativas (máximas e mínimas), como é o caso das espécies Aspidosperma polyneuron (peroba-rosa), para as 3 áreas de estudo, 
que há períodos com pequenas oscilações da largura dos anéis de crescimento como Balfourodendron riedelianum - pau-marfim) com maiores valores de crescimento do tronco nos primeiros anos e, posteriormente, mostrando pouca variação e com incrementos anuais baixos.

Tabela 10: Incremento médio anual e estimativa da idade das árvores das 3 áreas em estudo.

\begin{tabular}{|c|c|c|c|c|c|c|}
\hline ESPÉCIES & $\begin{array}{l}\mathrm{N} .^{\circ} \mathrm{da} \\
\text { arv. }\end{array}$ & Locais & $\begin{array}{c}\text { Anéis cres. } \\
\text { larg. (mm) }\end{array}$ & $\begin{array}{c}\text { Idade } \\
\text { estimada }\end{array}$ & $\begin{array}{l}\text { Idade } \\
\text { real * }\end{array}$ & $\begin{array}{l}\text { Fig. } \\
\left(\mathrm{n}^{\circ}\right)\end{array}$ \\
\hline \multirow{9}{*}{ Aspidosperma polyneuron (peroba-rosa) } & 1 & IB & 2,04 & 60 & - & \multirow{3}{*}{23} \\
\hline & 2 & IB & 2,43 & 36 & - & \\
\hline & 3 & IB & 2,44 & 55 & - & \\
\hline & 1 & $\mathrm{TP}$ & 1,88 & 29 & 49 & \multirow{3}{*}{28} \\
\hline & 2 & TP & 2,30 & 40 & 49 & \\
\hline & 3 & TP & 1,66 & 40 & 49 & \\
\hline & 1 & SG & 2,40 & 66 & - & \multirow{6}{*}{29} \\
\hline & 3 & SG & 2,23 & 72 & - & \\
\hline & 4 & SG & 1,99 & 58 & - & \\
\hline \multirow{3}{*}{ Balfourodendron riedelianum (pau-marfim) } & 1 & TP & 1,73 & 34 & 49 & \\
\hline & 2 & $\mathrm{TP}$ & 1,78 & 40 & 49 & \\
\hline & 3 & $\mathrm{TP}$ & 2,15 & 46 & 49 & \\
\hline \multirow{3}{*}{ Caesalpinia ferrea (pau-ferro) } & 2 & $\mathrm{TP}$ & 2,61 & 42 & 49 & \multirow{3}{*}{30} \\
\hline & 3 & $\mathrm{TP}$ & 2,06 & 42 & 49 & \\
\hline & 5 & TP & 1,54 & 40 & 49 & \\
\hline \multirow{3}{*}{ Cariniana estrellensis (jequitibá-branco) } & 1 & TP & 1,23 & 44 & 49 & \multirow{3}{*}{31} \\
\hline & 2 & TP & 3,17 & 42 & 49 & \\
\hline & 3 & TP & 2,65 & 20 & 49 & \\
\hline \multirow{3}{*}{ Cedrela fissilis (cedro) } & 1 & SG & 3,30 & 16 & - & \multirow{3}{*}{34} \\
\hline & 2 & SG & 3,41 & 16 & - & \\
\hline & 5 & SG & 5,02 & 12 & - & \\
\hline \multirow{3}{*}{ Centrolobium tomentosum (araribá) } & 2 & IB & 2,97 & 52 & - & \multirow{3}{*}{24} \\
\hline & 3 & IB & 2,20 & 63 & - & \\
\hline & 6 & IB & 2,97 & 48 & - & \\
\hline
\end{tabular}




\begin{tabular}{|c|c|c|c|c|c|c|}
\hline ESPÉCIES & $\begin{array}{c}\mathrm{N}^{\circ}{ }^{\mathrm{da}} \\
\text { arv. }\end{array}$ & Locais & $\begin{array}{l}\text { Anéis cres. } \\
\text { larg. (mm) }\end{array}$ & $\begin{array}{c}\text { Idade } \\
\text { estimada }\end{array}$ & $\begin{array}{l}\text { Idade } \\
\text { real * }\end{array}$ & $\begin{array}{l}\text { Fig. } \\
\text { n. }\end{array}$ \\
\hline \multirow{4}{*}{ Centrolobium tomentosum (araribá) } & 2 & SG & 2,84 & 43 & - & \multirow{4}{*}{35} \\
\hline & 3 & SG & 3,05 & 46 & - & \\
\hline & 4 & SG & 2,77 & 17 & - & \\
\hline & 4 & IB & 3,04 & 36 & - & \\
\hline \multirow{8}{*}{ Esenbeckia leiocarpa (guarantã) } & 7 & IB & 2,10 & 55 & - & \multirow[t]{2}{*}{25} \\
\hline & 11 & IB & 2,74 & 69 & - & \\
\hline & 6 & $\mathrm{TP}$ & 2,50 & 36 & 41 & \\
\hline & 8 & $\mathrm{TP}$ & 2,51 & 34 & 41 & 32 \\
\hline & 9 & TP & 2,25 & 31 & 41 & \\
\hline & 1 & SG & 3,64 & 26 & - & \\
\hline & 3 & SG & 2,70 & 26 & - & 36 \\
\hline & 4 & SG & 2,88 & 20 & - & \\
\hline \multirow{3}{*}{ Pachystroma longifolium (canxim) } & 1 & SG & 2,29 & 47 & - & \multirow{3}{*}{37} \\
\hline & 2 & SG & 1,97 & 39 & - & \\
\hline & 4 & SG & 2,65 & 31 & - & \\
\hline \multirow{6}{*}{ Piptadenia gonoacantha (pau-jacaré) } & 1 & IB & 4,13 & 22 & - & \multirow{3}{*}{26} \\
\hline & 2 & IB & 3,64 & 20 & - & \\
\hline & 6 & IB & 6,54 & 20 & - & \\
\hline & 1 & SG & 6,29 & 9 & - & \multirow{6}{*}{27} \\
\hline & 4 & SG & 8,44 & 14 & - & \\
\hline & 5 & SG & 8,11 & 14 & - & \\
\hline \multirow{3}{*}{ Savia.dyctiocarpa (guaraiúva) } & 1 & IB & 3,19 & 47 & - & \\
\hline & 4 & IB & 1,62 & 35 & - & \\
\hline & 5 & IB & 1,82 & 33 & - & \\
\hline \multirow{3}{*}{ Trichilia claussenii (catiguá) } & 1 & SG & 1,98 & 54 & - & \multirow{3}{*}{39} \\
\hline & 2 & SG & 1,43 & 29 & - & \\
\hline & 4 & SG & 1,72 & 24 & - & \\
\hline
\end{tabular}

No. da árv.: Número da árvore amostrada.

Locais: IB (Estação Ecológica de Ibicatu), TP (Estação Experimental de Tupi), SG (Reserva Florestal Mata de Santa Genebra).

* Idade Real.: Idade estimada em função da data de plantio

Fig. $n^{\circ}$. : número das figuras que estão representados, em forma de gráficos, a distâncias entre os anéis de crescimento. 



$$
\multimap \mathrm{AP} 1-\mathrm{AP2}-\mathrm{AP3}
$$

Figura 23 - Variação do incremento anual das árvores de Aspidosperma polyneuron (perobarosa) na Estação Ecológica de Ibicatu (Piracicaba). (A) Árvore 1; (B) Árvore 2; (C) Árvore 3; (D) Total. 

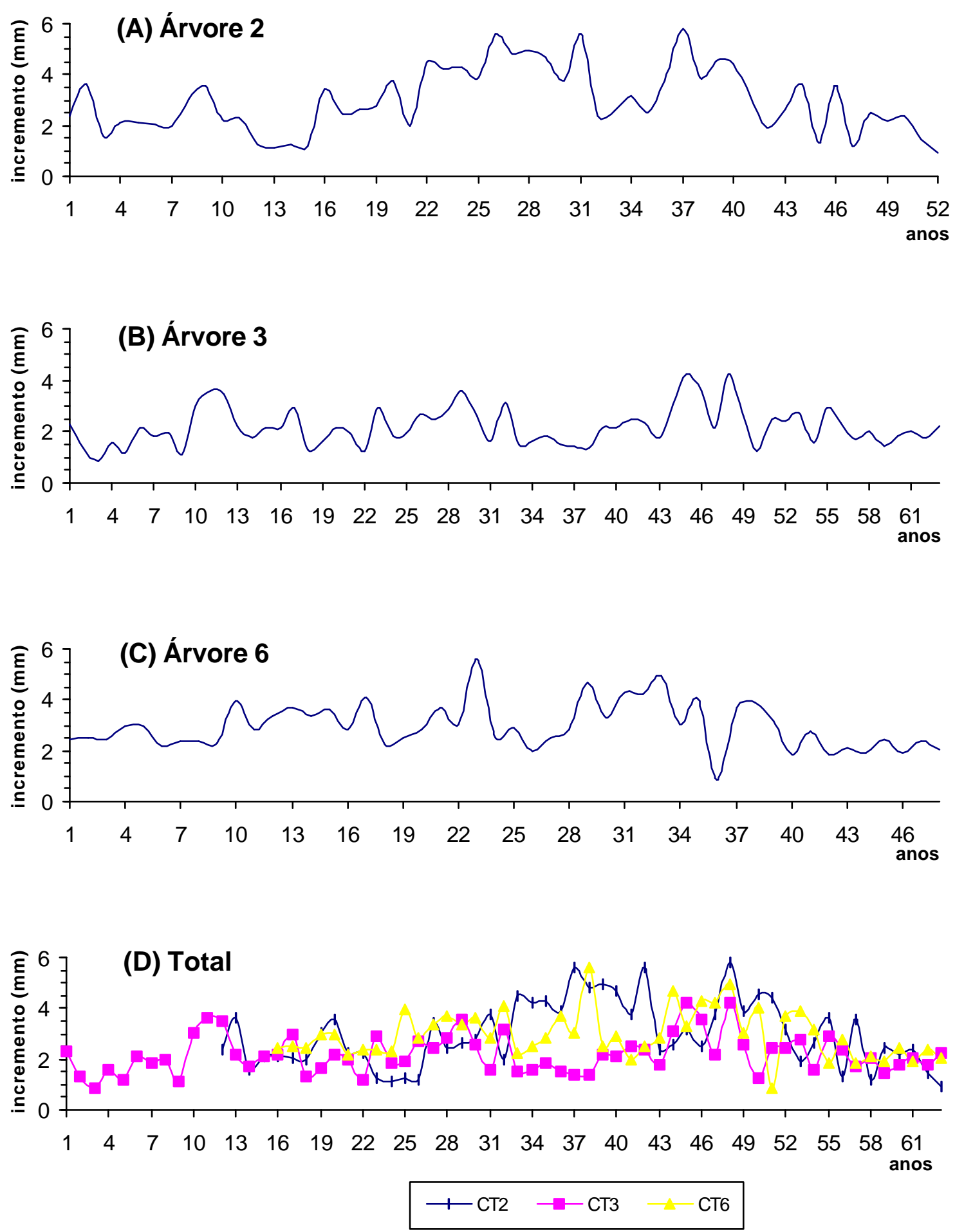

Figura 24 - Variação do incremento anual das árvores de Centrolobium tomentosum (araribá) na Estação Ecológica de Ibicatu (Piracicaba). (A) Árvore 2; (B) Árvore 3; (C) Árvore 6; (D) Total. 

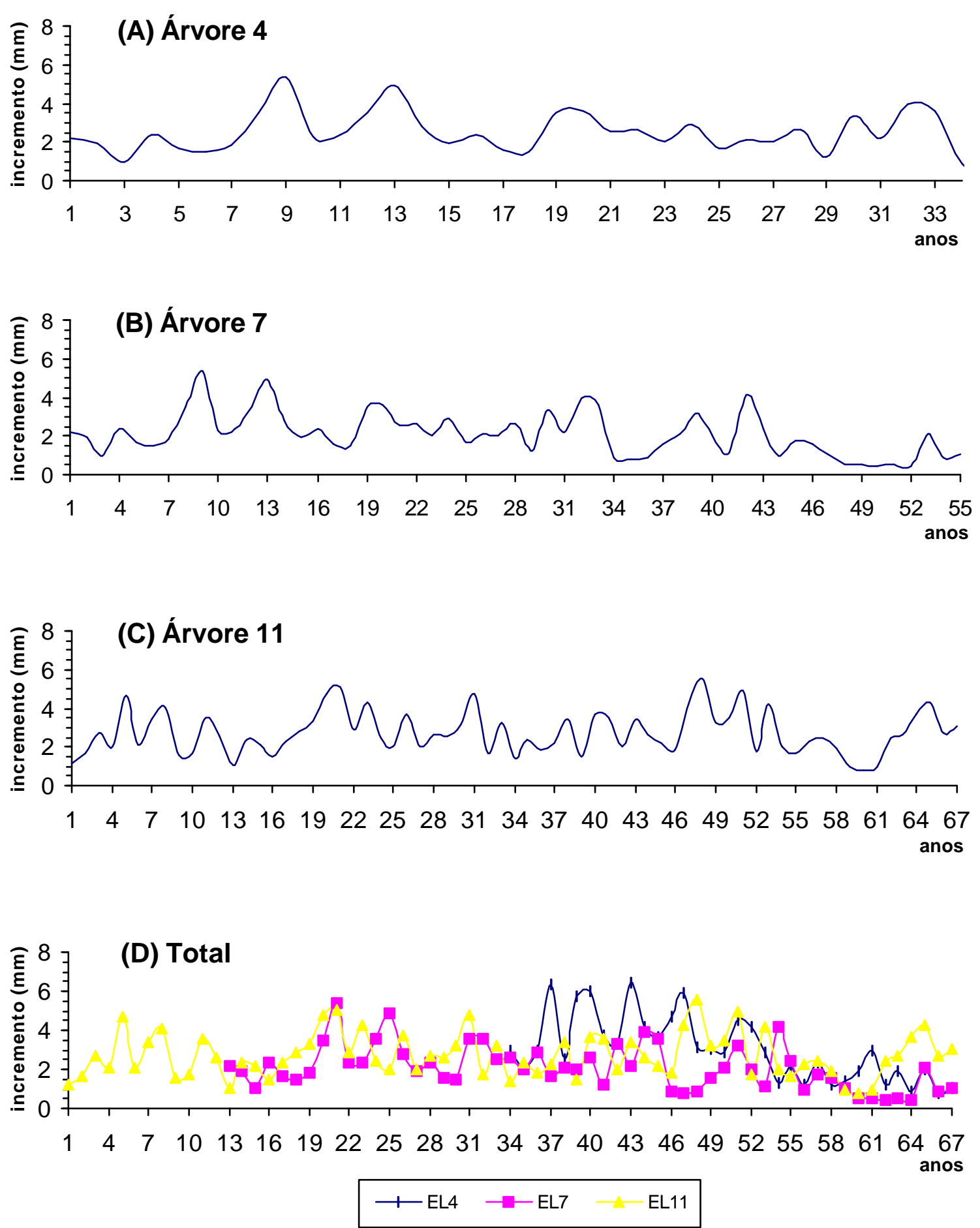

Figura 25 - Variação do incremento anual das árvores de Esenbeckia leiocarpa (guarantã) na Estação Ecológica de Ibicatu (Piracicaba). (A) Árvore 4; (B) Árvore 7; (C) Árvore 11; (D) Total. 

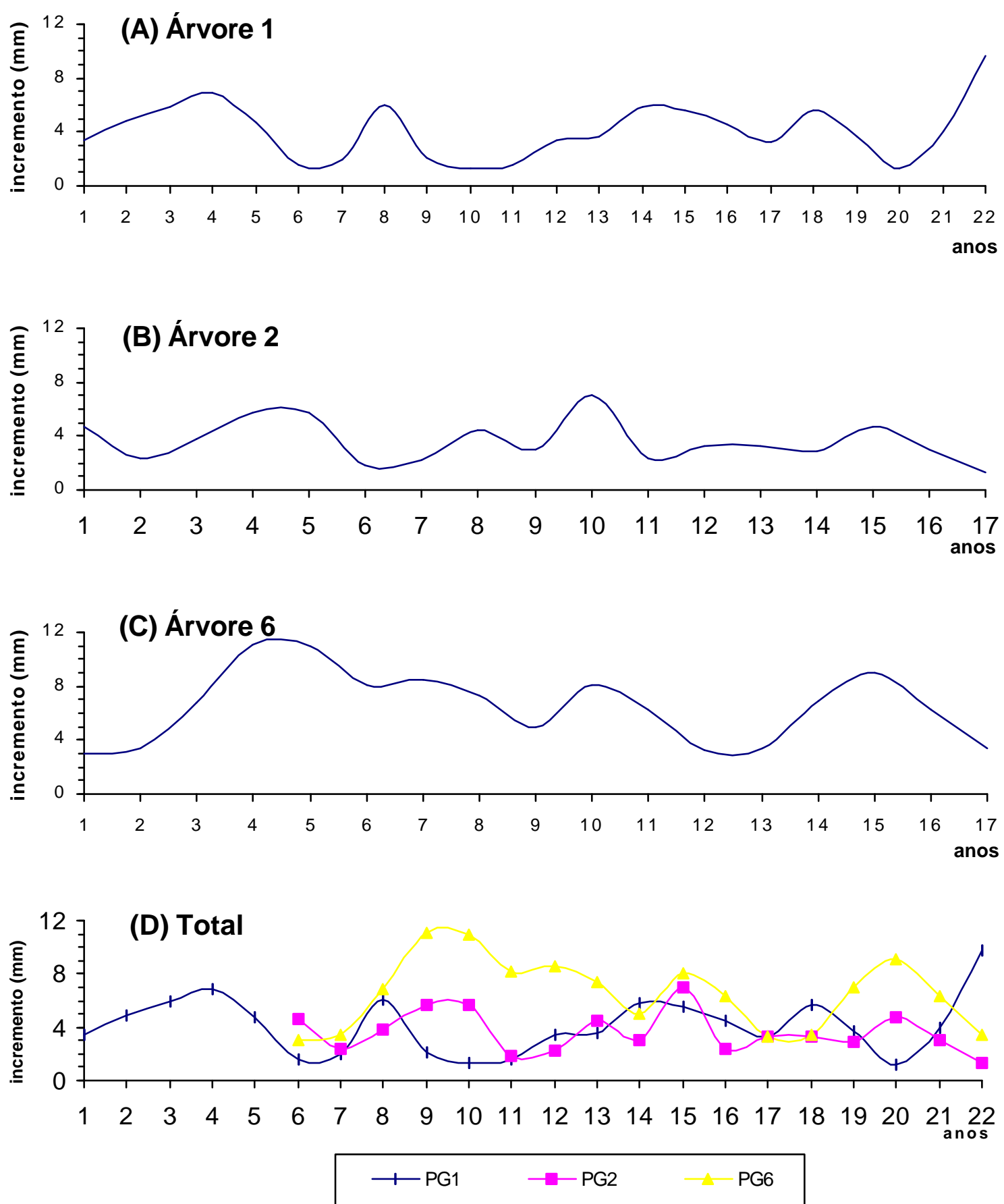

Figura 26 - Variação do incremento anual das árvores de Piptadenia gonoacantha (pau-jacaré) na Estação Ecológica de Ibicatu (Piracicaba). (A) Árvore 1; (B) Árvore 2; (C) Árvore 6; (D) Total. 



Figura 27 - Variação do incremento anual das árvores de Savia dyctiocarpa (guaraiúva) na Estação Ecológica de Ibicatu (Piracicaba). (A) Árvore 1; (B) Árvore 4; (C) Árvore 5; (D) Total. 

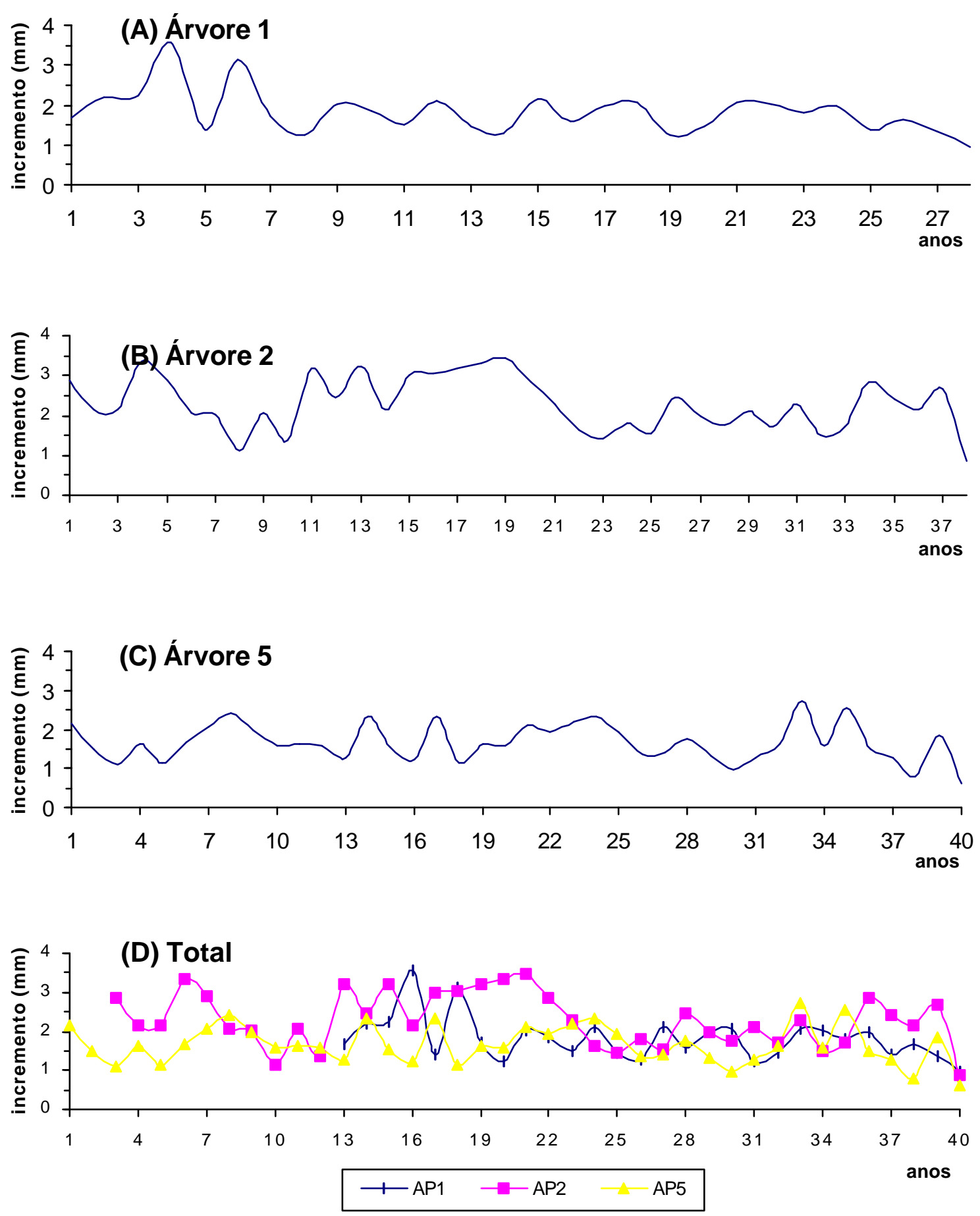

Figura 28 - Variação do incremento anual das árvores de Aspidosperma polyneuron (perobarosa) na Estação Experimental de Tupi (Piracicaba). (A) Árvore 1; (B) Árvore 2; (C) Árvore 3; (D) Total. 

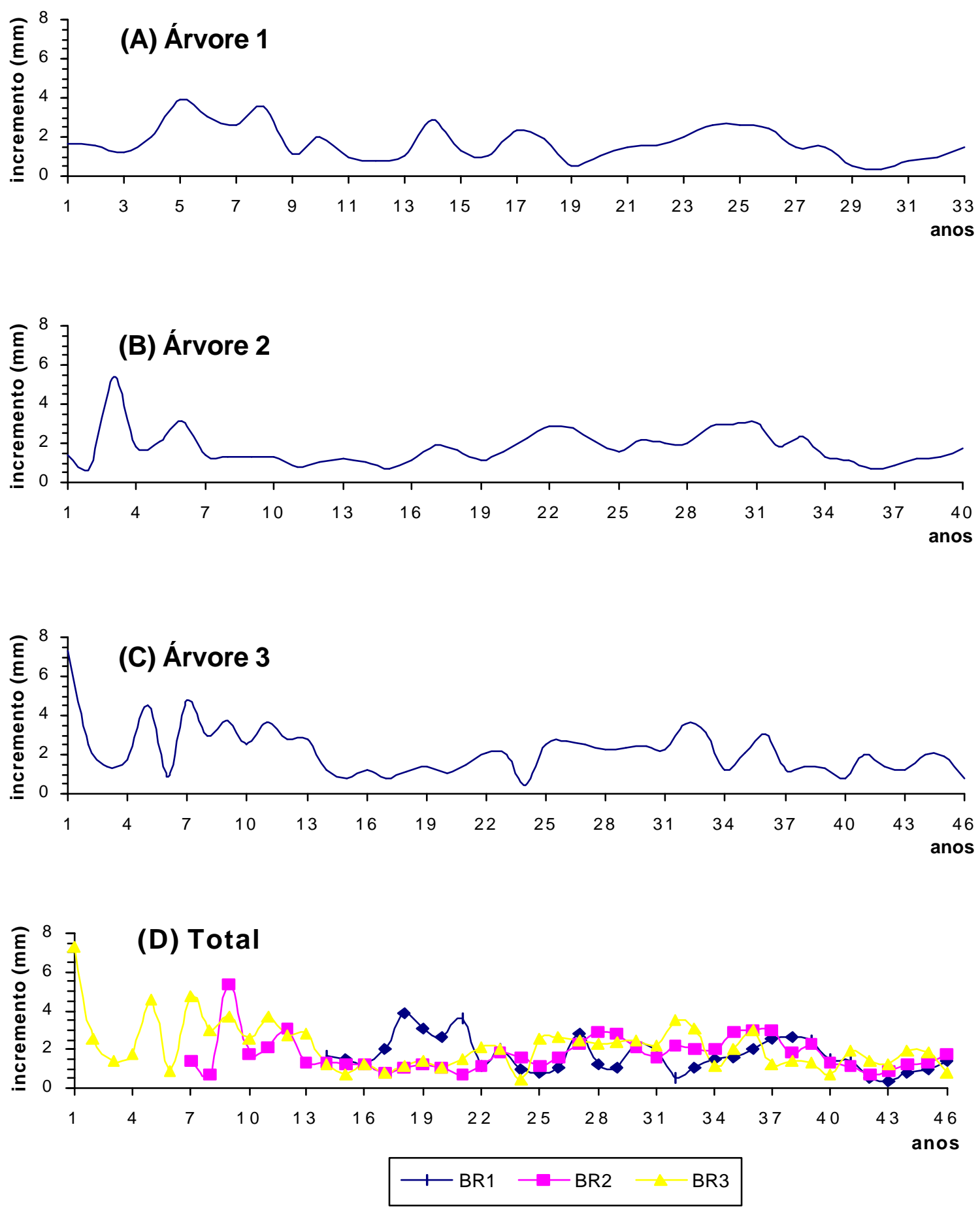

Figura 29 - Variação do incremento anual das árvores de Balfourodendron riedelianum (paumarfim) na Estação Experimental de Tupi (Piracicaba). (A) Árvore 1; (B) Árvore 2; (C) Árvore 3; (D) Total. 

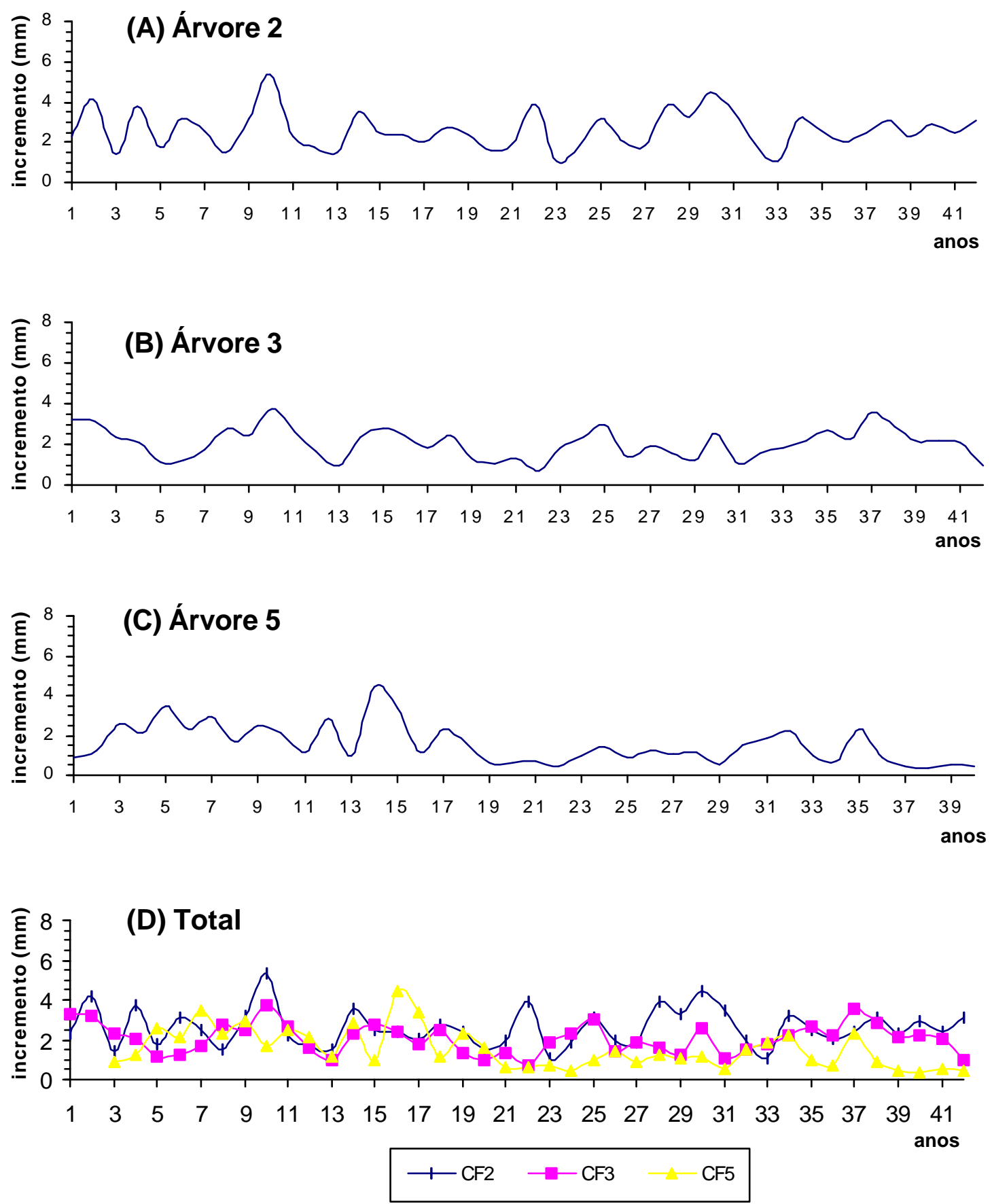

Figura 30 - Variação do incremento anual das árvores de Caesalpinia ferrea (pau-ferro) na Estação Experimental de Tupi (Piracicaba). (A) Árvore 2; (B) Árvore 3; (C) Árvore 5; (D) Total. 

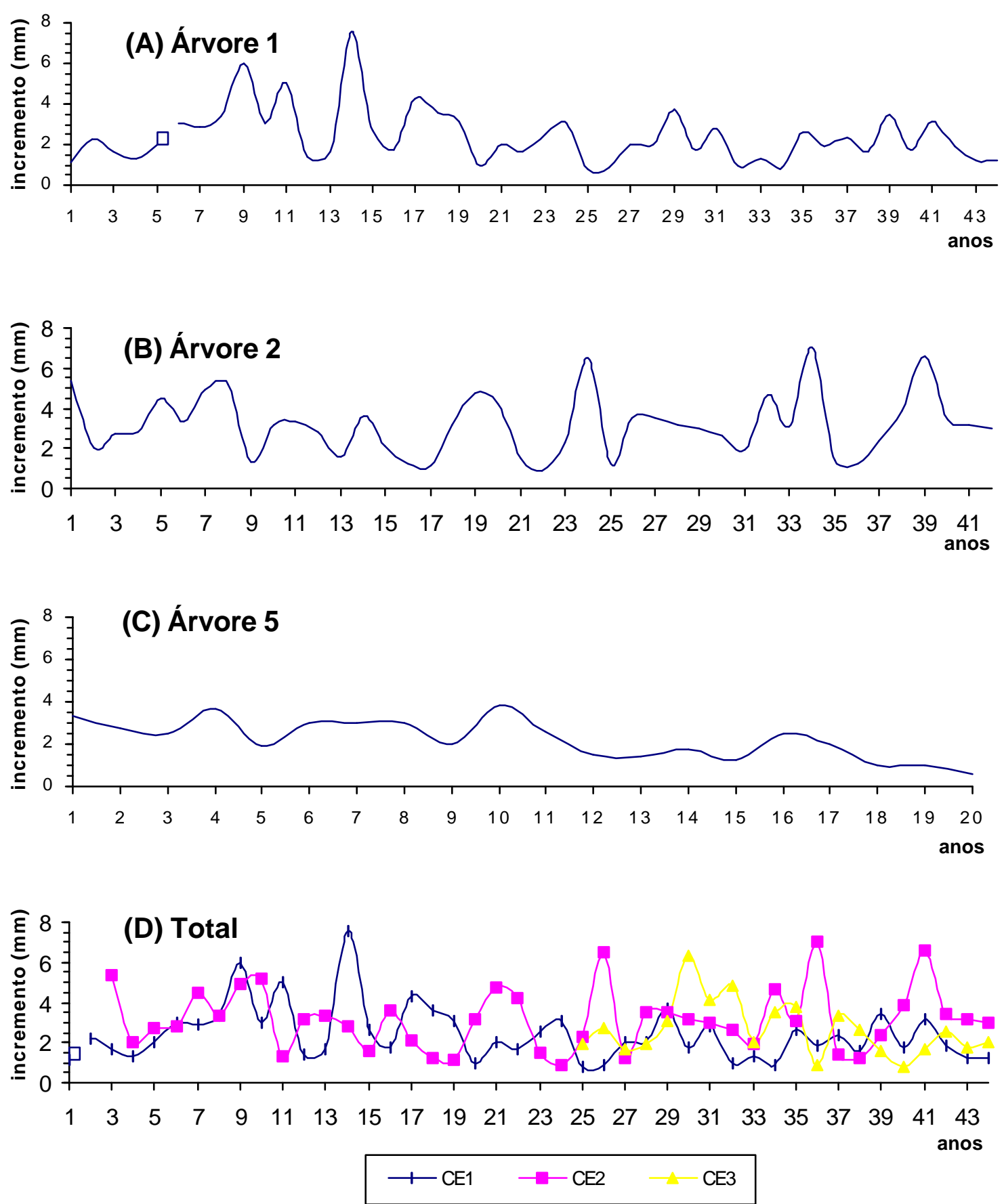

Figura 31 - Variação do incremento anual das árvores de Cariniana estrellensis (jequitibábranco) na Estação Experimental de Tupi (Piracicaba). (A) Árvore 1; (B) Árvore 2; (C) Árvore 3; (D) Total. 

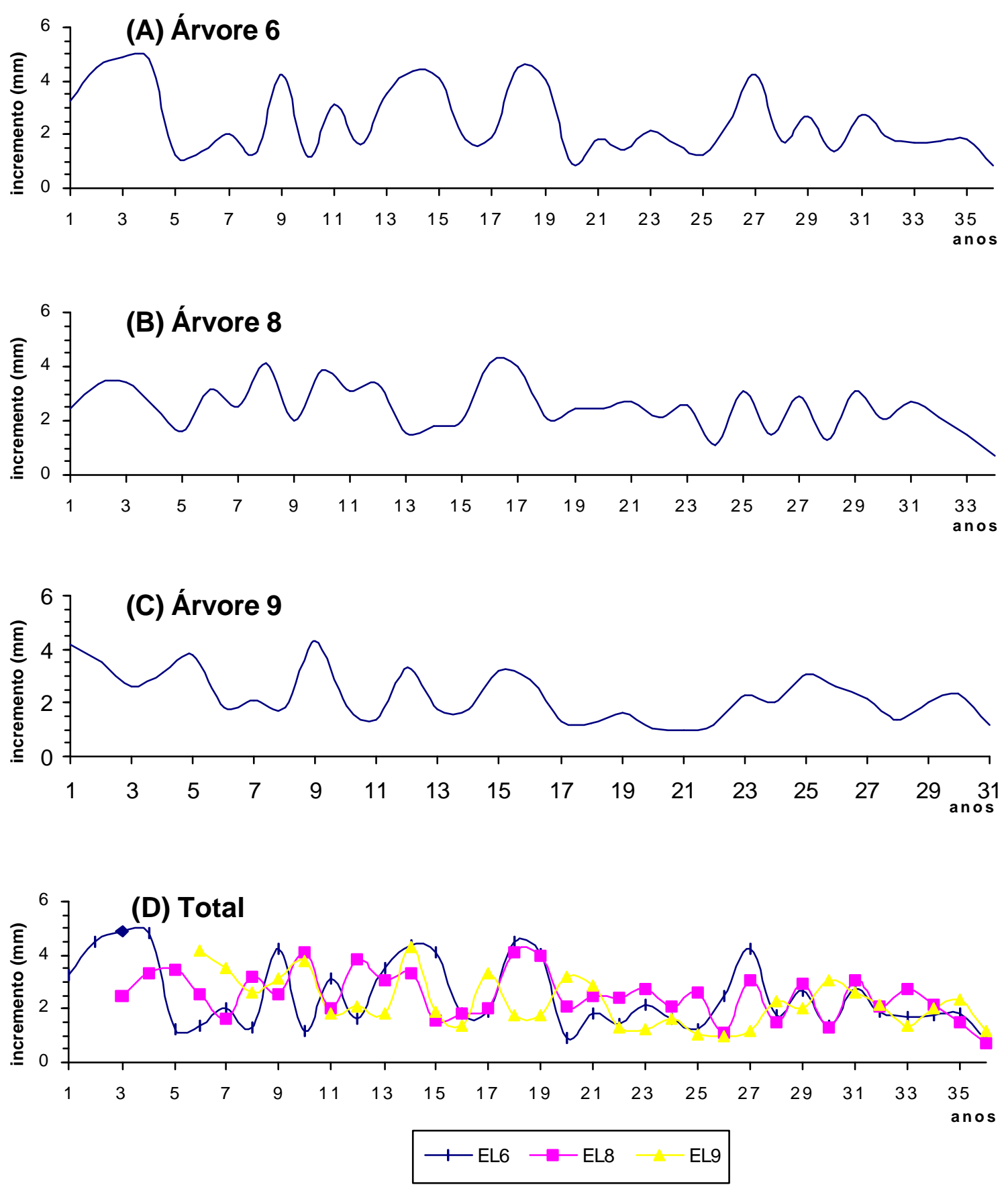

Figura 32 - Variação do incremento anual das árvores de Esenbeckia leiocarpa (guarantã) na Estação Experimental de Tupi (Piracicaba). (A) Árvore 6; (B) Árvore 8; (C) Árvore 9; (D) Total. 

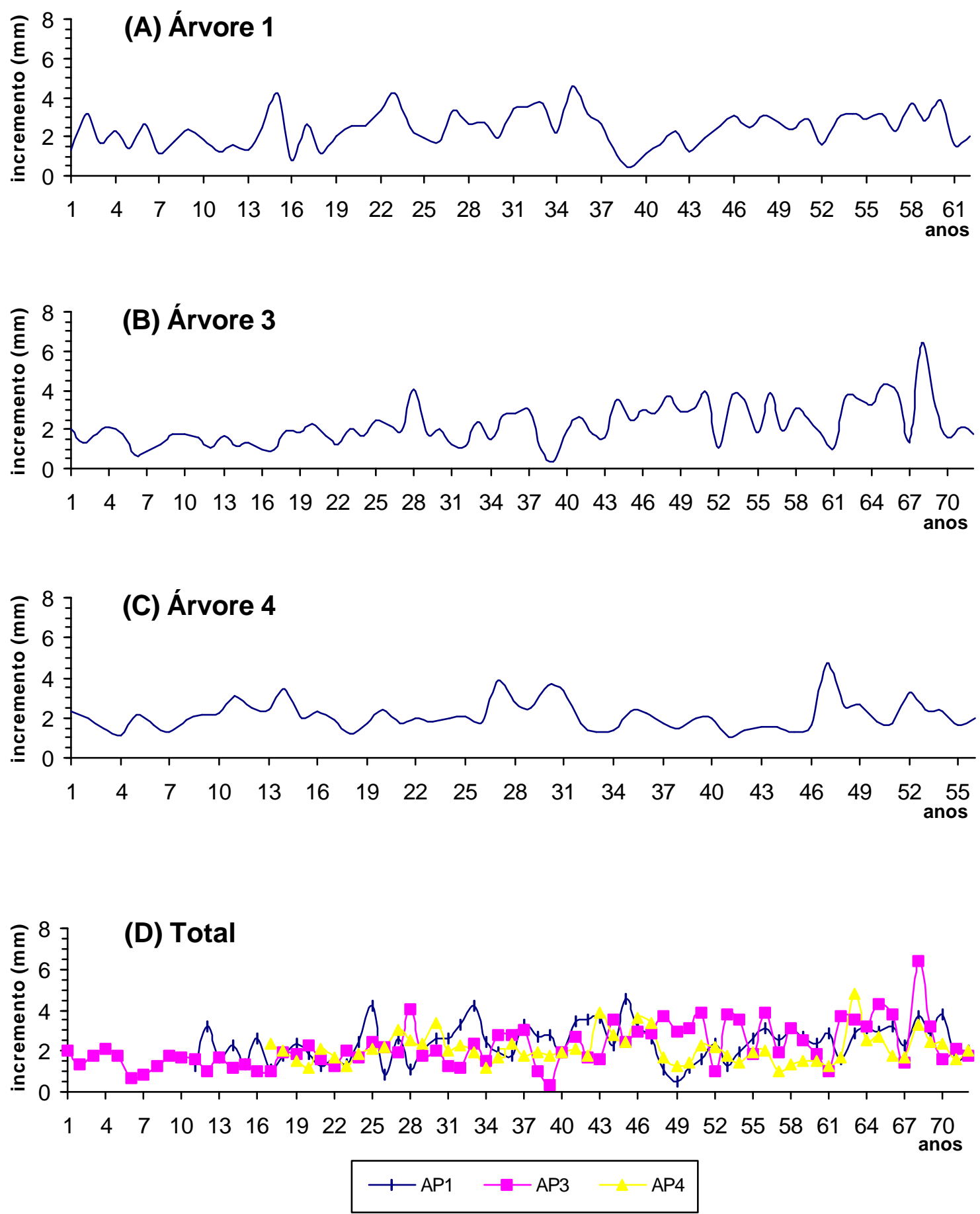

Figura 33 - Variação do incremento anual das árvores de Aspidosperma polyneuron (perobarosa) na Reserva Florestal Mata de Santa Genebra (Campinas). (A) Árvore 1; (B) Árvore 3; (C) Árvore 4; (D) Total. 



Figura 34 - Variação do incremento anual das árvores de Cedrela fissilis (cedro) na Reserva Florestal Mata de Santa Genebra (Campinas). (A) Árvore 1; (B) Árvore 2; (C) Árvore 3; (D) Total. 

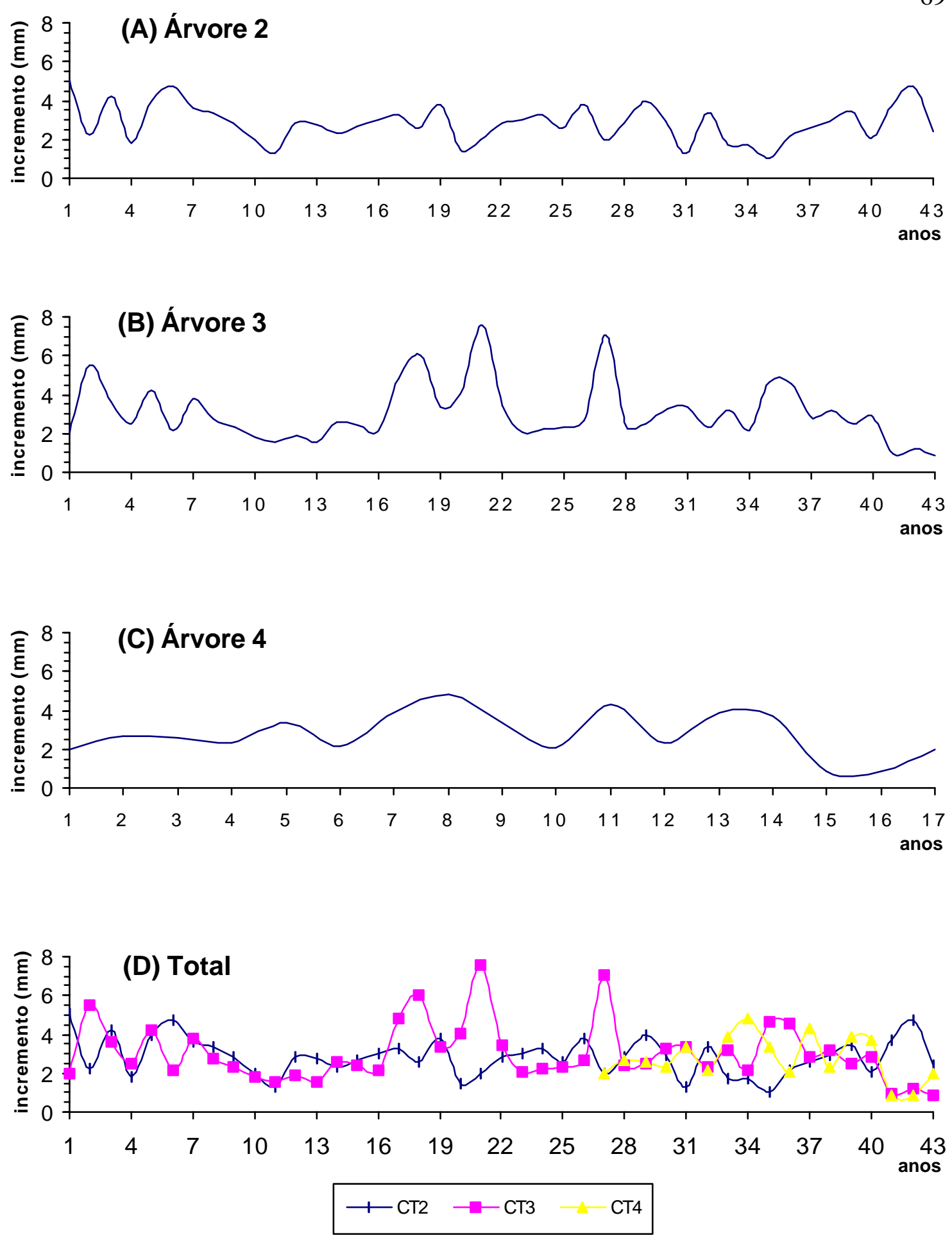

Figura 35 - Variação do incremento anual das árvores de Centrolobium tomentosum (araribá) na Reserva Florestal Mata de Santa Genebra (Campinas). (A) Árvore 2; (B) Árvore 3; (C) Árvore 4; (D) Total. 

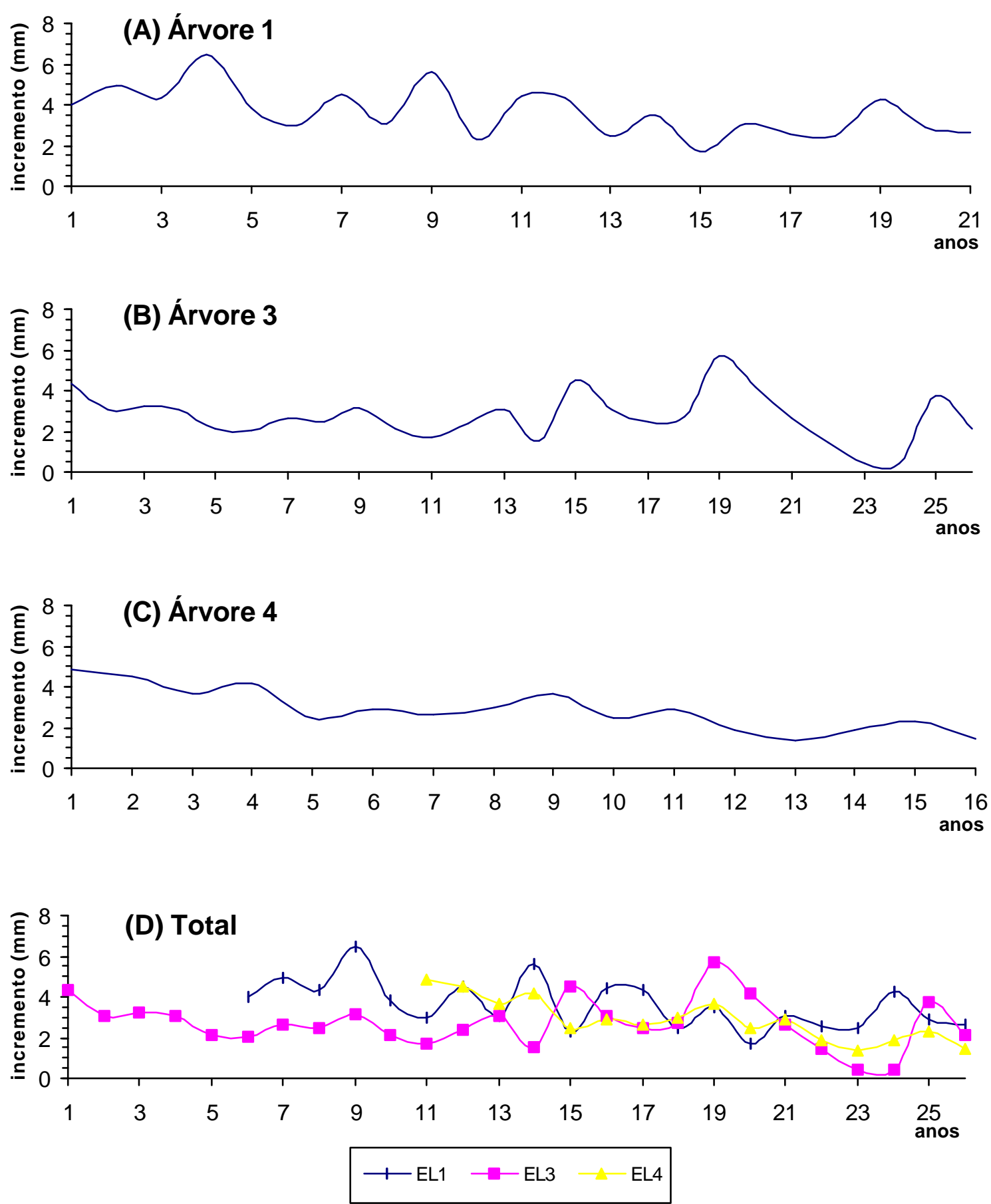

Figura 36 - Variação do incremento anual das árvores de Esenbeckia leiocarpa (guarantã) na Reserva Florestal Mata de Santa Genebra (Campinas). (A) Árvore 1; (B) Árvore 3; (C) Árvore 4; (D) Total. 

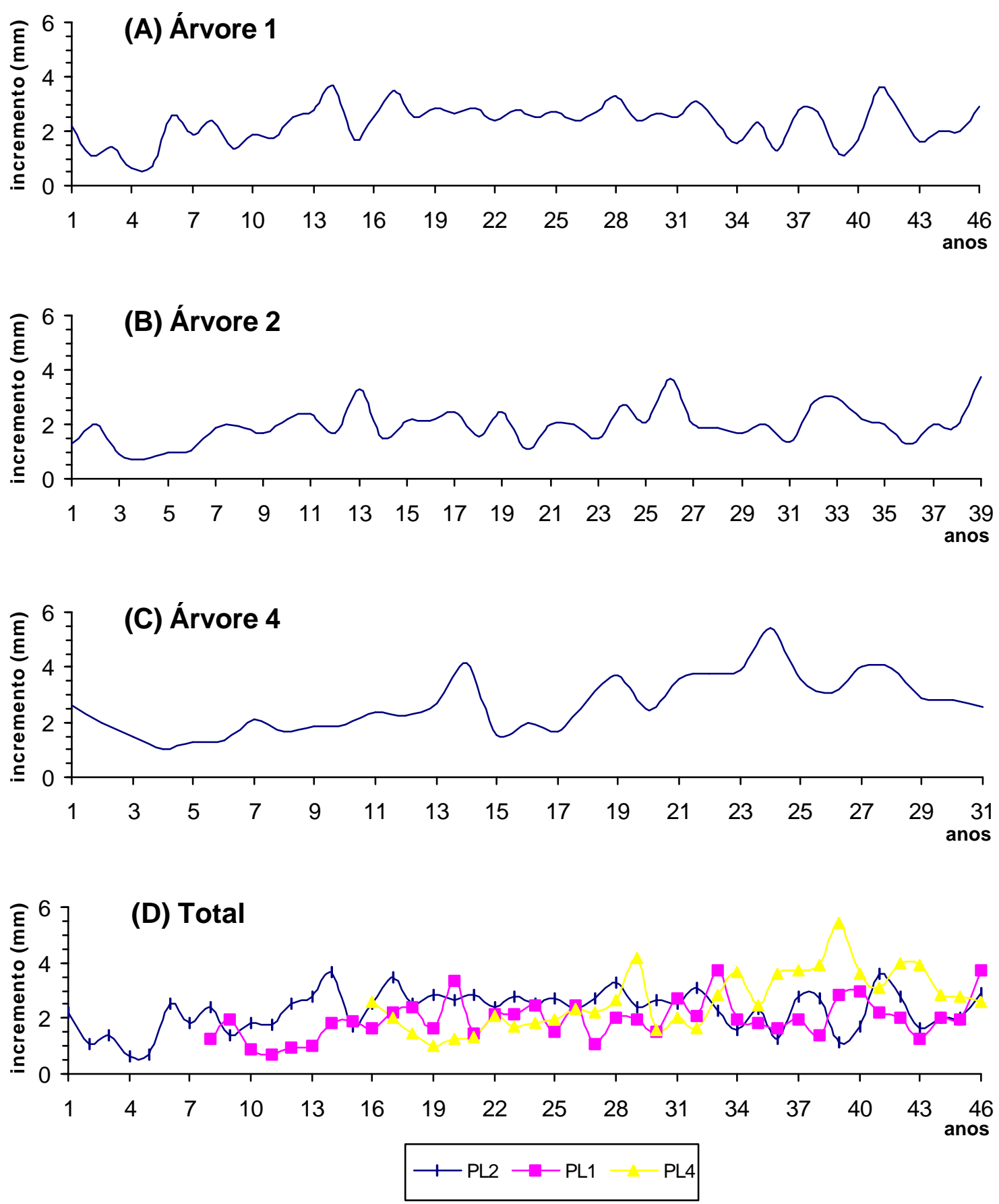

Figura 37 - Variação do incremento anual das árvores de Pachystroma longifolium (canxim) na Reserva Florestal Mata de Santa Genebra (Campinas). (A) Árvore 1; (B) Árvore 2; (C) Árvore 4; (D) Total. 



Figura 38 - Variação do incremento anual das árvores de Piptadenia gonoacantha (pau-jacaré) na Reserva Florestal Mata de Santa Genebra (Campinas). (A) Árvore 1; (B) Árvore 4; (C) Árvore 5; (D) Total. 

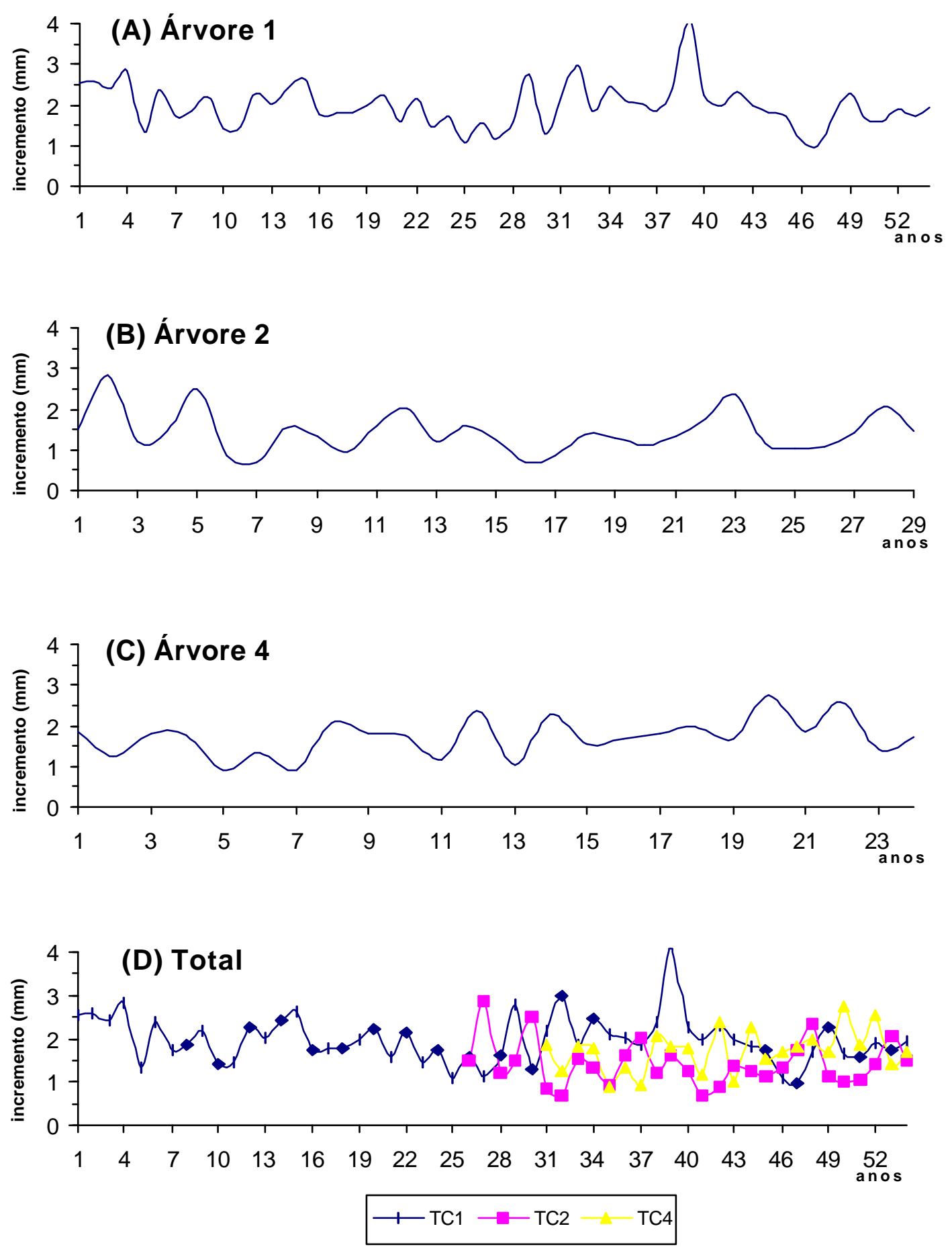

Figura 39 - Variação do incremento anual das árvores de Trichilia claussenii (catiguá) na Reserva Florestal Mata de Santa Genebra (Campinas). (A) Árvore 1; (B) Árvore 2; (C) Árvore 4; (D) Total. 


\subsection{Características anatômicas do lenho e dos anéis de crescimento}

As amostras do lenho retiradas do tronco das árvores foram analisadas sob lupa e, em seguida, descritas as suas características anatômicas macroscópicas (Tabela 11). As descrições da estrutura antômica macroscópica foram comparadas com as apresentadas na literatura especializada (Mainieri, 1983 e Mainieri \& Chimelo, 1989).

O lenho de cada espécie apresenta um conjunto de características anatômicas distintas possibilitando a identificação de camadas de crescimento com diferentes padrões estruturais. Entretanto, a afirmação precisa de que a formação destes anéis de crescimento é anual é de extrema importância, sendo possível de ser determinada através da metodologia de "janela de Mariaux" (Botosso, 2000). Nas Figuras 40 a 43, são apresentadas a estrutura macroscópica do lenho e dos anéis de crescimento em secção transversal. 
Tabela 11. Descrição macroscópica das principais características da estrutura anatômica das madeiras das espécies em estudo.

\begin{tabular}{|c|c|c|}
\hline Espécies estudadas & $\begin{array}{l}\text { Característica estrutural } \\
\text { (seção transversal) }\end{array}$ & $\begin{array}{l}\text { Fig. } \\
\left(\mathrm{n}^{\circ}\right)\end{array}$ \\
\hline $\begin{array}{l}\text { Aspidosperma polyneuron } \\
\text { (peroba-rosa) }\end{array}$ & $\begin{array}{l}\text { Parênquima axial indistinto, apotraqueal difuso. Vasos só } \\
\text { visíveis sob lente, muito pequenos, maioria solitários, com } \\
\text { alguns geminados. Raios visíveis sob lente no topo, muito } \\
\text { finos e numerosos. Camadas de crescimento pouco } \\
\text { demarcadas por zonas escuras ocasionadas por fibras de } \\
\text { paredes mais grossas. }\end{array}$ & $\begin{array}{c}40 \\
(\mathbf{A}, \mathbf{B})\end{array}$ \\
\hline $\begin{array}{l}\text { Balfourodendron riedelianum } \\
\text { (pau-marfim) }\end{array}$ & $\begin{array}{l}\text { Parênquima axial visível a olho nu contrastado, marginal em } \\
\text { faixas afastadas, as vezes descontínuos, paratraqueal escasso. } \\
\text { Vasos distintos só sob lente, pequenos e muito numerosos, a } \\
\text { maioria geminados. Raios distinto sob lente em todas as faces, } \\
\text { finos e numerosos. Camadas de crescimento distintas, } \\
\text { demarcadas pelas faixas de parênquima marginal. }\end{array}$ & $\begin{array}{c}40 \\
(\mathrm{C}, \mathrm{D})\end{array}$ \\
\hline $\begin{array}{l}\text { Caesalpinia ferrea } \\
\text { (pau-ferro) }\end{array}$ & $\begin{array}{l}\text { Parênquima marginal presente, aliforme, confluente, formando } \\
\text { faixas longas, estreitas, irregulares, aproximadas em trechos } \\
\text { curtos. Vasos pouco numerosos, solitários e geminados. Raios } \\
\text { visíveis no topo e na face tangencial. Camadas de crescimento } \\
\text { pouco distintas demarcadas por zonas fibrosas e linhas } \\
\text { marginais. }\end{array}$ & $\begin{array}{c}40 \\
(\mathbf{E}, \mathbf{F})\end{array}$ \\
\hline $\begin{array}{l}\text { Cariniana estrellensis } \\
\text { (jequitibá-branco) }\end{array}$ & $\begin{array}{l}\text { Parênquima axial contrastado, apotraqueal em linhas finas, } \\
\text { concêntricas. Vasos de distribuição difusa, pequenos a médios, } \\
\text { solitários e geminados. Raios visíveis a olho nu no topo, } \\
\text { regularmente espaçados e numerosos. Camadas de } \\
\text { crescimento aparentemente marcadas por zonas fibrosas, } \\
\text { provocadas por um maior afastamento do parênquima axial. }\end{array}$ & $\begin{array}{c}41 \\
(\mathbf{A}, \mathbf{B})\end{array}$ \\
\hline
\end{tabular}




\begin{tabular}{|c|c|c|}
\hline Espécies estudadas & $\begin{array}{c}\text { Característica estrutural } \\
\text { (seção transversal) }\end{array}$ & $\begin{array}{l}\text { Fig. } \\
\left(\text { n. }^{o}\right)\end{array}$ \\
\hline Cedrela fissilis (cedro) & $\begin{array}{l}\text { Parênquima axial apotraqueal marginal distintos a olho nu. } \\
\text { Vasos distintos a olho nu, solitário e geminados. Raios visíveis } \\
\text { a olho nu no topo, finos e irregularmente espessados. Camadas } \\
\text { de crescimento demarcadas pelas fixas do parênquima marginal } \\
\text { e pelos poros de maior diâmetro com tendência a formar anéis } \\
\text { porosos. }\end{array}$ & $\begin{array}{c}41 \\
(C, D)\end{array}$ \\
\hline Centrolobium tomentosum (araribá) & $\begin{array}{l}\text { Parênquima axial escasso, visível só sob lente, aliforme ou } \\
\text { quase vasicêntrico. Vasos visíveis só sob lente, pequenos a } \\
\text { médios, a maioria solitários, alguns geminados. Raios no topo } \\
\text { visíveis sob lente, muito finos e numerosos. Camadas de } \\
\text { crescimento pouco definidas, demarcadas por fibras achatadas } \\
\text { radialmente e de paredes espessas. }\end{array}$ & $\begin{array}{c}41 \\
(\mathbf{E}, \mathbf{F})\end{array}$ \\
\hline Esenbeckia leiocarpa (guarantã) & $\begin{array}{l}\text { Parênquima marginal irregular com finas linhas. Vasos } \\
\text { pequenos, muito numerosos e solitários. Raios visíveis sob } \\
\text { lente no topo. Camadas de crescimento distintas, demarcadas } \\
\text { pelas linhas do parênquima marginal e pelo arranjo tangencial } \\
\text { dos poros. }\end{array}$ & $\begin{array}{c}42 \\
(\mathbf{A}, \mathbf{B})\end{array}$ \\
\hline Pachystroma longifolium (canxim) & $\begin{array}{l}\text { Parênquima axial apotraqueal marginal. Vasos pequenos em } \\
\text { sua maioria solitários. Raios visíveis sob lente no topo. } \\
\text { Camadas de crescimento demarcadas por zonas escuras } \\
\text { constituídas por fibras de paredes mais grossas, às vezes, } \\
\text { achatadas radialmente. }\end{array}$ & $\begin{array}{c}42 \\
(\mathrm{C}, \mathrm{D})\end{array}$ \\
\hline $\begin{array}{l}\text { Piptadenia gonoacantha } \\
\text { (pau-jacaré) }\end{array}$ & $\begin{array}{l}\text { Parênquima axial visível sob lente, paratraqueal vasicêntrico, } \\
\text { aliforme e marginal. Vasos no lenho tardio são visíveis a olho } \\
\text { nu, e os do lenho inicial são visíveis sob lente. Raios visíveis } \\
\text { sob lente no topo, poucos. Camadas de crescimento } \\
\text { delimitadas pelo parênquima marginal e pelos anéis semi- } \\
\text { porosos. }\end{array}$ & $\begin{array}{c}42 \\
\text { (E,F) }\end{array}$ \\
\hline
\end{tabular}




\begin{tabular}{|c|c|c|}
\hline Espécies estudadas & $\begin{array}{c}\text { Característica estrutural } \\
\text { (seção transversal) }\end{array}$ & $\begin{array}{l}\text { Fig. } \\
\left(\mathrm{n}^{\circ}\right)\end{array}$ \\
\hline Savia dyctiocarpa (guaraiúva) & $\begin{array}{l}\text { Parênquima escasso, visíveis só sob lente, em finíssimas } \\
\text { linhas, irregularmente dispostas e muito aproximadas. } \\
\text { Vasos visíveis sob lente, muito pequenos, muito } \\
\text { numerosos, múltiplos predominantes. Raios distintos só } \\
\text { sob lente no topo. Camadas de crescimento às vezes } \\
\text { demarcadas por zonas fibrosas mais escuras }\end{array}$ & $\begin{array}{c}43 \\
(\mathrm{~A}, \mathrm{~B})\end{array}$ \\
\hline Trichilia claussenii (catiguá) & $\begin{array}{l}\text { Parênquima distinto somente sob lente, linhas de } \\
\text { parênquima marginal. Vasos visíveis somente sob lente, } \\
\text { pequenos, numerosos, maioria solitários. Raios visíveis } \\
\text { osmente sob lente, finos, numerosos. Camadas de } \\
\text { crescimento distintas, demarcadas pelas faixas de } \\
\text { parênquima marginal. }\end{array}$ & $\begin{array}{c}43 \\
(\mathrm{C}, \mathrm{D})\end{array}$ \\
\hline
\end{tabular}



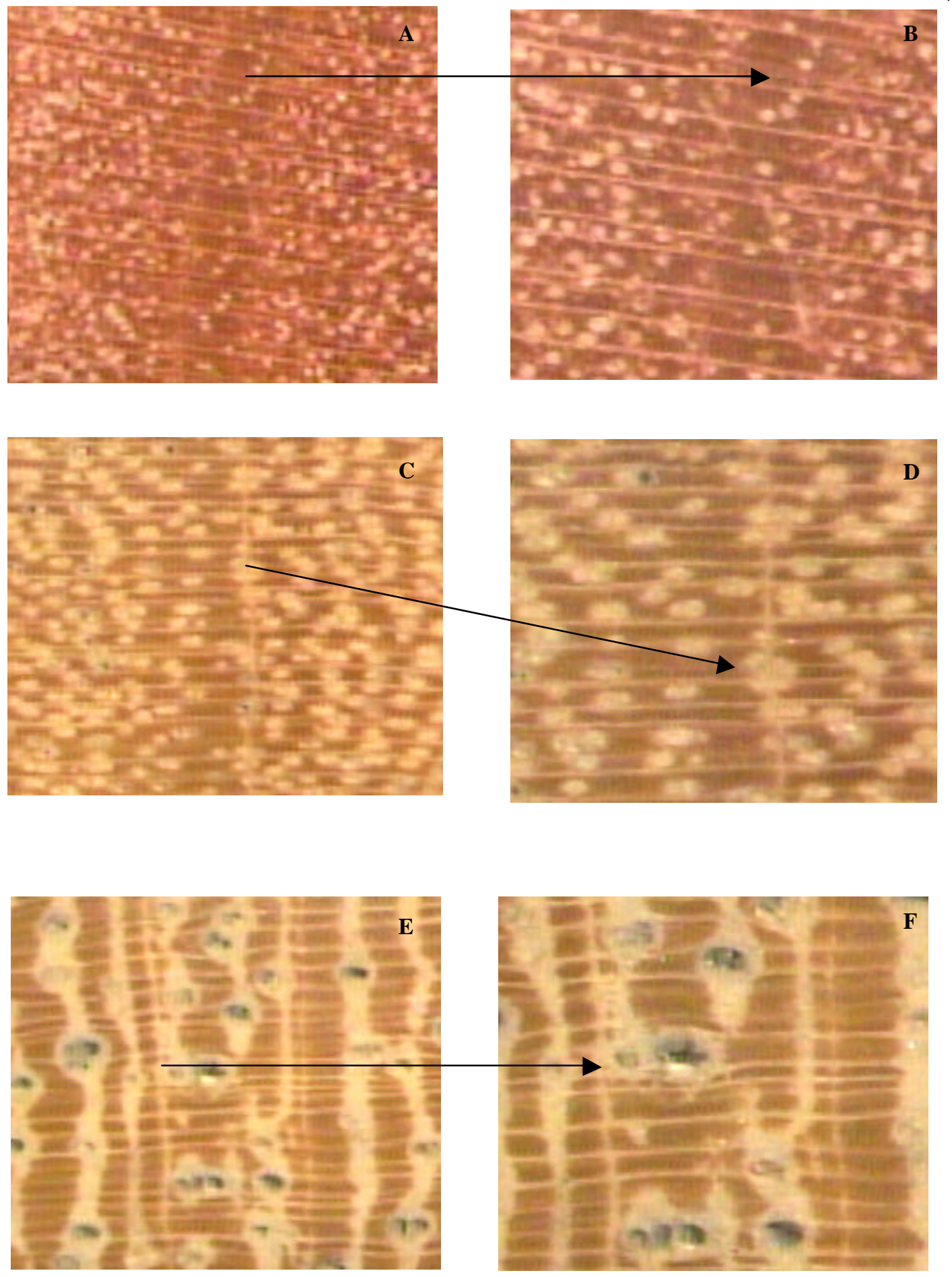

Figura 40 - Fotomacrografias das secções transversais do lenho das árvores das espécies florestais. Aspidosperma polyneuron (peroba-rosa) (A,B); Balfourodendron riedelianum (pau-marfim) (C,D); Caesalpinia ferrea (pau-ferro) (E,F) - aumento de 8x (esquerda) e 12x (direita). 



Figura 41 - Fotomacrografias das secções transversais do lenho das árvores das espécies florestais. Cariniana estrellenisis (jequitibá-branco). (A,B); Cedrela fissilis (cedro) (C,D); Centrolobium tomentosum (araribá) (E,F) - aumento de 8x (esquerda) e 12x (direita). 

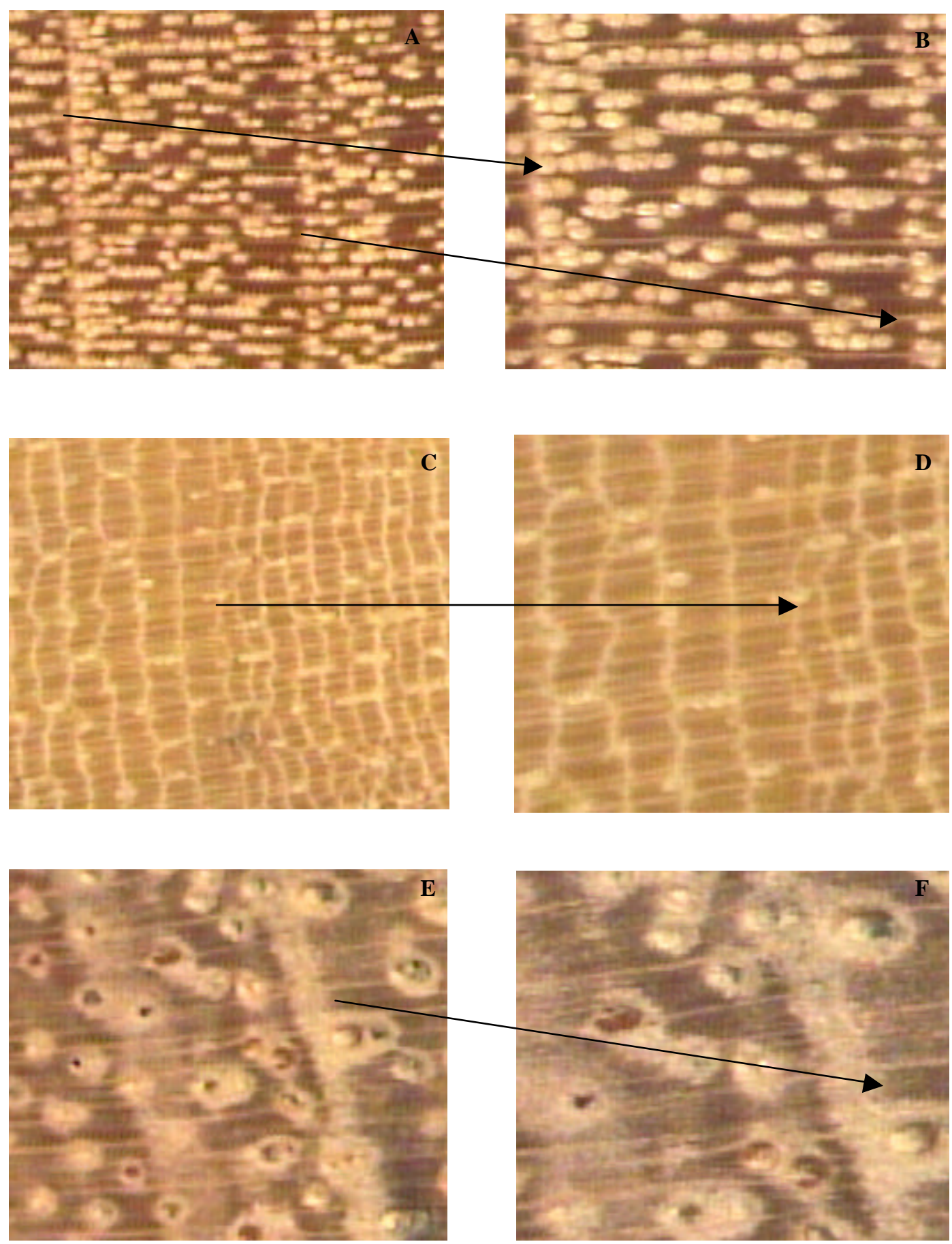

Figura 42 - Fotomacrografias das secções transversais do lenho das árvores das espécies florestais. Esenbeckia leiocarpa (guarantã). (A,B); Pachystroma longifolium (canxim) (C,D); Piptadenia gonoacantha (pau-jacaré) (E,F) - aumento de 8x (esquerda) e 12x (direita). 

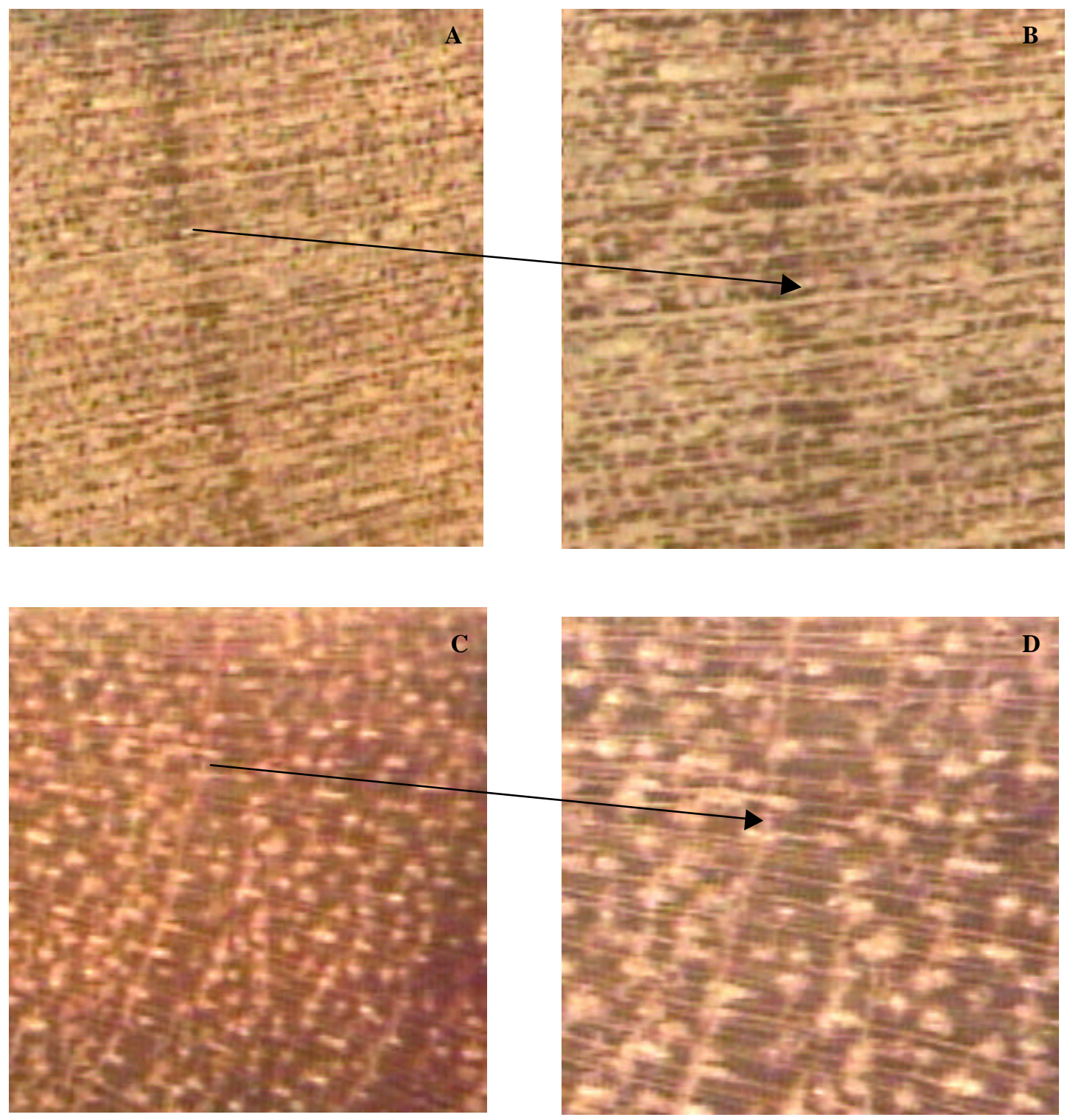

Figura 42 - Fotomacrografias das secções transversais do lenho das árvores das espécies florestais. Savia dyctiocarpa (guaraiúva) (A,B); Trichilia claussenii (cariguá) (C,D) - aumento de $8 x$ (esquerda) e 12x (direita). 


\section{DISCUSSÃO}

\subsection{Relação das condições de crescimento das árvores com a atividade cambial}

A posição sociológica, a localização das árvores, a presença de lianas são fatores importantes para a verificação da dinâmica do crescimento em diâmetro do tronco. Em populações naturais podem ocorrer diferenças nas condições de competição entre as árvores de uma mesma espécie e de várias espécies, na incidência de radiação solar na copa das árvores, nas quantidades de nutrientes disponíveis no solo, dentre outros fatores. Detectar estas diferenças é importante na análise das taxas de crescimento dos indivíduos e da população como um todo.

As árvores de algumas espécies encontram-se como co-dominantes, ocupando o subdossel, como Aspidosperma polyneuron (peroba-rosa) na Estação Experimental de Tupi, pela a presença de Schizolobium parahyba (guapuruvu) que se desenvolveu mais rapidamente, e com dominância no local. Trichilia claussenii (catiguá) é uma espécie dominada, com porte arbustivo-arbóreo e que ocupa o estrato inferior do seu ecossistema; tratando-se de uma espécie esciófita, ou seja, adaptada ao crescimento à sombra.

$\mathrm{Na}$ análise gráfica das taxas de crescimento em circunferência do tronco em relação à posição sociológica não é possível afirmar que todas as árvores dominantes apresentam maior taxa de crescimento em relação as outras, pois existem outros fatores que também afetam o crescimento. No entanto, isto ocorreu para Cariniana estrellensis (jequitibá-branco) (Figura 16B), Esenbeckia leiocarpa (guarantã) (Figura 15C), Piptadenia gonoacantha (pau-jacaré) (Figura 14A) e Savia dyctiocarpa (guaraiúva) (Figura 14B) e (Tabela 3). 
Desta forma, pode-se aferir que as árvores co-dominantes e dominadas não conseguiram iniciar, em alguns períodos, a ativação cambial nos seus troncos devido a competição com as árvores dominantes.

A condição do sítio não é um fator que isoladamente determina a taxa de crescimento em diâmetro do tronco das árvores, pois este pode ser influenciado pela idade da árvore e de outros fatores ambientais e genéticos. Para Détienne (1989), isto também é válido, mesmo com a completa interrupção da atividade cambial na árvore por um longo período de tempo, e que varia com a espécie.

Quanto a localização das árvores na população florestal, é importante avaliar se a competição causa algum impacto no crescimento em função da árvore estar presente no seu interior ou na borda da mata ou até mesmo em uma trilha interna. Os resultados obtidos não permitem afirmar que a localização das árvores foi fundamental para induzir diferenças das taxas de crescimento entre as árvores.

Lojan (1965) observou em árvores nativas tropicais de uma mesma espécie da Costa Rica variações na taxa de crescimento no início e término das fases de crescimento e na resposta aos fatores externos. Segundo o autor, parte desta resposta se deve à posição da árvore dentro da mata sendo que, dentro de cada espécie, a variação do crescimento é regra, apesar de ser observada uma tendência de similaridade do crescimento entre as árvores.

$\mathrm{Na}$ Reserva Florestal Mata de Santa Genebra apesar de 50\% das árvores apresentarem lianas nas suas copas há necessidade de um período maior de coleta de dados para verificar o seu efeito no crescimento dessas árvores. Leitão Filho \& Morellato (1995) em um estudo realizado nesta reserva, afirmaram que as lianas são tipos vegetais que têm grande habilidade competitiva e que impedem o desenvolvimento normal de plantas herbáceas, arbustivas e até arbóreas e para que não causem danos irreversíveis devem ser devidamente manejadas.

Entretanto, na Estação Ecológica de Ibicatu houve algumas diferenças na taxa de crescimento do tronco entre as árvores de mesma espécie, como para Piptadenia gonoacantha 4 (pau-jacaré), com crescimento muito baixo (Figura 14A), sendo quase nulo. 
Isto ocorreu devido a copa desta árvore estar tomada por lianas sobrevivendo apenas com um ramo que está crescendo em direção aos raios solares.

Botosso et al., (2000) estudando indivíduos de Centrolobium tomentosum (araribá) verificaram que a (a) sazonalidade do crescimento; (b) atividade cambial; (c) taxas de crescimento; (d) fenologia e (e) quebra da copa das árvores servem como indicadores da necessidade da aplicação de medidas de manejo florestal para a contenção de lianas e preservação das espécies florestais em reservas naturais.

Em contrapartida, Fonseca (1998) comenta sobre a importância das lianas na manutenção de recursos para polinizadores e dispersores em períodos críticos, evidenciando a sua contribuição para a fauna, principalmente nas áreas de floresta madura, onde ocorrem com maior diversidade.

Fazendo uma inter-relação entre os 3 critérios citados anteriormente observa-se, de um modo geral, que as árvores dominantes e com pouca presença ou ausência de lianas apresentaram maior taxa de crescimento do tronco.

\subsection{Relação da fenologia das árvores com a atividade cambial}

Segundo Pedroni et al. (1990), citado por Morellato (1991), a floresta estacional semidecídua típica muda de aspecto ao longo do ano. Durante os meses mais secos, de abril a setembro, cerca de $70 \%$ das espécies perdem total ou parcialmente suas folhas. Isto é marcado também pela redução de atividade cambial, onde a maioria das espécies estudadas, neste trabalho, diminuiu sua taxa de crescimento pouco antes do início da queda das folhas (no período seco). Esta diminuição pode ser causada pelo início de senescência das folhas uma vez que, quando isto ocorre, a taxa fotossintética também diminui e, consequentemente, há um decréscimo da atividade cambial. Os mesmos aspectos foram destacados por Botosso (2000), que observou que a queda das folhas das árvores das espécies em estudo coincide com o período de diminuição e/ou cessação da atividade cambial (período seco) em matas estacionais semidecíduas. 
Novembro e dezembro foram marcados pela retomada da atividade cambial das árvores das espécies em estudo (Tabela 6), sendo que meses antes ocorreu o início de brotamento das folhas (final do período seco e início do chuvoso). Esta fase coincide, praticamente, com o início da atividade fotossintética, onde há um aumento da produção de energia e hormônios e a árvore começando novamente a ativar o seu metabolismo.

Cardoso (1991) também observou o mesmo comportamente, relacionando os eventos fenológicos com a atividade cambial de árvores de Tectona grandis (teca) com o câmbio reiniciando sua atividade em dezembro, período em que as folhas estavam renovadas e em fase de desenvolvimento.

Para as árvores de algumas espécies como Cedrela fissilis (cedro), Tabebuia serratifolia (ipê amarelo) e Copaifera langsdorffi (copaíba), Botosso (2000) não obteve o mesmo resultado; o surgimento de novas folhas correspondeu diretamente com a reativação da atividade cambial e com a formação da madeira no período seco (agosto-setembro). Para Sass et al. (1995) o surgimento de novas folhas não foi observado no período chuvoso e verificou ainda que este foi irregular em diferentes ramos ocorrendo em qualquer época do ano.

A floração e frutificação das árvores ocorreram na maioria das espécies, um pouco depois do início da queda das folhas e alguns meses antes da retomada da atividade cambial, ou seja, no período em que o câmbio está dormente ou ainda em baixa atividade. Sass et al. (1995) verificou que no período de floração das árvores a atividade cambial é mantida sem muita variação no crescimento em diâmetro do tronco da espécie.

Com relação a classificação em pioneiras, secundárias iniciais e tardias notou-se que as árvores da espécie pioneira Schizolobium parahyba (guapuruvu) tiveram o maior incremento em circunferência do tronco. Entretanto, não foi possível definir um padrão de crescimento característico entre as espécies secundárias iniciais e tardias: nem todas as espécies secundárias iniciais apresentaram maiores taxas de crescimento em circunferência do tronco em comparação com as espécies secundárias tardias. 


\subsection{Relação das variações climáticas com a atividade cambial das árvores}

Os resultados obtidos (Figuras 6 - 12 e 21 - 22), mostraram que a taxa de crescimento em circunferência do tronco observada nas árvores está diretamente relacionada com a precipitação, temperatura e a disponibilidade de água no solo. No período chuvoso o incremento é maior, comparado ao período de seca, quando houve uma diminuição e/ou a cessação da atividade cambial.

Isto aconteceu também em 8 espécies arbóreas tropicais de floresta de Terra Firme (Amazônia), por um período de 20 meses caracterizado por baixos índices de precipitação pluviométrica (julho - setembro) com a diminuição ou até mesmo a cessação da atividade cambial (Botosso \& Vetter, 1991). O mesmo foi observado por Détienne (1989) na Guiana Francesa, Vetter \& Botosso $(1988,1989)$ na Amazônia Central e Worbes (1999) na Venezuela.

Lojan (1965, 1967 e 1968), comparou as variações climáticas com a periodicidade do crescimento do tronco de espécies florestais em Turrialba - Costa Rica, verificando que as árvores cresciam a cada mês, de acordo com o período de maior precipitação, temperatura e umidade relativa. Para Cardoso (1991) a alta precipitação e temperatura foram indicadores do início de desenvolvimento das células cambiais em Tectona grandis (teca).

Entretanto, em estudo realizado com 5 espécies m sul da Bahia foi verificado que apenas a precipitação estava diretamente relacionada com a taxa de crescimento em 2 espécies tropicais arbóreas e, nas demais espécies, o crescimento foi contínuo durante todo o período de estudo. Os autores comentam que, devido a falta de sazonalidade em algumas regiões, é difícil determinar da atividade periódica do câmbio vascular (Smith et al., 1997).

Os resultados obtidos, no presente trabalho (Figuras 6 - 12), indicam espécies menos sensíveis às mudanças climáticas, ou seja, com baixa variação da taxa de crescimento. Sobre isso, Détienne (1989) comenta que em algumas espécies nota-se uma baixa variação em circunferência do tronco das árvores durante um período inativo e que este fenômeno pode ser atribuído a uma pequena contração da casca na época de seca. 
Verificou-se, também, que a taxa de crescimento para a maioria das espécies aumentou no início das primeiras chuvas (agosto-setembro), este fato pode ser devido a turgescência da casca e não necessariamente pelo início da atividade cambial, visto que em fase posterior a este período a taxa de crescimento reduziu-se (outubro-novembro). Estes resultados serão analisados com maiores detalhes, mais adiante na discussão sobre a correlação da fenologia com as variáveis climáticas e a atividade cambial das árvores.

Apesar da sincronia observada da taxa de crescimento acumulado do diâmetro do tronco entre as árvores, houve variações dentro de algumas espécies. Esta mesma sincronia não foi observado por Botosso \& Vetter (1991) que constataram reações muito diferentes na estação seca com as árvores não obedecendo, sistematicamente, a um mesmo modelo de crescimento. Este mesmo comportamento ocorreu em árvores de espécies tropicais, segundo Détienne \& Barbier (1988), citados por Botosso \& Vetter, 1991).

\subsection{Correlação da fenologia, variáveis climáticas e atividade cambial}

\section{das árvores}

Observou-se que a fenologia apresentou uma estreita relação com as variáveis climáticas, principalmente com a precipitação e a temperatura e, consequentemente, com a atividade cambial das árvores. Inicialmente verificou-se que as folhas da maioria das espécies, tornaram-se senescentes e caíram da copa das árvores no início do período seco e com temperatura baixa e, logo após, a atividade cambial começou a diminuir. Com o início das primeiras chuvas as folhas começam a brotar sendo um período posterior a floração e a frutificação. No entanto, como discutido anteriormente, não ocorreu estímulo no crescimento em diâmetro, mas um aumento da espessura da casca das árvores, pela absorção de água com posterior contração, em agosto a novembro de 1999 e 2000, em praticamente todas as espécies (Figuras 6 - 12). A absorção de água ocorreu devido a necessidade da planta armazenar a água para as atividades fisiológicas, sem que as células do câmbio tenham retomado as suas atividades, quando é necessária maior quantidade de energia. Borchert (1999) observou uma correlação entre a quantidade da água, a fenologia e a atividade cambial 
em árvores de espécies de florestas decíduas na Costa Rica, mas verificou que esta não é tão intensa quanto em florestas temperadas.

\subsection{Largura dos anéis de crescimento}

As diferenças na largura dos anéis de crescimento podem fornecer informações importantes sobre a taxa de crescimento do tronco e o desenvolvimento das árvores e sua relação com as condições climáticas. Incrementos reduzidos indicam taxas de crescimentos pequenas e a existência de períodos desfavoráveis, ao contrário, os anéis de crescimento largos, representam altas taxas de crescimento com períodos favoráveis.

Nos resultados apresentados na Tabela 10 a média dos incrementos anuais do tronco das árvores variou de acordo com a espécie, em uma mesma área. Cita-se, como exemplo, as árvores de Aspidosperma polyneuron (peroba-rosa) e de Pachystroma longifolium (canxim) na Reserva Florestal Mata de Santa Genebra, com distintas médias de incrementos anuais do crescimento do tronco.

Botosso (2000) verificou que, para árvores de algumas espécies de matas estacionais semidecíduas, a largura média dos incrementos anuais variou de 2 a $4 \mathrm{~mm}$, caso de Anadenanthera macrocarpa (angico), Dipteryx alata (cumaru), Tabebuia serratifolia (ipê amarelo), Copaifera langsdorffii (copaíba) e Cedrela fissilis (cedro).

As taxas de incremento do tronco entre as árvores da mesma espécie (Figuras 23 a 39), mostram que os períodos com taxas de crescimento diferentes podem acorrer devido às variações climáticas, ou outra condição do ambiente que afeta o crescimento das árvores, sendo contínuas na maioria das árvores analisadas. O mesmo não ocorreu com Botosso (2000), verificando (para espécies de plantação florestal) que as condições de crescimento mais favoráveis ocorreram nos primeiros anos seguindo-se com um decréscimo gradual com o aumento da idade. Indicou que condições como a disponibilidade de água, nutrientes e luz, são favoráveis ao incremento em circunferência do tronco das árvores.

Ferreira (2000), analisando os anéis de crescimento de árvores de 4 espécies nativas em áreas urbanizadas e comparado com dados históricos, verificou uma diminuição das taxas 
de crescimento em circunferência para a maioria das árvores em períodos de intenso crescimento populacional e variações ambientais. Buckley et al. (1995) em um estudo dendroclimatológico e dendrocronológico com árvores de espécies arbóreas na Tailândia obtiveram respostas significativas quanto a temperatura e a precipitação com as diferenças entre espécies podendo ser causadas por fatores não climáticos, como a ação antrópica.

As diferenças de idade entre as árvores da floresta plantada com a sua idade real, podem ser atribuídas a vários fatores como a competição com outras árvores devido a posição sociológica das mesmas sendo exemplo a Cariniana estrellensis 3 (jequitibá-branco) que é uma árvore dominada em seu ecossistema apresentando menor circunferência também (Tabela 10 e Anexo C). Da mesma forma, a retirada de uma amostra do lenho no DAP (diâmetro da altura do peito) pode não representar a idade completa da árvore pela redução do número de anéis de crescimento a medida que se distancia da base do seu tronco.

Para determinar a causa das variações do incremento anual em diâmetro, é necessário um levantamento climático e histórico-ambiental de ocorrências nos locais estudados para determinar que fatores interferiram no crescimento das árvores em épocas passadas.

\subsection{Características anatômicas das madeiras e dos anéis de crescimento}

A análise das características anatômicas do lenho é importante para determinar a periodicidade de crescimento de árvores de uma espécie, as taxas de crescimento das árvores e sua relação com as variáveis climáticas. Segundo Détienne (1989), Worbes (1989 e 1995) e Vetter \& Botosso (1989) o lenho da maioria das espécies florestais apresenta padrões anatômicos estruturais característicos e bem definidos. Para Botosso (2000), as alterações anatômicas estruturais e periódicas presentes no lenho das árvores indicaram uma resposta a determinadas condições de crescimento em função das reações definidas e sazonais da atividade cambial. Para as espécies caracterizadas no presente estudo, não houve diferenças estruturais. 


\section{CONCLUSÕES}

Os resultados obtidos no presente trabalho permitem concluir que:

- As condições do local e a presença de lianas podem interferir no ritmo do crescimento em diâmetro das árvores das espécies florestais, sendo que esses fatores devem ser analisados no seu conjunto;

- As fenofases (queda e brotamento de folhas) estão relacionadas com o período de diminuição e reativação da atividade cambial das espécies florestais.

- As taxas de crescimento em diâmetro do tronco foram mais elevadas nas árvores das espécies pioneiras em relação as secundárias iniciais e tardias;

- As variáveis climáticas (precipitação e temperatura) foram correlacionadas com o crescimento circunferência do tronco das árvores na maioria das espécies florestais;

- A dinâmica do crescimento do tronco das árvores das espécies nas populações florestais pode ser melhor entendida pela análise da fenologia e das variações climáticas;

- A estrutura anatômica da madeira e as características dos anéis de crescimento das árvores das espécies florestais foram semelhantes em relação aos locais e a descrição apresentada na literatura especializada;

- Os métodos de dendrocronologia aplicados para as árvores das diferentes espécies podem contribuir para a determinação da sua idade e taxa de crescimento em circunferência; 
- A faixa dendrométrica de aço foi um instrumento preciso e eficiente na avaliação da taxa de crescimento do tronco das árvores das espécies florestais analisadas. 


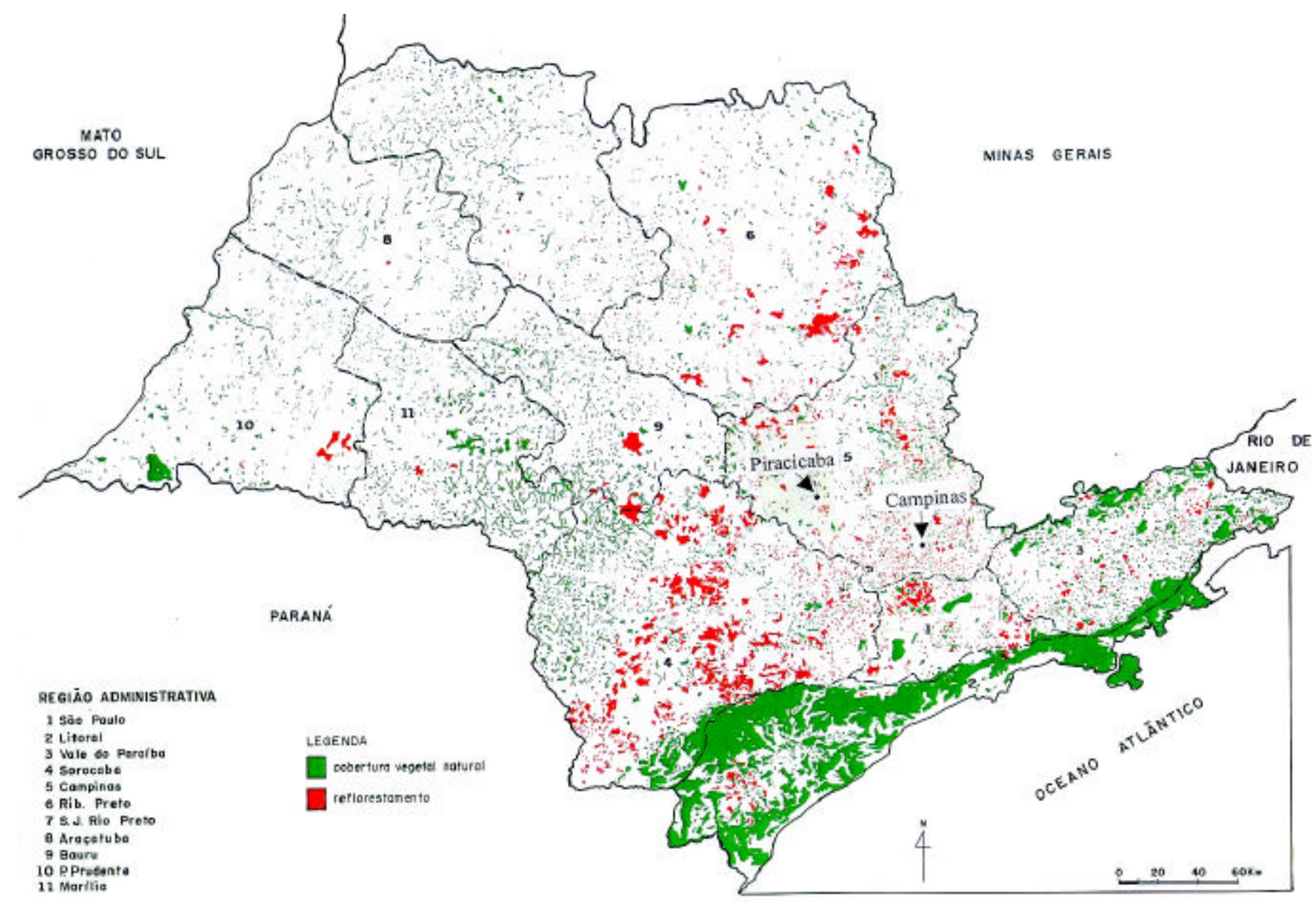

ANEXO A - Mapa da distribuição da cobertura vegetal no Estado de São Paulo e a localização das áreas experimentais (Fonte: KRONKA, F.J.N. et al, 1993) 


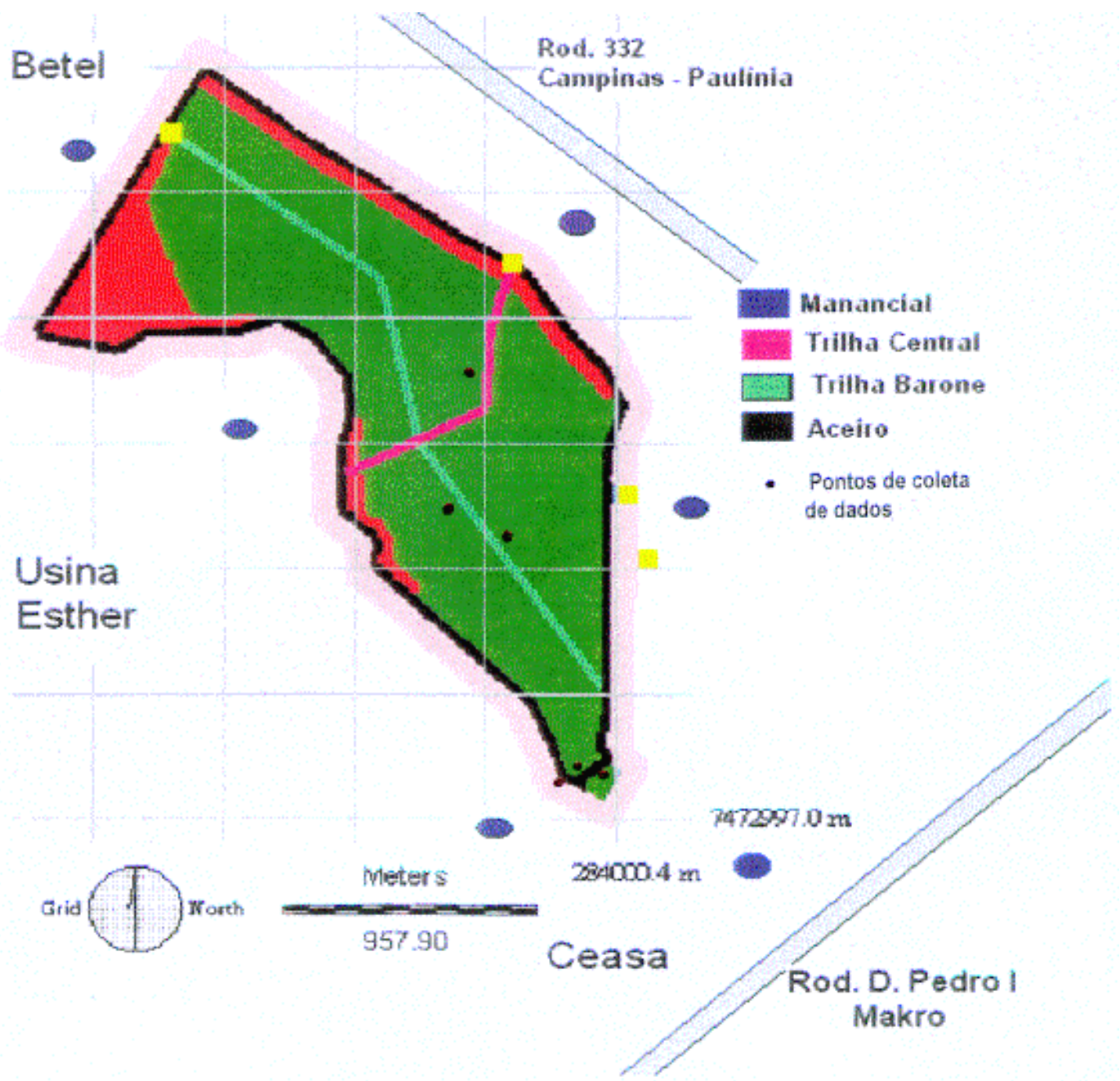

ANEXO B - Pontos de coleta de dados na Reserva Florestal Mata de Santa Genebra 
Anexo C: Circunferência das árvores das diferentes espécies florestais nos 3 locais de estudo.

\begin{tabular}{|c|c|c|c|}
\hline ESPÉCIES & $\operatorname{Arv} .\left(n^{\circ}\right)$ & Locais & Circunf. (cm) \\
\hline \multirow{19}{*}{ Aspidosperma polyneuron (peroba-rosa) } & 1 & IB & 81 \\
\hline & 2 & IB & 80,5 \\
\hline & 3 & IB & 90,5 \\
\hline & 1 & $\mathrm{TP}$ & 52 \\
\hline & 2 & $\mathrm{TP}$ & 59 \\
\hline & 3 & $\mathrm{TP}$ & 39,5 \\
\hline & 4 & TP & 44 \\
\hline & 5 & TP & 55 \\
\hline & 1 & SG & 102 \\
\hline & 2 & SG & 76 \\
\hline & 3 & SG & 117 \\
\hline & 4 & SG & 97 \\
\hline & 5 & SG & 119 \\
\hline & 6 & SG & 90 \\
\hline & 7 & SG & 87 \\
\hline & 8 & SG & 154 \\
\hline & 9 & SG & 53 \\
\hline & 10 & SG & 118 \\
\hline & 11 & SG & 57 \\
\hline \multirow{10}{*}{ Balfourodendron riedelianum (pau-marfim) } & 1 & $\mathrm{TP}$ & 41,5 \\
\hline & 2 & TP & 47 \\
\hline & 3 & $\mathrm{TP}$ & 48 \\
\hline & 4 & $\mathrm{TP}$ & 63,5 \\
\hline & 5 & $\mathrm{TP}$ & 132 \\
\hline & 6 & $\mathrm{TP}$ & 72,5 \\
\hline & 7 & TP & 54 \\
\hline & 8 & TP & 45 \\
\hline & 9 & $\mathrm{TP}$ & 46 \\
\hline & 1 & $\mathrm{TP}$ & 75 \\
\hline \multirow{4}{*}{ Caesalpinia ferrea (pau-ferro) } & 2 & TP & 83 \\
\hline & 3 & TP & 51 \\
\hline & 4 & TP & 80 \\
\hline & 5 & TP & 51,5 \\
\hline \multirow{4}{*}{ Cariniana estrellensis (jequitibá-branco) } & 1 & TP & 96 \\
\hline & 2 & TP & 100 \\
\hline & 3 & $\mathrm{TP}$ & 48,5 \\
\hline & 4 & TP & 60 \\
\hline \multirow{5}{*}{ Cedrela fissilis (cedro) } & 1 & SG & 47 \\
\hline & 2 & SG & 52 \\
\hline & 3 & SG & 31 \\
\hline & 4 & SG & 65 \\
\hline & 5 & SG & 63 \\
\hline
\end{tabular}




\begin{tabular}{|c|c|c|c|}
\hline ESPÉCIES & $\operatorname{Arv} .\left(n^{\circ}\right)$ & Locais & Circunf. (cm) \\
\hline \multirow{6}{*}{ Centrolobium tomentosum (araribá) } & 3 & IB & 90 \\
\hline & 4 & IB & 80 \\
\hline & 5 & IB & 86,5 \\
\hline & 6 & IB & 76,5 \\
\hline & 1 & SG & 55 \\
\hline & 2 & SG & 79 \\
\hline \multirow{7}{*}{ Copaifera langsdorffii } & 3 & SG & 99 \\
\hline & 4 & SG & 43 \\
\hline & 5 & SG & 28 \\
\hline & 2 & SG & 62 \\
\hline & 3 & SG & 177 \\
\hline & 1 & IB & 87 \\
\hline & 3 & IB & 41 \\
\hline \multirow{23}{*}{ Esenbeckia leiocarpa (guarantã) } & 4 & IB & 75 \\
\hline & 5 & IB & 53 \\
\hline & 6 & IB & 84 \\
\hline & 7 & IB & 85 \\
\hline & 8 & IB & 88 \\
\hline & 9 & IB & 37 \\
\hline & 10 & IB & 29 \\
\hline & 11 & IB & 121 \\
\hline & 12 & IB & 116 \\
\hline & 13 & IB & 33 \\
\hline & 1 & $\mathrm{TP}$ & 42 \\
\hline & 2 & $\mathrm{TP}$ & 47,5 \\
\hline & 3 & $\mathrm{TP}$ & 33 \\
\hline & 4 & $\mathrm{TP}$ & 35,5 \\
\hline & 5 & $\mathrm{TP}$ & 35,5 \\
\hline & 6 & TP & 55,5 \\
\hline & 7 & TP & 46,5 \\
\hline & 8 & TP & 61 \\
\hline & 9 & $\mathrm{TP}$ & 49,5 \\
\hline & 1 & SG & 60 \\
\hline & 3 & SG & 34,5 \\
\hline & 4 & SG & 38 \\
\hline & 1 & SG & 86,5 \\
\hline \multirow{4}{*}{ Pachystroma longifolium (canxim) } & 2 & SG & 75 \\
\hline & 3 & SG & 98 \\
\hline & 4 & SG & 65 \\
\hline & 5 & SG & 87 \\
\hline \multirow{3}{*}{ Piptadenia gonoacantha (pau-jacaré) } & 1 & IB & 58 \\
\hline & 2 & IB & 36,5 \\
\hline & 4 & IB & 45 \\
\hline
\end{tabular}




\begin{tabular}{cccc}
\hline ESPÉCIES & Arv. $\left(\mathrm{n}^{\mathbf{0}}{ }^{\text {) }}\right.$ & Locais & Circunf. (cm) \\
\hline & 5 & IB & 39 \\
Piptadenia gonoacantha (pau-jacaré) & 6 & IB & 75,5 \\
& 1 & SG & 48 \\
Savia.dyctiocarpa (guaraiúva) & 2 & SG & 40 \\
& 3 & SG & 41 \\
& 4 & SG & 105 \\
Schizolobium parahyba (guapuruvu) & 5 & SG & 85 \\
& 1 & IB & 91,5 \\
& 2 & IB & 66 \\
Trichilia claussenii (catiguá) & 3 & IB & 63,5 \\
& 4 & IB & 32 \\
& 5 & IB & 46 \\
& 1 & TP & 92,5 \\
& 2 & TP & 119 \\
& & & \\
& 1 & SG & 70 \\
& 2 & SG & 35,5 \\
& 3 & SG & 34 \\
& 4 & SG & 35 \\
& 5 & SG & 25
\end{tabular}

Arv. (n. $\left.{ }^{\circ}\right) .:$ Número da árvore no controle de campo.

Locais.: IB (Estação Ecológica de Ibicatu), TP (Estação Experimental de Tupi), SG (Reserva Florestal Mata de Santa Genebra).

Circunf. (cm).: Circunferência inicial das árvores estudas 


\section{REFERÊNCIAS BIBLIOGRÁFICAS}

ALVIM, T.P. Periodicidade do crescimento das árvores em climas tropicais. In: CONGRESSO DA SOCIEDADE BOTÂNICA DO BRASIL, Porto Alegre, 1964. Anais. Porto Alegre: UFRGS, 1964. p.405-422.

ASHTON, P.S. The need for information regarding tree age and growth in tropical forests. In: BORMANN, F.H.; BERLYN, G. Age and growth rate of tropical trees: new directions for research. New Haven: Yale University, 1981. p.3-6. (Bulletin 94).

BONINSEGNA, J.A.; VILLALBA, R.; AMARILLA, L.; OCAMPO, J. Studies on trees rings, growth rates and age-size relationships of tropical tree species in Misiones, Argentina. IAWA Bulletin New Series, v.10, n.2, p.161-169, 1989.

BORCHERT, R. Climatic periodicity, phenology, and cambium activity in tropical dry forest trees. IAWA Journal, v.20, n.3, p.239-247, 1999.

BOTOSSO, P.C. Periodicidade de taxa de crescimento e aspecto de formação de algumas espécies arbóreas em áreas de matas mesófilas semidecíduas na região sudeste do Estado de São Paulo. Piracicaba, 2000, 82 p. Relatório Final Projeto FAPESP/Pós-doutorado. Escola Superior de Agricultura "Luiz de Queiroz", Universidade de São Paulo.

BOTOSSO, P.C.; TOMAZELLO FILHO, M. Aplicação de faixas dendrométricas na dendrocronologia: avaliação da taxa e do ritmo de crescimento do tronco de árvores tropicais e subtropicais. In: SIMPÓSIO SOBRE INDICADORES AMBIENTIAIS, 2., Sorocaba, 2001. /No prelo/ 
BOTOSSO, P.C.; VETTER, R.E. Alguns aspectos sobre a periodicidade e taxa de crescimento em oito espécies arbóreas tropicais de floresta de Terra Firme (Amazônia). Revista do Instituto Florestal, v.3 n.2, p.163-180, 1991.

BOtOSSO, P.C.; VETTER, R.E.; TOMAZELlO FILHO, M. Periodicidade e taxa de crescimento de árvores de cedro (Cedrela odorata L.), jacareúba (Calophyllum angulare A. C. Smith) e muirapinga (Eperua bijuga Mart. Ex Benth.) de floresta de Terra Firme, em Manaus-AM. Dendrologia en America Latina, Mendonza: Argentina, p. 357-380, 2000.

BOTOSSO, P.C.; TOMAZELLO FILHO, M.; BAPTISTA, V.C.R.; FERREIRA, L. Efeitos das lianas nas taxas de crescimento em diâmetro do tronco das árvores de Centrolobium tomentosun (araribá) Leg. Caesalpinoideae, Sociedade Botânica de São Paulo, 8. São Paulo, 2000. In: CONGRESSO DAS GRANDES METRÓPOLIS; Resumo. São Paulo: USP Instituto de Biociências. 2000. p.44.

BURCKLEY, M.B.; BARBETTI, M.; WATANASAK, M.; D’ARRIGO, R.; BOONCHIRDCHOO, S.; SARUTANON, S. Dendrochonological investigation in Thailand. IAWA Bulletin New Series, v.16, n.4, p.303-409, 1995.

BURGER, L.M.; RICHTER, H.G. Anatomia da madeira. São Paulo: Nobel, 1991. $154 \mathrm{p}$.

CARDOSO, N. S. Caracterização da estrutura anatômica da madeira, fenologia e relações com a atividade cambial de árvores de teca (Tectona grandis) Verbenaceae. Piracicaba, 1991. 117p. Dissertação (Mestrado) - Escola Superior de Agricultura "Luiz de Queiroz", Universidade de São Paulo.

CO, M. C. Munsell soil color charts. New Windson : Munsell Color, 1994. 10p.

CUSTÓDiO FILHO, A.; FRANCO, G. A. D.; NEGREIROS, O. C.; MARIANO, G.;

GIANNOTTI, E.; DIAS A. C. Composição florística da vegetação arbórea da mata mesófila semidecídua. Estação Ecológica de Ibicatu, Piracicaba, S.P. Revista do Instituto Florestal, v.6, p. 99-111, 1994.

DÉTIENNE, P. Appearance and periodicity of growth rings in some tropical woods. IAWA Bulletin New Series, v.10, n.2, p.123-132, 1989. 
DEVALL, M. S.; PARRESOL, B.R.; WRIGHT, S. J. Dendroecological analysis of Cordia alliodora, Pseudobombax septenatum and Annona spraguei in central Panama. IAWA Journal, v.16, n.4, p.411-124, 1995.

ECKSTEIN D.; KRAUSE C. Dendroecological studies on spruce trees to monitor environmental changes. IAWA Bulletin New Series, v.10, n.2, p.175-182, 1989.

ECKSTEIN, D.; OGDEN, J.; JACOBY, G.C.; ASH, J. Age and growth rate determination in tropical trees: the aplication of dendrochronological methods. In: BORMANN, F.H.; BERLYN, G. (Ed), Age and growth rate of tropical trees:. new directions for research New Haven: Yale University, 1981. p. 83-100. (Bulletin, 94).

EMPRESA BRASILEIRA DE PESQUISA AGROPECUÁRIA. Sistema brasileiro de classificação de solos. Brasília: Embrapa Produção de Informação, 1999. 420p.

ENQUIST, B.; LEFFLER, A. J. Long-term tree ring chronologies from sympatric tropical dry-forest trees: individualistic responses to climatic variation. Journal of Tropical Ecology, v.17, pt 1, p.41-60, 2001.

FAHN, A.; BURLEY, J.; LONGMAN, K. A.; MAURIAUX, A.;. Possible contributions of wood anatomy to the determination of the age of tropical trees. In: BORMANN, F.H.; BERLYN, G. (Ed). Age and growth rate of tropical trees: new directions for research. New Haven: Yale University, 1981. p.83-100. (Bulletin, 94).

FERREIRA, L. Conhecendo árvores nativas e centenárias em áreas urbanizadas na cidade de Sorocaba. Sorocaba: Grafilínea, 2000. 32p.

FONSECA, R.C.B. Fenologia e estrutura de uma floresta semidecídua, em Botucatu SP: relação com as fases de desenvolvimento sucessional. Piracicaba, 1998. 86p. Dissertação (Mestrado) - Escola Superior de Agricultura "Luiz de Queiroz", Universidade de São Paulo.

FRITTS, H. C. Tree rings and climate. Academic, London: Press, 1976. 567p.

JACOBY, G.C. Overview of tree-ring analysis in tropical regions. IAWA Bulletin New Series, v.10, n.2, p.99-108, 1989. 
JALIL, N.R.A.; ITOH, T.; SAHRI, M. H.; JUSOH, M.Z. Periodicity of xylem growth of rubberwood (Hevea brasiliensis) grown in Malaysia. Holzfoschung, v.52, n.6, p.567-572, 1998.

KRONKA, F.J.N.; MATSUKUMA, C.K., NALON, M.A.; DEL CALI, I. A.; ROSSI, M.; MATTOS, I.F.A.; SHIN-IKE, M.S.; PONTINHAS, A.A.S. Inventário Florestal do Estado de São Paulo. São Paulo: Instituto Florestal. Secretaria do Meio Ambiente do Estado de São Paulo, 1993. 199p.

LARCHER,W. Ecofisiologia vegetal. São Paulo: EPU, 1986. 339p.

LATIMER, S.D.; DEVALL, M.S.; THOMAS, C.; ELLGAARD, E.G.; KUMAR, S.D.; THIEN, L. B. Dendrochronology and heavy metal deposition in tree rings of balcypress. Journal of Environmental Quality, v.25, p.1411-1419, 1996.

LEITÃO FILHO, H.F.; MORELLATO, P.C. (Org). Ecologia e preservação de uma floresta tropical urbana: Reserva de Santa Genebra. Campinas: UNICAMP, 1995. $136 \mathrm{p}$.

LOJAN, L. Tendencias del crescimento radial de 23 especies forestales del tropico. Turrialba, v.18, n.3, p.275-281, jul/set, 1968.

LOJAN, L. Aspectos del crescimiento diamétrico quincenal de algunos arboles tropicales. Turrialba, v.15, n.3, p.231-237, 1965.

LOJAN, L. Periodicidad del clima y del crecimiento de especies forestales en Turrialba, Costa Rica. Turrialba, v.17, n.1, p.71-83, jan/mar. 1967.

LORENZI, H. Árvores brasileiras: manual de identificação e cultivo de plantas arbóreas nativas do Brasil. Nova Odessa: Plantarum, 1992, 382p.

MAINIERI, C. Manual de identificação das principais madeiras comerciais brasileiras. Chimelo J. P,. \& Alfonso V. A. (colab.) IPT, São Paulo, 1983, 241p.

MAINIERI, C.; CHIMELO, J.P. Fichas de características das madeiras brasileiras. São Paulo: IPT, 1989,432p.

MARCATI, C.R. Sazonalidade cambial em espécies tropicais, 2000. 147p. Tese (Doutorado) - Instituto de Biociências, Universidade de São Paulo.

MARIAUX, A. La périodicité des cernes dans le bois de 1'oukoume. Bois et Fôrests des Tropiques, v.131, p.37-50, 1970. 
MARIAUX, A. Marques et rubans dendroétres. Information Technique, 238. CTFT, Nogent-sur-Marne, 1977. 10p.

MATTHES, L.A.F. Composição florística, estrutura e fenologia de uma floresta residual do planalto paulista: Bosque dos Jequitibás (Campinas-SP). Campinas, 1980, 209p. Dissertação (Mestrado) - Instituto de Biologia, Universidade Estadual de Campinas.

MORELLATO, L.P.C. Estudo da fenologia de árvores, arbustos e lianas de uma floresta semidecídua no sudeste do Brasil. Campinas, 1991, 203p. Tese (Doutorado) - Universidade Estadual de Campinas.

PINHEIRO, G.S.; GIANNOTTI, E.; CRESTANA, C.S. M.; PFEIFER, R.M.; SILVA, D.A.; NEGREIROS, O.C.; BARBOSA, A.F.; MARIANO, G.; GUTMANIS, D.; ROMANELli, R.C.; SILVA, A., Plano de Manejo da Estação Experimental de Tupi, Piracicaba, SP. Série Registros, Instituto Florestal, n.19, p.1-61, 1999.

RAVEN, P. H.; EVERT, R.F.; EICHHORN, S. E. Biologia vegetal. Rio de Janeiro: Guanabara Koogan, 1996. 728p.

SASS, U.; KILLMANN, W.; ECKSTEIN, D. Wood formation in two species of Dipterocarpaceae in Peninsular Malaysia. IAWA Journal, v.16, n.4, p.371-384, 1995.

SMITH, R.B.; SILVA, E.A.M.; ALVIM, P.T.; MAESTRI, M. Periodicidade do crescimento do tronco em cinco espécies no sul da Bahia, Brasil. Agrotrópica, v.9, n.3, p.99-106, 1997.

TOMAZELLO FILHO, M.; BOTOSSO P.C.; Growth periodicity of semi-deciduous tree species in south-east of Brazil. In: INTERNATIONAL SYMPOSIUM ON MULTIFACETED ASPECTS OF TREE RING ANALYSIS. Indian, 1999. p.15-19. VETTER, R.E.; BOTOSSO, P.C. Observações preliminares sobre a periodicidade e taxa de crescimento em árvores tropicais. Acta Amazônica v.18, n.1/2, p.189-195, maio-jun. 1988.

VETTER, R.E.; BOTOSSO, P.C. Remarks on age and growth rate determination of Amazonian trees. IAWA Bulletin New Series, v.10, n.2, p.133-145, 1989. 
VETTER, R.E.; BOTOSSO, P.C. A idade de árvores da Amazônia. In: FERREIRA, E.J.G.; SANTOS, G.M.; LEÃO, E.L.; OLIVEIRA, L. A. (Ed). Bases científicas para estratégias de preservação e desenvolvimento da Amazônia. Manaus: 1993. v.2, p. 403-417.

VILLALBA, R.; BONINSEGMA, J.A. Dendrochronogical studies on Prosopis flexuosa DC. IAWA Bulletin New Series, v.10, n.2, p.155-160, 1989.

VILLALBA, R.; VEBLEN, T.T. Climatic influences on the growth of subalpine trees in the Colorando front range. Ecology, v.75, n.5, p.1450-1462, 1994.

VILLALBA, R.; HOLMES, R.L.; BONINSEGNA, J.A. Spatial patterns of climate and tree growth variations in subtropical. Journal of Biogeography, v.19, n.6, p.631649, 1992.

VILLALBA, R.; GRAU, H.R.; BONINSEGNA, J.A.; JACOBY, G.C.; RIPALTA, A. Tree-ring evidence for long-term precipitation changes in subtropical South America. International Journal of Climatology, v.18, n.13, p.1463-1478, 1998.

WAISEL, L.; LIPHSCHITZ, N.; FAHN, A cambial activity in Zygophyllum dumosun Boiss. Annals of Botany, v.34, n.135, p.409-415, 1970.

WILKINS, A.P.; PAPASSOTIRIOU, S. Wood anatomical variation of Acacia melanoxylon in relation to latitude. IAWA Bulletin New Series, v.10, n.2, p.201207, 1989.

WORBES, M. Annual rings of trees from Central Amazonian inundation forests. In: PROCAINE’S INTERNATIONAL SYMPOSIUM. Ecological Aspects Tree-Ring Analysis. New York, 1987. p.272-280.

WORBES, M. Variety in structure of annual growth zones in Tabebuia barbata E. Mey. Sandw., Bignoniaceae, a tropical tree species from Central Amazonian inundation forests. Dendrochronologia , v.6, p.71-89, 1988.

WORBES, M. Growth rings, increment and age of trees in inundation forests, savannas and a mountain forest in the Neotropics. IAWA Bulletin New Series, v.10, n.2, p.109-122, 1989.

WORBES, M. How to measure growth dynamics in tropical trees - a review. IAWA Journal, v.16, n.4, p. 337-351, 1995. 
WORBES, M. Annual growth rings, rainfall - dependent growth and long-term growth patterns of tropical trees from the Caparo Forest Reserve in Venezuela. Journal of Ecology, v.87, n.3, p.391-403, 1999. 